\title{
RECENT ADVANCES IN THEORETICAL INVESTIGATION OF TITANIUM DIOXIDE NANOMATERIALS. A REVIEW
}

\author{
M.M. Blazhynska ${ }^{\dagger, a}$, A.V. Kyrychenko ${ }^{\dagger, b}$, D.S. Stepaniuk ${ }^{\dagger, c}$, O.M. Korsun ${ }^{\dagger, d}$, \\ S.M. Kovalenko ${ }^{\dagger, \mathrm{e}}$, V.V. Ivanov ${ }^{\dagger, f}$, F.-A. Miannay ${ }^{\ddagger, g}$, A. Idrissi ${ }^{\ddagger, h}$, O.N. Kalugin ${ }^{\dagger, i}$
}

\author{
† V.N. Karazin Kharkiv National University, School of Chemistry, 4 Svobody sqr.,61022 Kharkiv, \\ Ukraine
}

‡ University Lille, LASIR UMR8516, Cité Scientifique, 59655, Villeneuve d'Ascq Cendex, France
a) $₫$ blazhynska@gmail.com
b) $₫$ a.v.kyrychenko@karazin.ua
c) $₫$ d.s.stepaniuk@gmail.com
d) $\square$ oleksandr.korsun@gmail.com
e) $₫$ kovalenko.sergiy.m@gmail.com
f) $₫$ vivanov@karazin.ua
g) $\bowtie$ francois-alexandre.miannay@univ-lille.fr
h) $₫$ abdenacer.idrissi@univ-lille.fr
i) $₫$ onkalugin@gmail.com

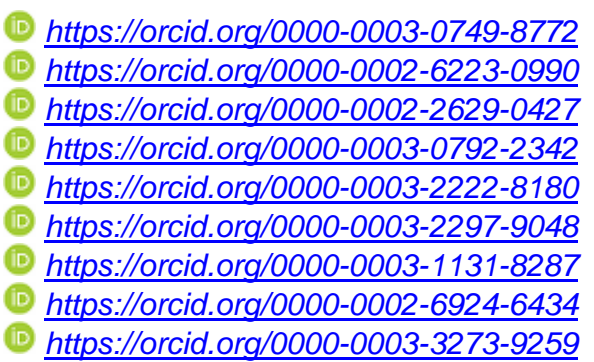

Titanium dioxide $\left(\mathrm{TiO}_{2}\right)$ is one of the most widely used nanomaterials in many emerging areas of material science, including solar energy harvesting and biomedical implanting. In this review, we present progress and recent achievements in the theory and computer simulations of the physicochemical properties of small $\mathrm{TiO}_{2}$ clusters, middle-size nanoparticles, as well as the liquid-solid interface. The historical overview and the development of empirical force fields for classical molecular dynamics (MD) of various $\mathrm{TiO}_{2}$ polymorphs, such as rutile, anatase, and brookite, are given. The adsorption behavior of solvent molecules, ions, small organic ligands, and biomacromolecules on $\mathrm{TiO}_{2}$ interfaces are examined with the aim of the understanding of driving forces and mechanisms, which govern binding and recognition between adsorbate and surfaces. The effects of crystal forms, crystallographic planes, surface defects, and solvent environments on the adsorption process are discussed. Structural details and dynamics of adsorption phenomena, occurring at liquid-solid interfaces, are overviewed starting from early empirical potential models up to recent reactive ReaxFF MD simulations, capable of capturing dissociative adsorption of water molecules. The performance of different theoretical methods, ranged from quantum mechanical (QM) calculations ( $a b$ initio and the density functional theory) up to classical force field and hybrid MM/QM simulations, is critically analyzed. In addition, the recent progress in computational chemistry of light-induced electronic processes, underlying the structure, dynamics, and functioning of molecular and hybrid materials is discussed with the focus on the solar energy applications in dye-sensitized solar cells (DSSC), which are currently under development. Besides, dye design principles, the role of anchoring moiety and dye aggregation in the DSSC performance are crucially analyzed. Finally, we outline the perspectives and challenges for further progress in research and promising directions in the development of accurate computational tools for modeling interactions between inorganic materials with not perfect structures and natural biomacromolecules at physiological conditions.

Keywords: titanium dioxide, rutile, anatase, brookite, dye sensitization, nanoparticle, liquid-solid interface, molecular dynamics simulations, ab initio molecular dynamics.

\section{Introduction}

Nanocrystalline titanium dioxide $\left(\mathrm{TiO}_{2}\right)$ is one of the most widely used nanomaterials because of its chemical stability and environmental compatibility. In addition to many traditional applications in pigment chemistry, metallurgy, and catalysis, nano-sized $\mathrm{TiO}_{2}$ has become a very appealing material for novel emerging areas of material science, including solar energy harvesting and hydrogen generation from water through photochemical reactions [1-2]. The performance of these applications depends critically upon size, shape, crystallinity, and morphology of $\mathrm{TiO}_{2}$ nanomaterials.

$\mathrm{TiO}_{2}$ exists in various polymorphs, such as rutile, anatase, brookite, and other rare phases (Fig. 1) [3]. Rutile and anatase have been widely used in the industry over the last decades [2,4]. Due to its large dielectric constant and its high reflectivity across the visible spectrum, rutile is commonly used in electronic devices, such as thin-film capacitors, interference filters, and optical waveguides. Anatase

(C) Blazhynska M.M., Kyrychenko A.V., Stepaniuk D.S., Korsun O.M., Kovalenko S.M., Ivanov V.V., Miannay F.-A., Idrissi A., Kalugin O.N., 2020 
is frequently used as a photocatalyst [1] because of its high photoreactivity in homogeneous and heterogeneous catalysis. Chemical reactions on $\mathrm{TiO}_{2}$ surfaces play decisive roles in photocatalysis and photoconduction reactions.

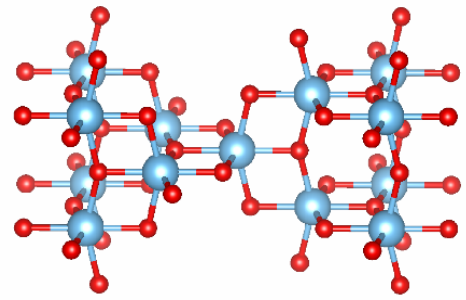

anatase

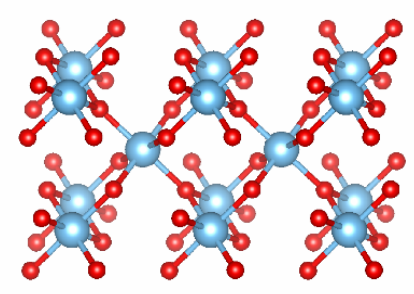

rutile

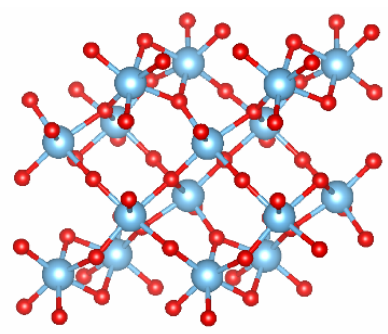

brookite

Figure 1. Crystallographic structure of anatase, rutile, and brookite $\mathrm{TiO}_{2}$. Visualization and graphics were drawn with the VESTA program package [5].

One of the advantages of $\mathrm{TiO}_{2}$ nanomaterials is their biocompatibility. Engineered $\mathrm{TiO}_{2}$ nanostructures can exist in contact with human body tissue without causing an unacceptable degree of harm to the body [6]. Due to this unique capability, $\mathrm{TiO}_{2}$ has emerged in many biomedical applications, such as artificial bones, joints and dental implants [7]. Therefore, significant experimental and computational efforts have been invested in studying phenomena occurring at the liquid-solid interface because their mechanisms and driving forces can point to new directions for biomaterial design and evaluation [8]. It has been shown that $\mathrm{TiO}_{2}$ contributed to the development of a novel class of composite materials that physically integrates inorganic nanoparticles and biological molecules [9-10]. These hybrid conjugates can offer new opportunities for diverse applications in biosensing, site-selective recognition, and may potentially be incorporated into living organisms and biological cells [11]. Therefore, understanding protein adsorption on biomaterial surfaces is of great importance since, alongside water-surface interactions, it can significantly affect the performance of a biomaterial [10].

In this contribution, we discuss recent progress and achievements in the theory and computational modeling of $\mathrm{TiO}_{2}$ nanomaterials and their applications across a wide range of research fields [12-13]. The effects of crystal morphology, crystallographic planes, surface defects, on the adsorption process are discussed. The role of the environmental effects, such as solvent, $\mathrm{pH}$, and temperature, in the adsorption behavior of small organic ligands and biopolymers, is analyzed in detail. In addition, we overview the recent progress in classical MD simulations and some advanced MD sampling techniques, such as replica exchange and umbrella sampling, examining the energetics and dynamics of the interactions of single amino acids, small peptides, and proteins with $\mathrm{TiO}_{2}$ surfaces [6]. Some quantitative insights into molecular recognition mechanisms between biopolymers and inorganic interfaces, including structure-function relationships are also considered. Particular focus is given to how MD simulations have contributed to our current understanding of peptide-surface adsorption at atomic detail. Finally, the perspectives, challenges, and promising directions in computational modeling interactions between inorganic materials and natural biomacromolecules are outlined.

\section{Modeling of $\mathrm{TiO}_{2}$ Surfaces and Aqueous Interfaces}

The first empirical force-field (FF) for bulk $\mathrm{TiO}_{2}$ was developed by Matsui and Akaogi (MA) [14] in 1991, in which the non-bonded interaction parameters between $\mathrm{Ti}$ and $\mathrm{O}$ were determined by reproducing the crystal structure of various polymorphic forms of $\mathrm{TiO}_{2}$ (Fig. 1). In the MA force-field, the energetic interactions in $\mathrm{TiO}_{2}$ were assumed to be completely non-covalent. The dispersion and repulsion interactions were represented by the Buckingham potential (1) (Table 1) [14]. The electrostatic contributions were treated with the pairwise additive Coulomb potential.

$$
U_{L J}\left(r_{i j}\right)=A_{i j} \cdot \exp \left(\frac{r_{i j}}{B_{i j}}\right)-\frac{C_{i j}}{r_{i j}^{6}}
$$

The Buckingham potential parameters of the MA force-field were derived to reproduce the observed crystal structures, volume compressibilities, and thermal expansivities of rutile, anatase, and brookite, respectively. The effective partial charges at $\mathrm{O}$ and Ti atoms were assumed to be $q_{\mathrm{O}}=-\mathrm{q}_{\mathrm{Ti}} / 2$, where $q_{\mathrm{O}}=-1.098$ and $q_{\mathrm{T}}=+2.196$, respectively. Since the development, the MA force-field has become a paradigm for modeling of a broad range of $\mathrm{TiO}_{2}$ nanomaterials [15-25]. 
Table 1. Parameters of the Buckingham potential suitable for modeling of $\mathrm{TiO}_{2}$ polymorphs [14].

\begin{tabular}{|c|c|c|c|}
\hline ion-ion & $A_{\mathrm{ij}}(\mathrm{kcal} / \mathrm{mol})$ & $B_{\mathrm{ij}}(\AA)$ & $C_{\mathrm{ij}}\left(\mathrm{kcal} \cdot \AA^{6} \cdot \mathrm{mol}^{-1}\right)$ \\
\hline Ti-Ti & $7.177 \times 10^{5}$ & 0.154 & $1.210 \times 10^{2}$ \\
Ti-O & $3.911 \times 10^{5}$ & 0.194 & $2.904 \times 10^{2}$ \\
O-O & $2.717 \times 10^{5}$ & 0.234 & $6.969 \times 10^{2}$ \\
\hline
\end{tabular}

In succeeding years, the MA force-field has been used as an initial guess for further extension and the development of more complex computational models, suitable for simulations of $\mathrm{TiO}_{2}$ surfaces, interfaces, nanoparticles and small clusters [26-27]. The first attempt to follow this approach has been performed by Bandura et al. [28-29] by using periodic density functional theory (DFT) calculations to derive new empirical FF parameters for modeling the $\mathrm{TiO}_{2}(110)$ surface. A primary interest in modeling and simulations of $\mathrm{TiO}_{2}$ interfaces was focused on studying of adsorption of biological molecules, especially peptides and proteins [30-31].

Because the most experimental studies were conducted in aqueous solution, it was vital that the adsorption interactions between $\mathrm{TiO}_{2}$ and water molecules were adequately described. Since then, numerous MD simulations have been focused on modeling $\mathrm{TiO}_{2}$-water interfaces [32-35].

The adsorption behavior and the interfacial structure of water molecules on the uncharged and negatively charged rutile (110) surface were studied by classical MD simulations at $298 \mathrm{~K}$ and $1 \mathrm{~atm}$. [32-33]. The original interaction parameters of the MA force-field for $\mathrm{TiO}_{2}$ were further adjusted by $a b$ initio calculations of relaxed structures, and charges of the ideal rutile (110) surface. As a result, new modified interaction parameters were suggested for interfacial and deeper layers of $\mathrm{TiO}_{2}$ atoms. Water molecules were treated with the SPC/E water model [36]. Therefore, the interactions between $\mathrm{Ti}$ atoms and the oxygen atoms of water molecules $\left(\mathrm{Ti}-\mathrm{O}_{\mathrm{H} 2 \mathrm{O}}\right)$ were optimized by ab initio structure optimization and are described by a Buckingham potential (1). It was found that the positions of water molecules at the interface were found to be above each terminal titanium atom. A single additional layer of adsorbed water molecules occupies distinct sites related to the underlying crystal surface structure [32]. The water structure and mobility quickly decay to the bulk liquid properties beyond the second water layer. It was concluded that the influence of the interface for all simulated physicochemical properties, including spatial orientation and diffusivity of water molecules, is negligible beyond distances of about $15 \AA$ from the surface [32].

Starting from the interatomic potentials proposed by Bandura and Kubicki [28], Alimohammadi and Fichthorn [34] have developed a new set of FF parameters for modeling the interaction of water molecules adsorbed either molecularly or dissociatively onto the $\mathrm{TiO}_{2}$ surface. The proposed FF was validated by computing binding energies and conformations for molecular adsorption of water molecules on the (101) and (112) surfaces of anatase, and the (110) surface of rutile. Moreover, the dissociative adsorption on water molecules onto the bulk-terminated (001) surface of anatase and the (110) surface of rutile was considered for various water surface coverages. The MD simulation results were found to be in good agreement with those of first-principles DFT calculations and experimental observations [34].
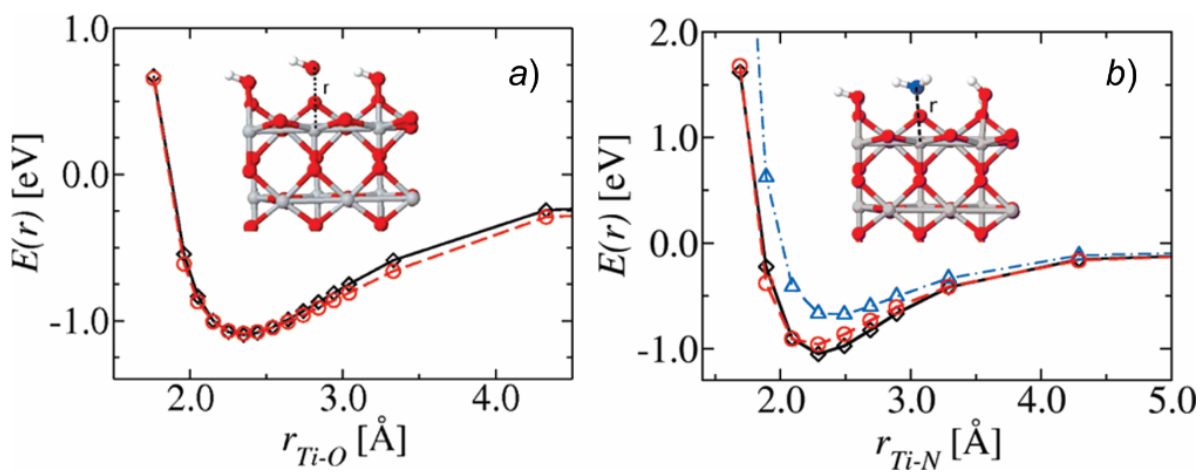

Figure 2. Potential energy surfaces of a water molecule $(a)$ and an ammonia molecule $(b)$ at various separations from the $\mathrm{TiO}_{2}$ rutile(110) surface: DFT (black diamonds, $\diamond$ ) and classical MD calculations (red circles, $\bigcirc$ ). The corresponding structure is displayed in the inset. Adapted with permission from [37]. Copyright (C) 2011, American Chemical Society. 
Schneider and Ciacchi have performed a robust computational procedure of the development and validation of empirical potentials for classical MD simulations of the $\mathrm{Ti} / \mathrm{TiO}_{\mathrm{x}} /$ water interface employing ab initio MD simulations [37]. The procedure was based on the mapping of the adsorption energy profile of a single water molecule on the rutile $\mathrm{TiO}_{2}(110)$ surface with Coulomb and Lennard-Jones potentials (Fig. 2). The following LJ parameters were suggested: $\sigma(\mathrm{Ti})=0.07827 \mathrm{~nm}, \sigma(\mathrm{O})=0.1615 \mathrm{~nm}$ and $\varepsilon(\mathrm{Ti})=1.402557 \mathrm{~kJ} / \mathrm{mol}$ and $\varepsilon(\mathrm{O})=1.91151 \mathrm{~kJ} / \mathrm{mol}$, respectively. The proposed FF was then validated over a representative series of small organic molecules, such as $\mathrm{CH}_{3} \mathrm{OH}, \mathrm{CH}_{3} \mathrm{NH}_{2}, \mathrm{HCOOH}$, as well as the tripeptide Arg-Gly-Asp (RGD) adsorbed onto the oxidized Ti surface [37].

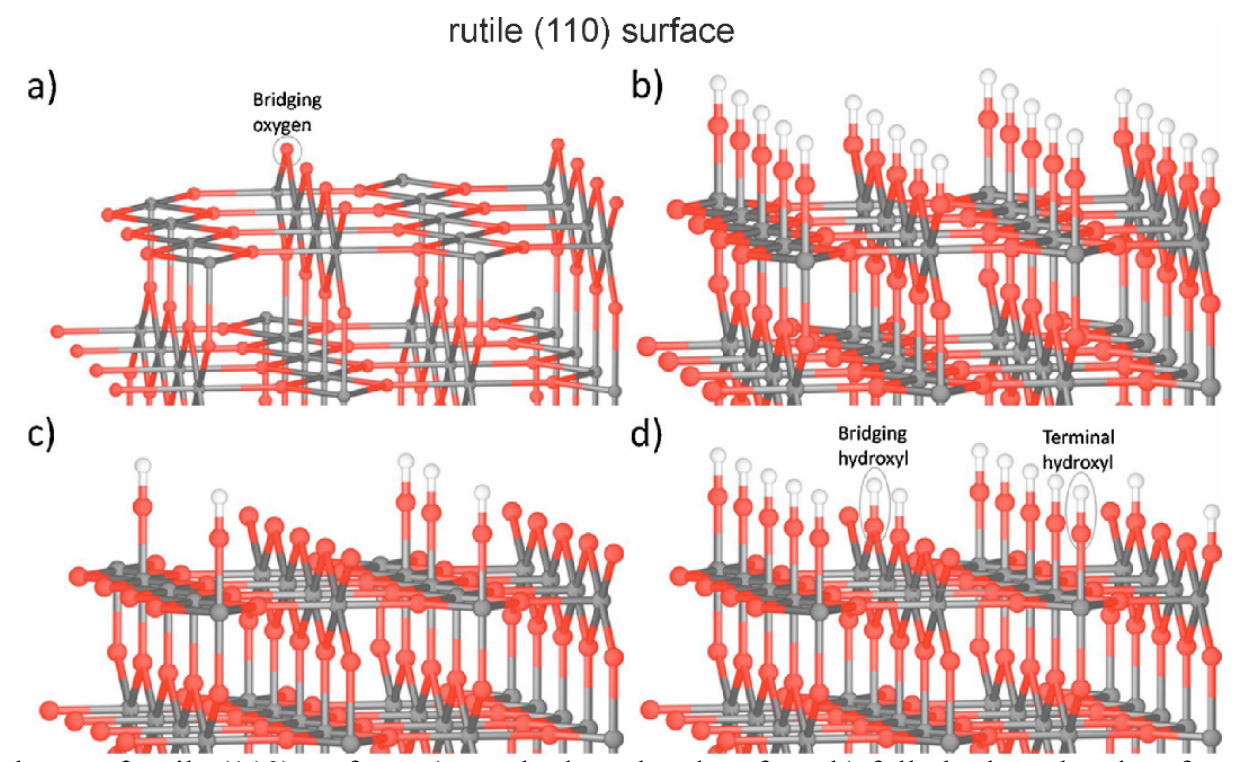

Figure 3. Scheme of rutile (110) surface: a) non-hydroxylated surface, b) fully hydroxylated surface showing the bridging and terminal hydroxyl groups, c) the surface partially covered by terminal hydroxyl groups, d) the surface covered completely by terminal hydroxyl groups and partially covered of bridging hydroxyl groups. Adapted from with permission from [32]. Copyright (C) 2004, American Chemical Society.

Skelton and Walsh have studied the interactions of liquid water and dissolved $\mathrm{Na}^{+}$and $\mathrm{Cl}^{-}$ions with the non-hydroxylated and hydroxylated rutile (110) surface (Fig. 3) by using a modified TIP3P water model, which is compatible with the CHARMM FF [38]. Moreover, further extension of the original MA FF has been released by MD simulations of the adsorption of water molecules onto different surfaces of $\mathrm{TiO}_{2}$, such rutile $(110,100,101,001)$ and anatase $(101,001)$, in which water molecules were represented with a flexible SPC model. A primary goal of this study was focused on studying the structure, ordering, and orientation of water molecules located in the first and second interfacial layers [39-41].

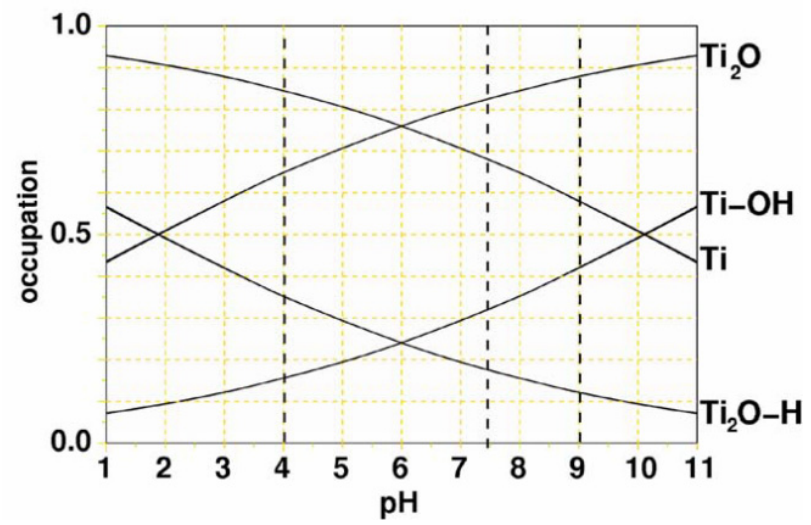

Figure 4. Occupation of surface adsorption sites: $\mathrm{Ti}_{2} \mathrm{O}$ un-protonated, $\mathrm{Ti}_{2} \mathrm{O}-\mathrm{H}$ protonated bridging $\mathrm{O}$ atoms, $\mathrm{Ti}$ non-hydroxylated, Ti-OH hydroxylated surface Ti atoms. Adapted from [42]. Copyright (C) 2006 Elsevier B.V. All rights reserved. 
In 2006, Köppen and Langel developed a new set of empirical FF parameters, suitable for modeling of the interfacial phenomena occurring at the rutile (100) surface in contact with $\mathrm{NaCl}$ aqueous solutions by using a two-particle interaction model with the Morse potential and Coulombic interactions [42]. Their FF model was able to mimic acid-base properties, such as the protonation and hydroxylation equilibriums of the $\mathrm{TiO}_{2}$ interface, which could be adjusted to specific $\mathrm{pH}$ values $(4,7.4$, and 9$)$. Interfacial $\mathrm{pH}$ changes were mimicked by varying a ratio of protonated and hydroxylated residues at the interface, according to Fig. 4. The primary focus of their study was on validation of the Stern model by confirming of a dense layer of counterions on the charged $\mathrm{TiO}_{2}$ surface and a diffuse layer propagated into the bulk water [42].

Conventional MD simulations of the $\mathrm{TiO}_{2}$ interface are able to sample statistical mechanical ensembles with a fixed surface composition, which are well described by classical non-bonded interactions or fixed valence FF models. In classical MD simulations, an initially assigned protonation state of the $\mathrm{TiO}_{2}$ interfacial atoms can not be altered during the simulation, which imposes some limitations for modeling the acid-base interfacial phenomena. One of the promising approaches, overcoming these restrictions, has recently been proposed by the development of a new ReaxFF reactive FF [43], capable of modeling chemosorption reactions in the Ti-O- $\mathrm{H}$ system [44-46]. The ReaxFF force field parameters have been fitted to a quantum mechanical (QM) structures and energies related to bond dissociation energies, angle, and dihedral distortions. Fig. 5 shows snapshots of the rutile (110) surface with layers of water molecules [46]. Moreover, reactions between water and $\mathrm{TiO}_{2}$, as well as experimental crystal structures, heats of formation, and bulk modulus data were also compared. The authors demonstrated that the results of the ReaxFF calculations match reasonably well with those of DFT results for water binding energies, surface energies, and $\mathrm{H}_{2} \mathrm{O}$ dissociation energy barriers [46]. The agreement between the DFT/MD simulation and ReaxFF simulations of water dissociation levels was reported to be within a $10 \%$ error $[44,46]$.
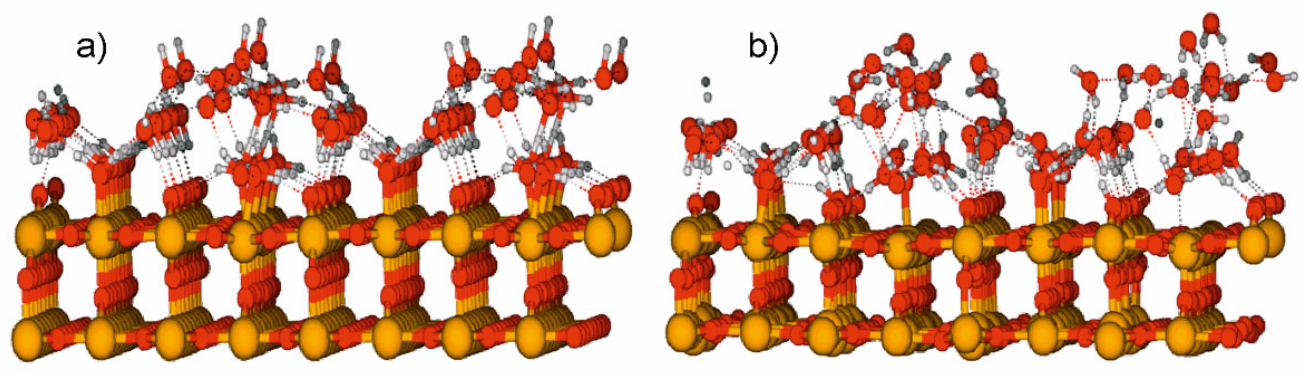

Figure 5. ReaxFF MD simulations of the amount of water dissociated on the 3 layers of the rutile (110) surface taken at the beginning $(a)$ and the end $(b)$ of the sampling. Adapted with permission from [46]. Copyright $(\underset{2}{2013}$, American Chemical Society.

One of fundamental simplification of classical MD simulations of the water- $\mathrm{TiO}_{2}$ interfaces is that a site charge located at each $\mathrm{Ti}$ and $\mathrm{O}$ atom kept fixed during modeling so that the variations of the surface dipoles in $\mathrm{TiO}_{2}$ induced by water and the dipole moments of water molecules near the $\mathrm{TiO}_{2}$ surfaces are not taken into consideration. Recently, a novel polarizable FF for water/rutile interfaces was developed [47]. This polarizable model takes into account the effect of the surface polarity induced by liquid-solid interactions explicitly. The model represents some extension of the charge response kernel (CRK) method [48-50] for molecules to solid surfaces by introducing the surface CRK (SCRK) (Fig. 6a-b), in which the CRK parameters were systematically derived by the first-principles calculations in the $\mathrm{TiO}_{2}$ slab with the dipole-correction method.

The proposed polarizable $\mathrm{FF}$ was validated for the water/clean rutile $\mathrm{TiO}_{2}(110)$ interface (Fig. $6 c$ ). Good agreement was observed between structures and induced charges of a single water molecule, adsorbed onto the $\mathrm{TiO}_{2}$ surface, obtained by the polarizable FF and those predicted by the firstprinciples calculations [50-51]. In addition, $\mathrm{MD}$ simulations of the liquid water $/ \mathrm{TiO}_{2}$ interface were benchmarked over stable structures of water adsorbed onto the $\mathrm{TiO}_{2}$ surface, indicating that the dipole moments of water and $\mathrm{TiO}_{2}$ induced by the water- $\mathrm{TiO}_{2}$ interactions have a significant impact on the structure and dynamics of the water/ $\mathrm{TiO}_{2}$ interface $[47,52]$. 

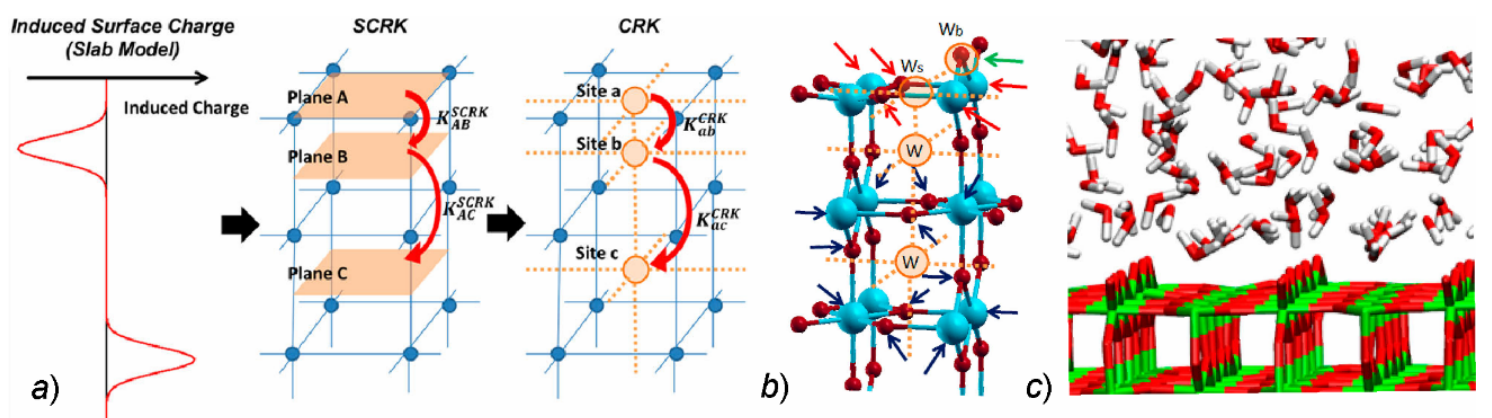

Figure 6. (a) Calculation scheme for the SCRK and CRK for the solid surfaces. (b) Schematic representation of the CRK sites. Ti and $\mathrm{O}$ atoms are represented by sky blue and dark red balls, while the CRK sites are represented by orange circles. (c) A snapshot of the water/clean rutile $\mathrm{TiO}_{2}(110)$ interface. Adapted with permission from [47]. Copyright (C) 2013, American Chemical Society. (For interpretation of the references to color in this figure legend, the reader is referred to the Web version of this article.)

It should be noted that the numerous studies of the absorption behavior and the structure of water layers at water $/ \mathrm{TiO}_{2}$ interfaces have many similar features with computational studies of other liquid/solid interfaces [53]. To identify interface criteria, it would be instructive to apply a concept of the "10-90 width", which is defined as the distance from the solid surface over which a specific interfacial order parameter changes from $10 \%$ to $90 \%$ of the bulk value [53]. This concept was successfully utilized in MD simulations of the basal and prism interfaces formed by ice $1 \mathrm{~h}$ and water molecules, approximated with the rigid SPC/E model [54]. The use of this concept by analyzing of the translational and window average-density order parameters allowed the authors to show that the interfaces consist of a series of relaxed double layers, which differ in diffusion coefficients and bond arrangement. The thickness of the interfaces was found to be $0.9-1.1 \mathrm{~nm}$, which was consistent with ellipsometry measurements [54]. Importance of the "10-90 width" concept was recently highlighted for the proper setup of $a b$ initio/DFT MD simulations of water/ice interfaces, for which a relatively large size of $\sim 1.1 \mathrm{~nm}$ of water interface should be utilized [55].

It has long been recognized that the structure of water molecules confined into nano-sized volumes differs significantly from that of bulk water. In ref [56], MD simulations of the SPC/E water molecules, confined in $\mathrm{TiO}_{2}$-rutile pores of diameters $1.3,2.8$, and $5.1 \mathrm{~nm}$, were carried out at various water contents. It has been found that the proximity to the interface affects density and diffusivity of water molecules within a distance of around $10 \AA$ from the walls, beyond which all structural and dynamics properties tend to converge [56].

To understand the difference between polar $\mathrm{TiO}_{2}$ and hydrophobic graphite surfaces, the microstructure of water molecules absorbed at the nano-slits of the rutile (110) surfaces with the separation distance ranging from 0.8 to $2.0 \mathrm{~nm}$ were analyzed by using MD simulations [57]. MD simulation results show that the residence time of water at a $\mathrm{TiO}_{2}$ surface is considerably longer than that at the graphite surface. Besides, the bound water molecules at the $\mathrm{TiO}_{2}$ surface and the hydrogen bond network reduce the diffusivity of water through the $\mathrm{TiO}_{2}$ slits. These MD simulations show that the surface chemistry is crucial to the diffusion of water inside nanoscale pores as compared to geometric size effects [57]. To investigate the microstructure and lubrication of water molecules confined in $\mathrm{TiO}_{2}$ nano-slits under shearing, a series of non-equilibrium MD simulations have also been carried out [58]. To shed light on the role of the confined water molecules on lubrication, the effects of varying slit gap widths $(0.8,1.2,1.6$, and $2.0 \mathrm{~nm})$ and shear velocities $(200,100,50$, and $10 \mathrm{~m} / \mathrm{s})$ on the friction coefficients between $\mathrm{TiO}_{2}$ and water molecules (SPC/E) were evaluated. It has been shown that the friction coefficient decreased as the slit width increased. The detailed analysis of the microstructure of water layers revealed that water molecules confined in the slits were ordered up to two interfacial layers [58].

Using MD simulations with the LAMMPS package, the static and dynamic properties of water on $\mathrm{TiO}_{2}$ nanotubes $\left(\mathrm{TiO}_{2}-\mathrm{NTs}\right)$ with a diameter of $\sim 1.0 \mathrm{~nm}$ (Fig. $\left.7 a-b\right)$ were studied [59]. The MA forcefield was used for $\mathrm{TiO}_{2}$, whereas the SPC/E model was utilized for water. The MD simulation results showed that the water molecules outside $\mathrm{TiO}_{2}-\mathrm{NT}$ conform to the two-layer model for water, which is typical for water adsorbed onto a planar surface. The difference was that the first water layer was further affected by the surface curvature, indicating the more facile water desorption from the surface. 
This layer disappears for water inside $\mathrm{TiO}_{2}-\mathrm{NT}$, leaving a water layer with the hydrogen atoms pointing to the oxygen atom $\mathrm{O}_{2 c}$ to form hydrogen bonds (Fig. 7c-d) [59].

The mechanical behavior of anatase $\mathrm{TiO}_{2}$ nanotubes in axial loading was examined by using MD simulations with the MA force-field [60]. The nanotubes of different radii and lengths were modeled at $300 \mathrm{~K}$ and subjected to both stretching and compression. The MD simulations demonstrated that, as the radius of the nanotubes increases, their surface was wrinkled axially, which in turn caused their axial behavior to change dramatically. The threshold radius was observed to be $50 \AA$ for a length of $300 \AA[60]$.

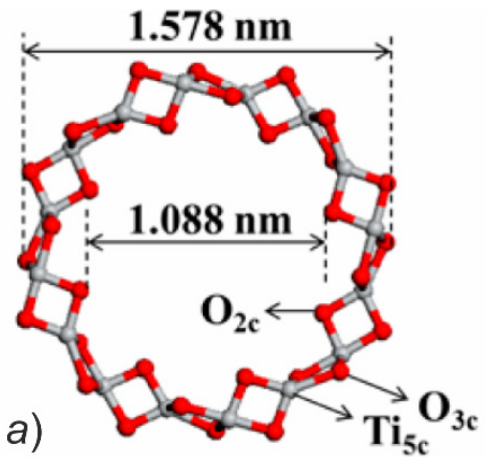

b)
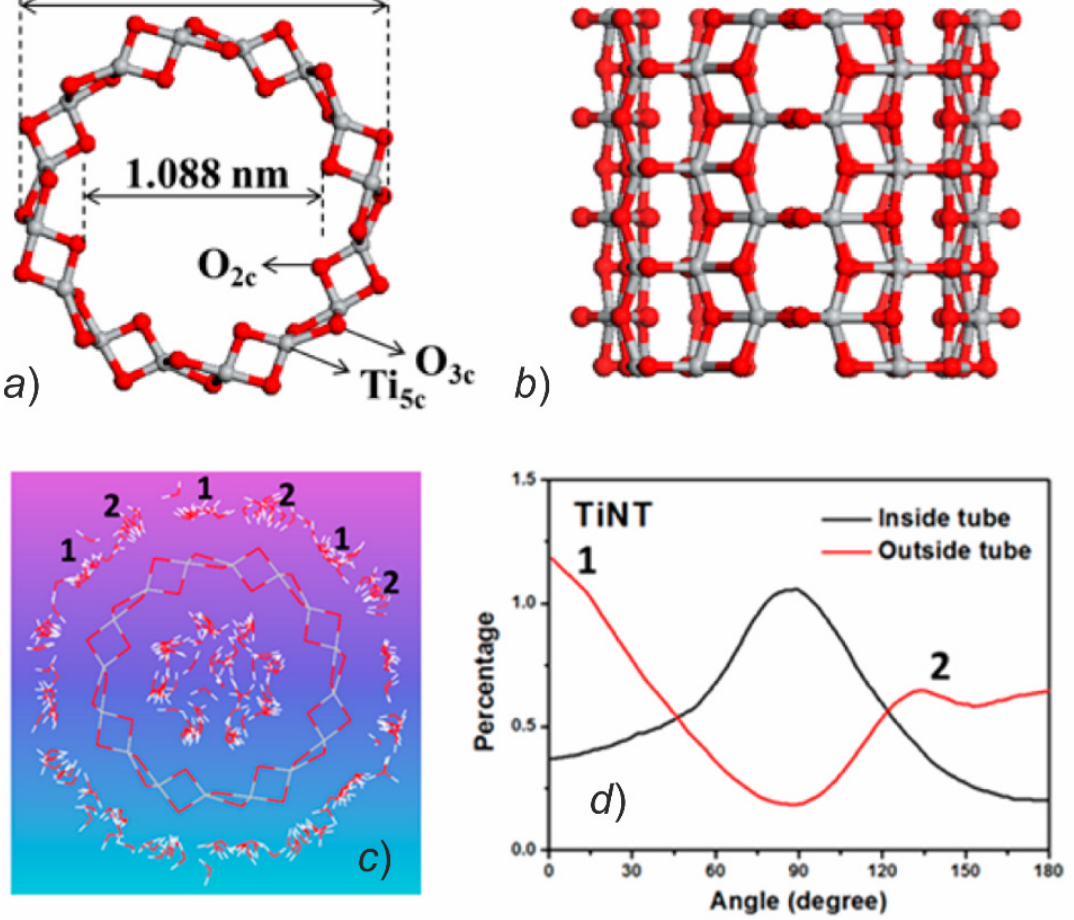

Figure 7. (a) Atomic structure of $\mathrm{TiO}_{2}-\mathrm{NT}$ viewed along the axial direction. (b) Side view of $\mathrm{TiO}_{2}$-NT. (c) Snapshots of the equilibrium structure of a water-NT system (along the axial direction). (d) Distribution of the angle of the water molecules' dipole vectors along the radial direction of NT (point from the tube center to the tube wall). Adapted with permission from [59]. Copyright (C) 2016, American Chemical Society.

The phase behavior of the $n$-octacosane $\left(n-\mathrm{C}_{28}\right)$-water mixture inside $\mathrm{TiO}_{2}$ nanopores was considered with classical MD simulations [61]. Three model systems having different $\mathrm{TiO}_{2}(101)$ anatase pore sizes of 34, 40, and $55 \AA$ were examined (Fig. $8 a$ and $8 c$ ). $\mathrm{TiO}_{2}$ atoms were modeled as LennardJones spheres with $\sigma(\mathrm{Ti})=0.092 \mathrm{~nm}, \quad \sigma(\mathrm{O})=0.303 \quad \mathrm{~nm} \quad$ and $\quad \varepsilon(\mathrm{Ti})=0.17138 \mathrm{~kJ} / \mathrm{mol}$ and $\varepsilon(\mathrm{O})=0.5016 \mathrm{~kJ} / \mathrm{mol}$ as taken from [62]. Water molecules were treated with the SPC/E model, whereas the united-atom TraPPE (transferable potential for phase equilibria) FF was used for $n-\mathrm{C}_{28}$. The standard Lorentz-Berthelot combining rules were used for calculations of nonbonded Lennard-Jones interactions between sites of a different type. It was found that even though phase segregated mixtures retained their structural properties, as compared to their bulk counterparts, some significant deviations were observed in the density profiles inside the nanopore (Fig. $8 b$ and $8 d$ ). Water molecules were organized into two discrete layers on the $\mathrm{TiO}_{2}$ surface so that $n-\mathrm{C}_{28}$ was shielded from the nanopore walls (Fig. 8d). It was suggested that octacosane's self-diffusion was influenced only slightly by confinement. However, water molecules were severely hindered by the $\mathrm{TiO}_{2}$ nanopore surface. Similarly to other studies, it was found that water diffusivity revealed a strong dependence on the distance from the nanopore center [61].

Recently, the MA force-field has been utilized as the initial guess for the development of interatomic potentials for modeling the deposition of calcium and phosphate species (calcium phosphate, $\left.\mathrm{Ca}_{3}\left(\mathrm{PO}_{4}\right)_{2}\right)$ on the anatase $\mathrm{TiO}_{2}(101)$ and (100) surfaces, respectively [63]. The authors have parameterized the missing two-body interactions between $\mathrm{Ca}^{2+}, \mathrm{PO}_{4}{ }^{3-}$ and $\mathrm{TiO}_{2}$, and performed classical MD simulations of the deposition of calcium phosphate on the anatase surface in aqueous solution, which 
were further benchmarked over DFT results. The comparison between the DFT and MD simulations results have shown the outstanding performance of the new set of FF parameters in describing the adsorption of $\mathrm{Ca}_{3}\left(\mathrm{PO}_{4}\right)_{2}$ on the most stable (101) surface of anatase [63].

a)

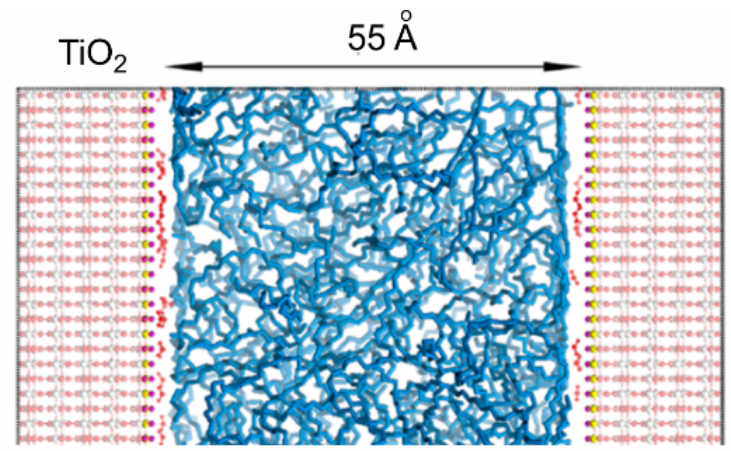

b)

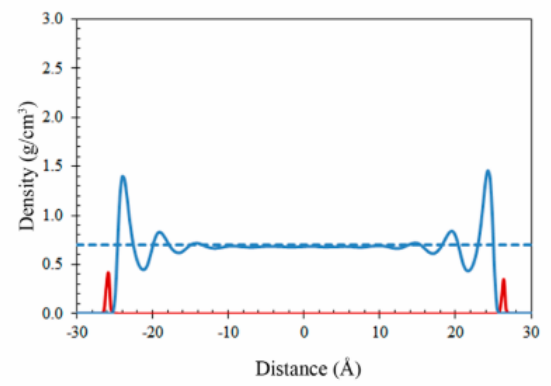

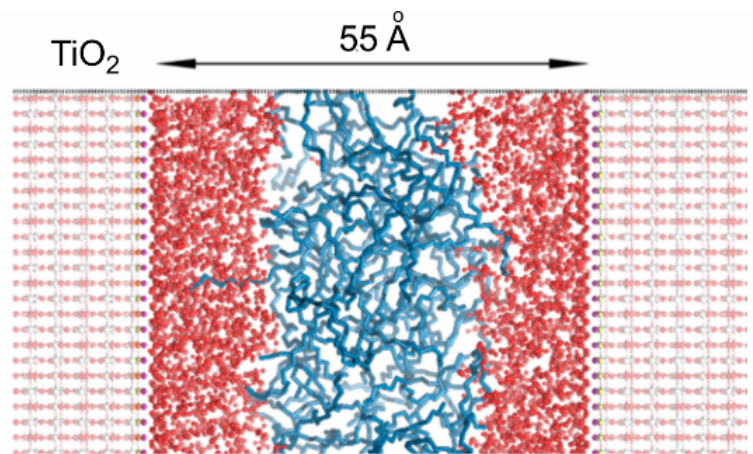

c)

d)

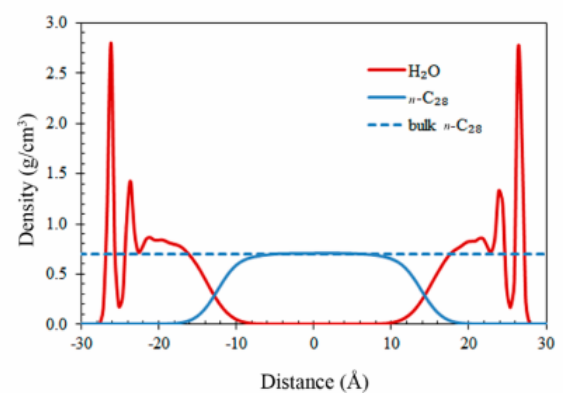

Figure 8. Final MD configuration of $n-\mathrm{C}_{28}-\mathrm{H}_{2} \mathrm{O}$ mixture taken at $473 \mathrm{~K}$ and the corresponding density profile of water and $n$ - $\mathrm{C}_{28}$ in the z-direction: $(a) \chi\left(\mathrm{H}_{2} \mathrm{O}\right)=0.20$ and $(c) \chi\left(\mathrm{H}_{2} \mathrm{O}\right)=0.9655$ confined in the $\mathrm{TiO}_{2} 55 \AA$ diameter pore. Adapted with permission from [61]. Copyright @ 2016, American Chemical Society.

New insights on the molecular processes in the initial nucleation of $\mathrm{Ca}_{3}\left(\mathrm{PO}_{4}\right)_{2}$ on the rutile $\mathrm{TiO}_{2}$ surfaces were obtained by using classical (MD) simulations [64]. Five kinds of $\mathrm{TiO}_{2}$ substrates were considered: nonhydroxylated and fully hydroxylated perfect $\mathrm{TiO}_{2}$ surfaces, and the stepped-, grooved-, and ridged-structured $\mathrm{TiO}_{2}$ surfaces with full surface hydroxylation. The FF parameters for the surface hydroxyls were obtained from Předota's work [32]. The FF interaction parameters between $\mathrm{Ca}_{3}\left(\mathrm{PO}_{4}\right)_{2}$ and $\mathrm{TiO}_{2}$ were previously derived from the ab initio calculations [65]. The MD simulation results suggested that the surface hydroxylation and the shape and the structure of the $\mathrm{TiO}_{2}$ substrate contributed significantly to the initial nucleation of calcium phosphate. Surface hydroxyls on $\mathrm{TiO}_{2}$ provided active sites for the aggregation of calcium phosphate. Both $\mathrm{Ca}^{2+}$ and $\mathrm{PO}_{4}{ }^{3-}$ ions were able to bind to the hydroxylated $\mathrm{TiO}_{2}$ surface directly or indirectly via the first water layer (Fig. 9a-b). Surface nanotopographies (e.g., grooves or ridges) were able to restrict the diffusion of $\mathrm{Ca}^{2+}$ and $\mathrm{PO}_{4}{ }^{3-}$ ions (Fig. 9c) [64].
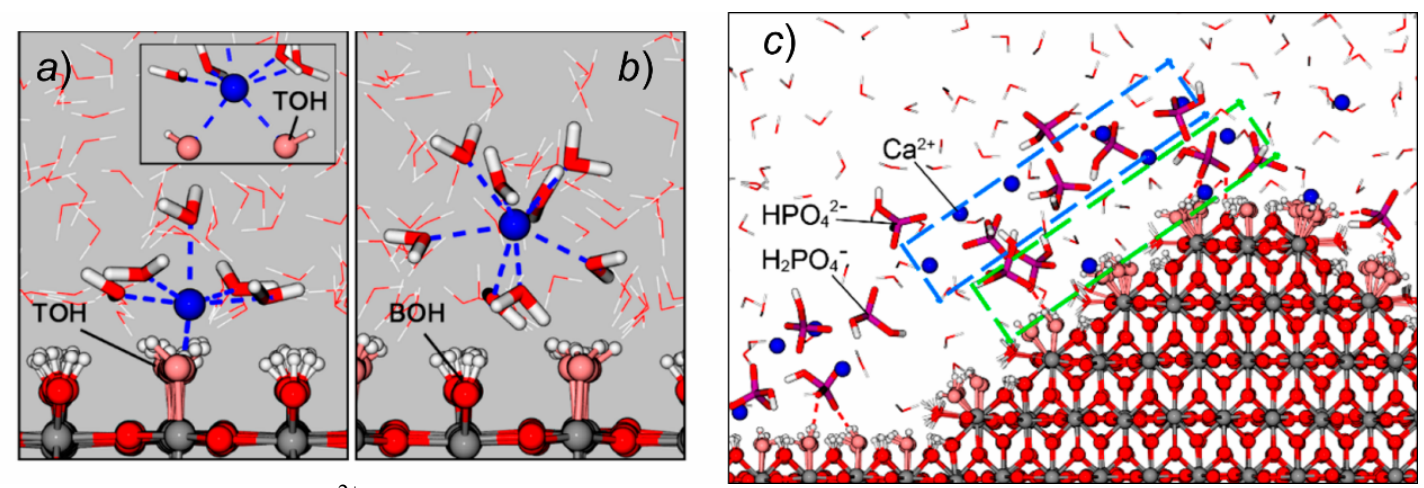

Figure 9. MD snapshots of $\mathrm{Ca}^{2+}$ onto the rutile $\mathrm{TiO}_{2}(110)$ surface shown in the direct adsorption conformations $(a)$ and the hydrated adsorption conformations $(b)$. Adsorption conformation of calcium phosphate ions on the ridge-structured $\mathrm{TiO}_{2}$ surface (c). Adapted with permission from [64]. Copyright (c) 2018, American Chemical Society. 


\section{Adsorption of small additives onto $\mathrm{TiO}_{2}$}

Crystal growth and morphology of crystalline $\mathrm{TiO}_{2}$ are governed by adsorption of small organic additives. These parameters are also essential for the development of novel functional materials. Therefore, MD simulations of the binding modes and thermodynamically stable conformations of small ligands at the surfaces of $\mathrm{TiO}_{2}$ crystals have become attractive tools for understanding the mechanisms underlying additive-surface interactions. As results, numerous computational studied have been devoted to examining the adsorption behavior of small organic compounds, such as ammonium [66], methane [67], methanol [66], formic acid [67], benzene [66-67], and dimethyl methylphosphonate [68], on $\mathrm{TiO}_{2}$ surfaces. Adsorption of a rhodamine dye [69] and some biologically-relevant molecules, such as phospholipids (DOPC, DOPS, and DMTAP) [70], onto $\mathrm{TiO}_{2}$ was also examined.

Recently, the use of the electronic continuum correction (ECC) theory, which suggests some adjustment of point charges at $\mathrm{Ti}$ and $\mathrm{O}$ atoms to reproduce the adsorption phenomena occurring at the $\mathrm{TiO}_{2}$-liquid interface, has received significant attention [32-33,71-75]. MD simulations, augmented by free energy calculations and supported by ab initio calculations, were used to study the adsorption of oxalic acid ions (oxalate and hydrogen oxalate) on the rutile (110) surface [76-77]. The predicted adsorption on perfect non-hydroxylated and hydroxylated surfaces (Fig. 3) was found in agreement with experimental adsorption data and predictions of the charge-distribution multisite ion complexation model [76]. The most favorable surface species were identified to be outer-sphere complexes because of the strong hydrogen bonding of oxalic acid ions with surface hydroxyls and adsorbed water molecules [76]. Moreover, MD simulations were performed to identify the thermodynamically stable conformations of glycolate $\left(\mathrm{CH}_{2}(\mathrm{OH}) \mathrm{COO}^{-}\right)$, lactate, and 2-hydroxybutyrate ions (Fig. 10) at the (001) and (110) planes of rutile crystals by using the MA force field [78-79]. The MD results suggested that, for both planes, the conformation and dynamics of the glycolate ion were strongly dominated by a layered structure of water on the surface. It was found that the glycolate ion was bound to the surface more stably on the (110) plane than on the (001) plane [78]. Besides, the bound conformation in which the $\mathrm{COO}^{-}$group was oriented toward the rutile surface was found to be the most stable for the lactate and 2-hydroxybutyrate ions. In contrast, a conformation, in which the $\mathrm{COO}^{-}$group was oriented toward bulk water, was found to be the most stable for the glycolate ion [79].

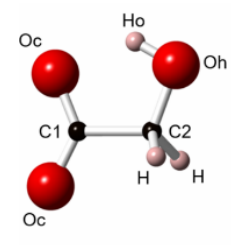

glycolate ion

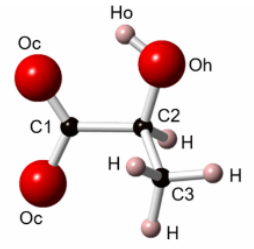

lactate ion

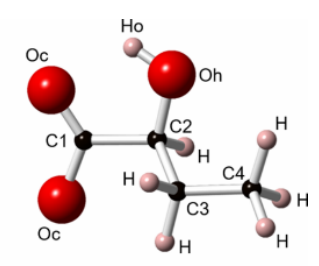

2-hydroxybutyrate ion

Figure 10. Minimum-energy structures of the glycolate, lactate, and 2-hydroxybutyrate ions. Adapted with permission from [79]. Copyright $\odot$ 2019, American Chemical Society.

The adsorption process of a nanodroplet of cysteine molecules onto a perfect and the defective rutile (110) surface was simulated in the gas phase using classical MD approaches, based on reactive and nonreactive FF parameterizations [44]. Three molecular forms of cysteine species, namely, one neutral and two zwitterionic ones, were considered. It has been shown that the adsorption of cysteine molecules on perfect and defective rutile surfaces indicates that both of the computational approaches are able to recognize the importance of the sulfur atom in the binding process. However, it was also pointed out that only through a reactive FF description, the protonation state of cysteine at the interfaces produced by environmental effects could be correctly identified [44].

\section{Interaction of biomacromolecules with $\mathrm{TiO}_{2}$ surfaces}

Understanding the interaction mechanism between metal and metal oxide surfaces and biomolecules, such as proteins/peptides/aminoacids, is crucial to the successful usage of hybrid biomaterials in complex physiological environments [13,15,80-81]. Therefore, the development of theory and computational approaches for modeling organic/inorganic interfaces may accelerate the development of novel biomaterials [10,81-83]. 
The MA force-field has attracted essential interest in MD simulations $\mathrm{TiO}_{2}$ nanomaterials: however, its applicability for nano-bio MD simulations remains limited because of its discrepancy with the standard force fields for biomolecular simulations already available in the literature (e.g., AMBER, CHARMM, OPLS). So, some long-standing problems of accurate sampling of biomolecules near inorganic surfaces and calculation of binding free energies of amino acid side chain analogs and a peptide to the $\mathrm{TiO}_{2}$ surface require the development of the compatible FF parameters. To accomplish this goal, Brandt and Lyubartsev [84] developed bonded and non-bonded interaction parameters for classical MD simulations of $\mathrm{TiO}_{2}$ surfaces in contact with aqueous media (including biomatter) (Fig. 11a).

The proposed FF was designed in agreement with the following criteria: (1) compatibility with standard FFs for biomolecular simulations; (2) transferability of $\mathrm{TiO}_{2}$ interactions to a wide variety of biomolecules: proteins, lipids, and nucleic acids so that Lennard-Jones nonbonded interactions with new molecules could be estimated by standard combination rules; (3) the force field should reproduce interactions at biologically relevant conditions, such as room temperature and atmospheric pressure; (4) the FF parameters were derived in a thermodynamically consistent manner from known experimental data. The modeling was performed by quantum mechanical geometry optimizations of water on $\mathrm{TiO}_{2}$ surfaces using density functional theory using the Perdew-Wang exchange-correlation functional and ultrasoft pseudopotentials (Fig. 11b). A bonded $\mathrm{TiO}_{2}-$ surface model was developed based on these optimized geometries [84]. The performance of the proposed bonded $\mathrm{TiO}_{2} \mathrm{FF}$ was validated by calculations of adsorption profiles and adsorption free energies for the side chain analogs of the 20 naturally occurring amino acids and a titanium binding peptide on the $\mathrm{TiO}_{2}(100)$ surface [85]. Finally, adsorption simulations of a titanium binding RKLPDA-peptide were benchmarked to identify peptide binding modes on a $\mathrm{TiO}_{2}(100)$ surface (Fig. 11c-d) [85].

The adsorption behavior of the four DNA bases (adenine, guanine, thymine, and cytosine) on a charged partially hydroxylated rutile (110) surface was studied through classical MD simulations [86]. The FF parameters reported by Predota et al. was used for the hydroxylated rutile (110) slab [32]. The AMBER FF was used for the DNA bases and the modified TIP3P FF for water [87].

To identify the best binding arrangement, and quantify the strength of their interactions with the inorganic surface, the potential of mean constrained force (PMF) was calculated. The general tendency was observed so that each DNA base adsorbed onto structured solvent layers, which were in direct contact with the $\mathrm{TiO}_{2}$ substrate. Upon the surface binding, the DNA bases were located to be perpendicular to the slab without adopting a preferential orientation. The DNA base binding to the $\mathrm{TiO}_{2}$ surface was rather weak, so that desorption back into the bulk solvent was observed [86].
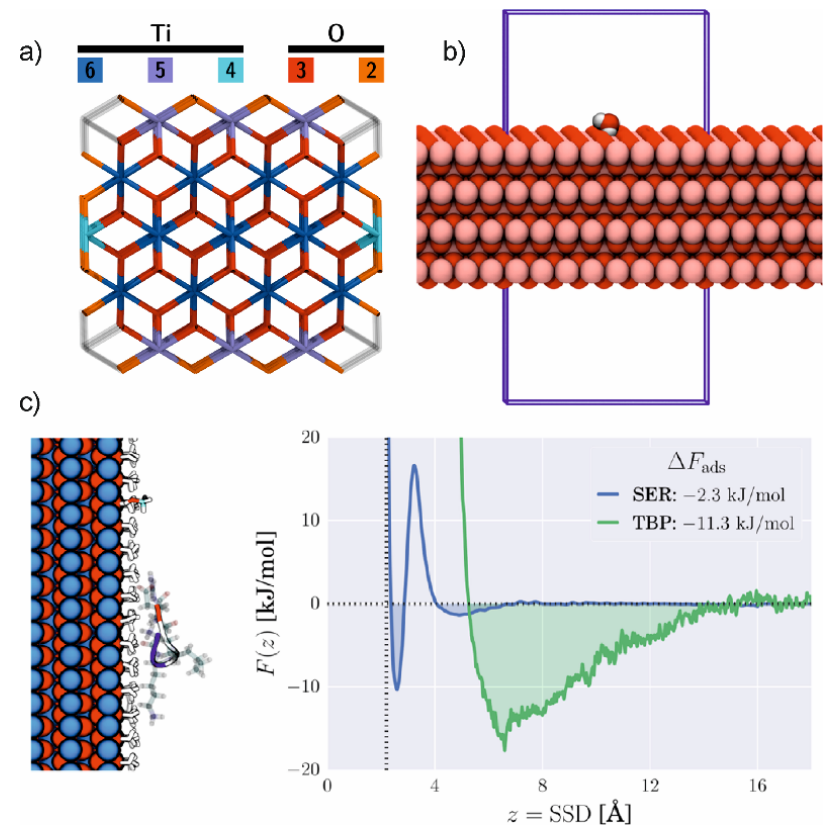

Figure 11. (a) The coordination number for Ti and $\mathrm{O}$ atoms. (b) Interface simulations of a (5×8) $\mathrm{TiO}_{2}$ slab were used for calibration of $\mathrm{TiO}_{2}$-water adsorption enthalpy. (c) Snapshot of a peptide on the $\mathrm{TiO}_{2}(100)$ surface and an adsorption free energy profile calculated by MD simulations. Adapted with permission from [84-85]. Copyright (C) 2015, American Chemical Society. 
Single amino acids or short peptides have been the first molecules to be computationally studied [13,80-81,88-89]. Ab initio periodic calculations and classical MD simulations were performed to investigate the adsorption mode, conformational characteristics, and inter-adsorbate interactions of alanine and several dipeptides, such as alanine-glutamic acid and alanine-lysine onto the $\mathrm{TiO}_{2}(110)$ rutile surface $[30,90]$.

Among the many possible peptides, the RGD (Arg-Gly-Asp) and RKLPDA sequences of amino acids are of great interest [6]. After the placement of a Ti implant inside the body, integrin receptors at the cell membrane will search for specific ligands on the surface for binding. If the ligand is present and its conformation on the surface is suitable, further interaction between the cell and the implant can occur. Protein ligands, such as fibronectin, vitronectin, and collagen, are present in the extracellular matrix $(\mathrm{ECM})$. The cellular response induced by these extracellular matrix proteins, however, is mainly through the Arg-Gly-Asp (RGD) sequence (Fig. 12a) [91].

The adsorption of RGD-peptide onto the rutile $\mathrm{TiO}_{2}(110)$ surface was modeled by using the MA force-field for $\mathrm{TiO}_{2}$ and TIP3P for waters [92-93]. It was found that RGD-peptide was able to adsorb rapidly on the surfaces by amino groups $\mathrm{NH}_{2}$ and $\mathrm{NH}_{3}{ }^{+}$, and the carboxyl group $\mathrm{COO}^{-}$could edge out the adsorbed water molecules and bond to the surface titanium atom (Fig. 12b).
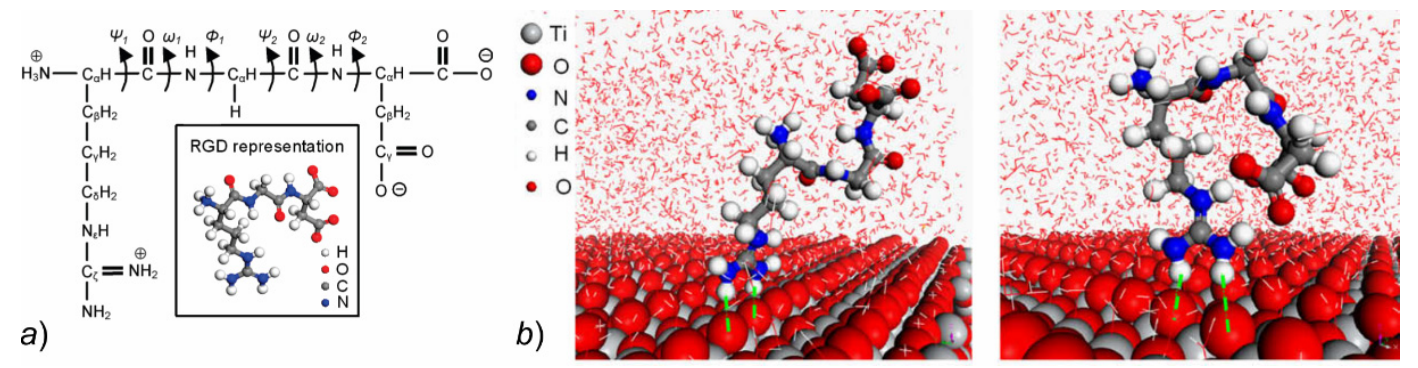

Figure 12. (a) RGD-peptide (Arg-Gly-Asp). (b) Snapshots of a conformation of RGD-peptide adsorbed on the perfect $\mathrm{TiO}_{2}$ (110) in at $2.0 \mathrm{~ns}$ and $4.0 \mathrm{~ns}$, respectively. Adapted with permission from [92-93]. Copyright $\mathbb{C}$ 2010, American Chemical Society.

Since earlier computational studies [93], RGD-peptide has become a benchmark system for the understanding of the origin and molecular mechanism of the molecular recognition between proteins and peptides, and the $\mathrm{TiO}_{2}$-aqueous interface [37,65,94-99]. While the physicochemical aspects of the adsorption of RGD-peptide onto $\mathrm{TiO}_{2}$ surfaces were studied in detail, the mechanism by which other peptides adsorb to titanium surfaces is not yet fully understood [65,100-103].

Two experimentally identified 12-mer peptide sequences referred to as the titania-binding peptides Ti-1 (QPYLFATDSLIK) and Ti-2 (GHTHYHAVRTQT) [88,100] revealed the unusual adsorption affinity to for titania that efficiently promote titania mineralization from an aqueous titanium bisammonium lactatodihydroxide (TiBALDH) solution [104]. Influences of $\mathrm{Ca}^{2+}$ ions at the aqueous $\mathrm{TiO}_{2}$ interface on the binding modes of Ti-1 and Ti-2 peptides was investigated using replica exchange MD simulations combined with solute tempering MD simulations [105]. It was observed that for Ti-1, $\mathrm{Ca}^{2+}$ ions enhanced the adsorption of the negatively charged Asp8 residue in this sequence to the negatively charged surface, via Asp-Ca ${ }^{2+}-\mathrm{TiO}_{2}$ bridging. However, for Ti-2, fewer residues were predicted to adsorb directly to the surface in the presence of $\mathrm{Ca}^{2+}$, possibly due to competition between the other peptide residues and $\mathrm{Ca}^{2+}$ ions to adsorb to the surface [105]. Recently, a new Ti-binding peptide of 13 amino acids (AMRKLPDAPGMHC) was identified by using a series of multiple $300 \mathrm{~ns}$ MD samplings of adsorption dynamics of the peptide at the aqueous interface of a $\mathrm{TiO}_{2}$ anatase surface, started from different peptide orientations with respect to the surface [106]. It was suggested that the peptide anchoring was mediated by the interfacial water layers by means of the charged groups of the side chains of the peptide [106].

Bone morphogenetic protein-2 (BMP-2), a dimeric cysteine knot protein, has therapeutic effects for ectopic bone [107]. Moreover, it plays a crucial role in osteoblast differentiation and proliferation [107]. Classical MD simulations and a hybrid approach of steered molecular dynamics (SMD) combined with MD simulations were employed to investigate the initial stages of the adsorption of BMP-2 upon approaching hydrophilic surfaces of rutile $\mathrm{TiO}_{2}$ [62]. Surface adsorption was evaluated for six different orientations of the protein, two end-on, and four side-on, in an explicit water environment. It 
was observed that BMP-2 adsorbed only loosely to the hydrophilic $\mathrm{TiO}_{2}$ surface. Despite favorable interaction energy between BMP-2 and the $\mathrm{TiO}_{2}$ surface, the rapid formation of a two-layer water structure prevented the direct interaction between protein and $\mathrm{TiO}_{2}$. It was suggested that the first water adlayer had a strong repulsive effect on BMP-2, while the second attracted the protein toward the surface [62].

Adsorption orientation and conformation of myoglobin on perfect rutile (110) and (001) surfaces were investigated by combining Monte Carlo and MD simulations [108]. Myoglobin was modeled with the CHARMM27 FF, whereas the modified MA force-field [103] re-fitted to the Lennard-Jones potential, was utilized for rigid $\mathrm{TiO}_{2}$ surfaces. It was found that the adsorbed myoglobin conformations were not influenced by the physicochemical properties of the rutile (110) and (001) surfaces (Fig. 13). These findings were understood in terms of the strong hydrophilicity of both surfaces. The adsorption behavior of myoglobin was governed by two layers of adsorbed water molecules formed on both rutile surfaces. After $80 \mathrm{~ns}$ MD simulation, the heme of myoglobin was found to be close to the rutile (001) surface and far away from the rutile (110) surface [108].

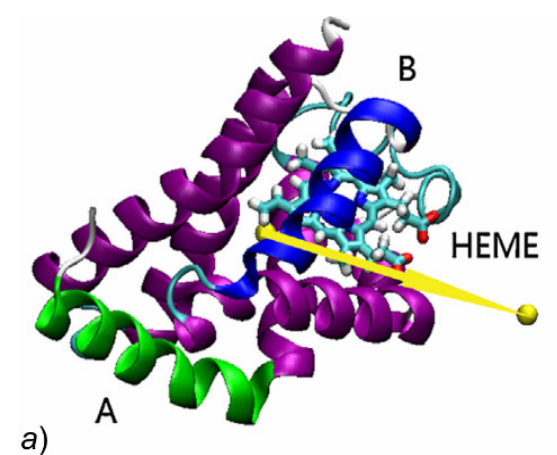

b)
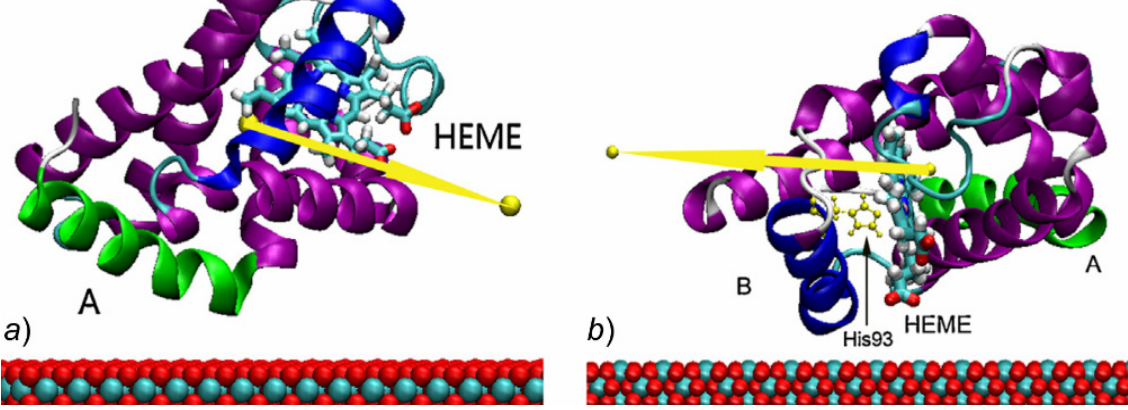

Figure 13. Final representative adsorption configurations of myoglobin $(a)$ on rutile $(110) ;(b)$ on rutile $(001)$ after $80 \mathrm{~ns}$ MD simulations. The arrows indicate the dipole direction of myoglobin. Adapted from [108]. Copyright (C) 2013 Elsevier B.V. All rights reserved.

RNA aptamers with unique tertiary structure and high affinity for binding to a specific target with high affinity and specificity targets are used as therapeutic agents [109]. The adsorption behavior of an RNA aptamer with (101), (100) and (110) surfaces of $\mathrm{TiO}_{2}$ anatase was investigated by using $\mathrm{MD}$ simulations [110]. Analysis of the structural parameters and interaction energies demonstrated that the (110) surface was energetically more favorable for the adsorption of the RNA aptamer than the (100) and (101) surfaces, respectively [110].

Collagen is the main structural protein in the extracellular matrix, which plays an important and irreplaceable role in biomineralization [111]. Collagen is used to modify biomaterial surfaces so that the pre-adsorbed collagen on $\mathrm{TiO}_{2}$ could improve adhesion. It stimulates cell behaviors mainly through the amino acid sequence Arg-Gly-Asp interacting with the integrin at the cell membrane in cell adhesion. It is believed that the carboxyl groups in collagen play a key role in hydroxyapatite nucleation [112]. The adsorption of collagen on the perfect and grooved rutile (110) surface in aqueous solution was modeled by classical MD simulation [113-114]. Preferable binding modes were examined, including direct and indirect binding modes, in which the peptide interacted with the substrate surface directly or via the first layer water molecules (Fig. 14). The MD simulations suggested that the initial poses of collagen on the rutile surface could influence the final adsorption conformation of collagen. The reduced rutile surface provided active sites for collagen adsorption. It was concluded that the direct binding mode was responsible for the stable adsorption of collagen. The indirect binding mode might also play an important part at the initial adsorption stage, but itself alone could not 'trap' the collagen on the surface stably unless the direct binding mode had already been formed [113]. The nonspecific adsorption of noncollagenous bone matrix proteins (NCPs) onto a titania interface was examined for the case of the adsorption of the $\alpha-1$ domain of osteocalcin [115].

Fibronectin (FN) is a major component of the extracellular matrix in tissue, which influences cell adhesion and migration through interactions with other extracellular components [116]. FN contains the important cell-binding sequence - arginine-glycine-aspartic acid (RGD), which can serve as a 
primary attachment site for $\mathrm{TiO}_{2}$. To investigate the topographical dependency of $\mathrm{FN}$ adsorption, $\mathrm{MD}$ simulations were employed to describe its adsorption behavior on nanostructured rutile (110) surfaces (Fig. 15) [117]. It was found that the residence time of adsorbed FN was relied on its binding mode (direct or indirect) with the substrate and the surface interior. In the direct binding mode, FN molecules were found to be 'trapped' at the anchoring sites of the rutile surface, or even penetrate deep into the interior of nanostructures, regardless of the initial configuration on the surface [117].
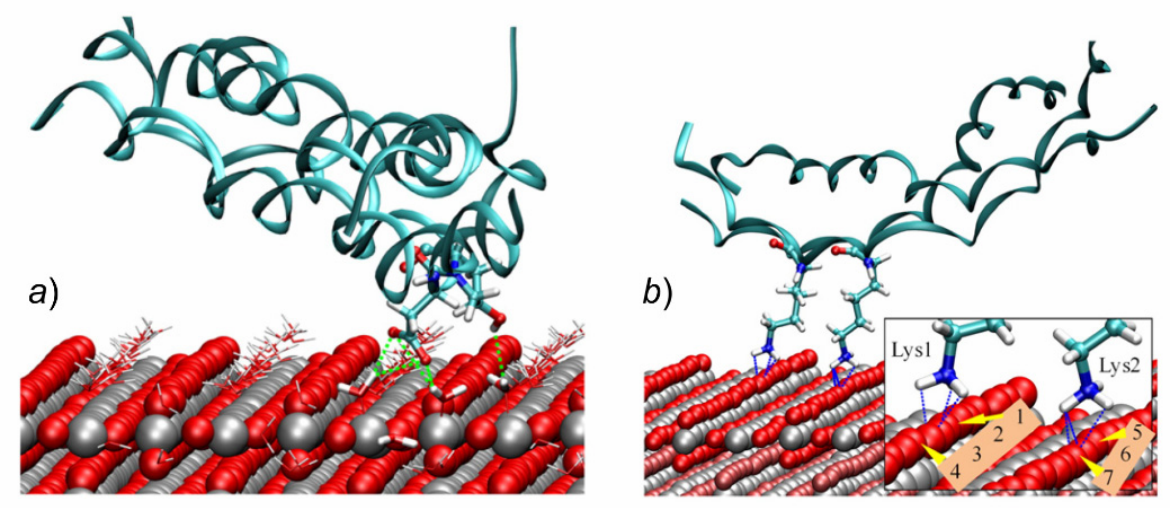

Figure 14. (a) MD snapshot of collagen interacted with the rutile surface via the water molecules near the surface. (b) Adsorption conformation of the collagen segment interacted with the rutile surface directly via the hydrogen bonds between Lys and the rutile oxygen atom. Inserts show the bridging atoms along the (001) directions interacted with the Lys residues, respectively. Adapted from [113]. Copyright (C) 2013 Elsevier B.V. All rights reserved.
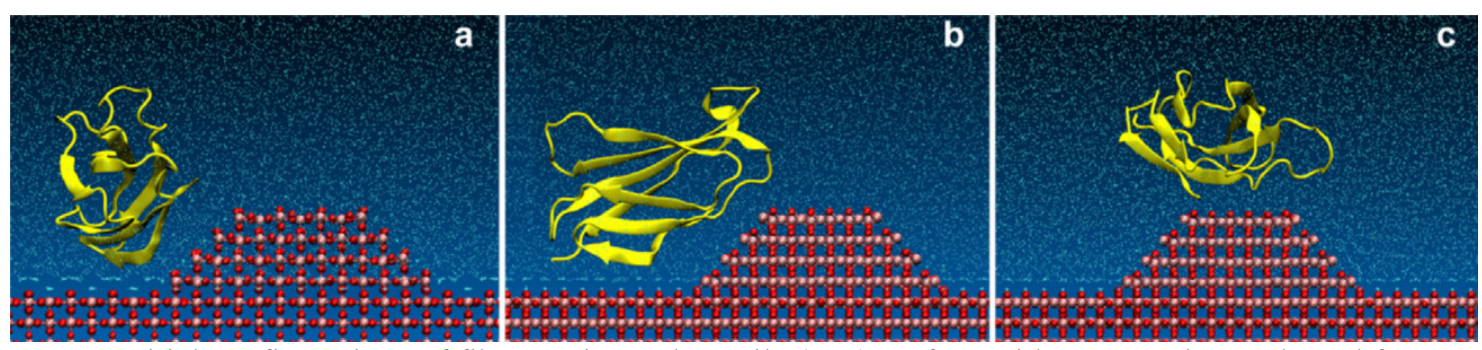

Figure 15. Initial configurations of fibronectin on the rutile (110) surface with a protrusion. Adapted from [117]. Copyright (C) 2016 Elsevier B.V. All rights reserved.

\section{Interaction of polymers with $\mathrm{TiO}_{2}$ surfaces}

Passivation of metal and metal oxide nanoparticles by polymer coating is the conventional approach to improve their colloidal stability and biocompatibility [118-122].

MD simulations of the interface between poly(ethylene oxide) $\left(\mathrm{PEO}_{54}\right)$ and $\mathrm{TiO}_{2}$ were performed at $423 \mathrm{~K}$ using a quantum chemistry-based FF [123]. A representative model system, used for the FF parameterization, consisted of a PEO monomer (dimethyl ether) complexed with the $\mathrm{TiO}_{5} \mathrm{H}_{9}$ cluster. It was found that the PEO density was significantly perturbed by $\mathrm{TiO}_{2}$ surfaces so that layers of highly dense polymer were formed that persisted up to $15 \AA$ from the surface. Conformational and structural relaxations of the interfacial PEO were found to be dramatically slower than those of bulk PEO. It was suggested that the surface structure and electrostatic interactions between $\mathrm{PEO}$ and $\mathrm{TiO}_{2}$ governed the nature of PEO relaxation at the $\mathrm{TiO}_{2}$ interface [123]. Adsorption of poly(3-hexylthiophene) on the nanostructured titania (110) rutile surface in vacuo was studied using MD simulations as a function of local surface curvature and roughness [124].

Coating of $\mathrm{TiO}_{2}$ with polyethylene glycol (PEG) is particularly convenient because it is inexpensive, FDA-approved prevents opsonization from the immune system and therefore increases the in vivo circulation time [125-127]. In addition, it has been reported that poly(vinylpyrrolidone) (PVP) and PEG oligomers and may be used as co-adsorbents, which reduce electron recombination by the effective coverage of vacant sites on $\mathrm{TiO}_{2}$ surfaces that improve the performance of dye-sensitized solar cells [128-129]. 
${ }^{13} \mathrm{C}$ NMR measurements combined with dispersion-corrected density functional theory (DFT-D2) calculations [130] and classical MD simulations were performed to determine the operating condition that guarantee very high grafting densities of PEG on amorphous $\mathrm{TiO}_{2}-\mathrm{NPs}$, which are desirable in any biomedical application [131]. For $\mathrm{TiO}_{2}$, a simplified version of the MA FF model [132] was used, while as for water, the TIP3P model was utilized. Polyethylene PEG was described with Generalized Amber Force Field (GAFF). It was shown that classical and popular models of polymer conformation on surfaces failed in determining the mushroom-to-brush transition point and proved that it takes place only at a rather high grafting density value (Fig. 16) [131].

a)

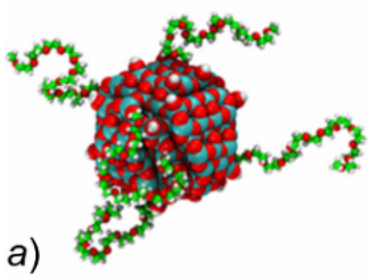

b)

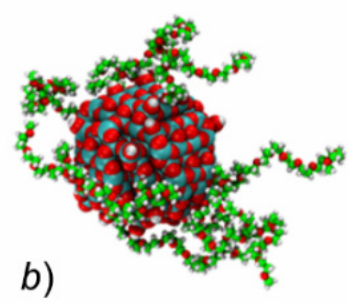

c)

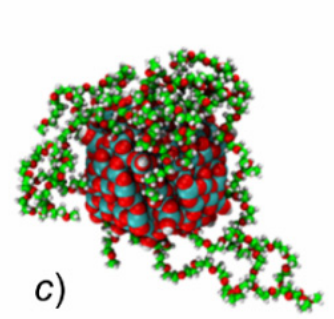

d)

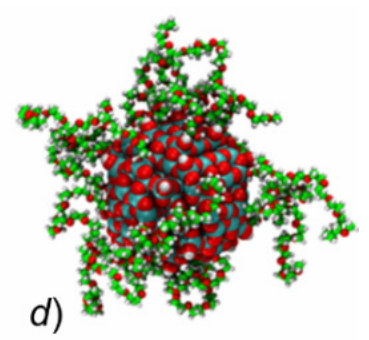

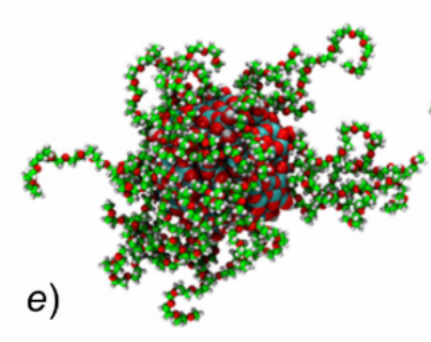
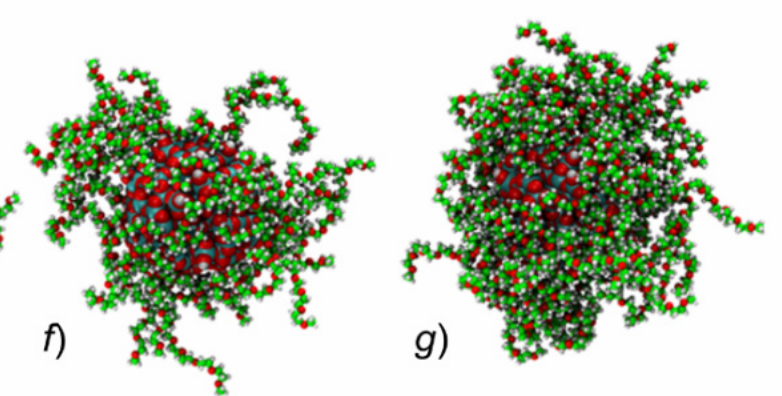

Figure 16. Final MD snapshots for the $m \mathrm{PEG}_{500}-\mathrm{TiO}_{2}$-NP systems at different coverages $\left(\sigma\right.$ in chain $\left./ \mathrm{nm}^{2}\right)$ in water: (a) $m=5, \sigma=0.255$, (b) $m=10, \sigma=0.440$, (c) $m=15, \sigma=0.676$, (d) $m=20, \sigma=0.901$, (e) $m=25, \sigma=1.126$, (f) $m=30, \sigma=1.351,(g) m=50, \sigma=2.252$, respectively. Adapted from [131]. Copyright $(02019$ American Chemical Society.

\section{Modeling of $\mathrm{TiO}_{2}$ in Non-Aqueous Environment}

Chemisorption of solvent molecules and ligands onto the $\mathrm{TiO}_{2}$ surface may strongly affect its electronic structure [133]. For these reasons, growing interest has been focused on modeling and simulation of $\mathrm{TiO}_{2}$ in the non-aqueous environment [134-139].

Acetonitrile is commonly used as a polar organic solvent for Grätzel DSSCs. Schiffmann and coworkers have studied the structure and dynamics of the anatase(101)-acetonitrile interface by combined ab initio and classical MD simulations [134]. The CP2K simulation package and the Gaussian plane wave (GPW) approach were employed to derive the empirical FF for the $\mathrm{TiO}_{2}$ /acetonitrile interactions. A rigid slab of $\mathrm{TiO}_{2}$ was modeled in contact with neat acetonitrile. It has been found that the strong dipolar interactions between acetonitrile molecules result in pronounced layering of adsorbed molecules propagated further away from the interface to bulk solvent up to seven distinct solvent layers $(\sim 12 \AA)$. Each successive layer was characterized by an alternate orientation of the acetonitrile dipoles. Such capability of the solvent to make a strong interaction with the $\mathrm{TiO}_{2}$ wall rather than with bulk solvent might have several significant practical effects, which, for instance, could lead to passivation of the solar cell surface [134].

Singh et al. examined the dynamics of ionic liquids (ILs) inside the nanopores of $\mathrm{TiO}_{2}$ and suggested that the pore size plays a crucial role in the determination of the macroscopic electrical resistance of IL-bases DSSCs [135]. The object of their study was the interplay of the rutile wall, containing nanopores of various shapes, which were confined with 1-ethyl-3-methylimidazolium bis(trifluoromethylsulfonyl)imide [EMIM ${ }^{+}$[TFMSI ${ }^{-}$. The previously developed all-atom force field parameters [140] were used for modeling the cations [EMIM $\left.{ }^{+}\right]$and anions [TFMSI${ }^{-}$, respectively. The authors were able to identify major factors, which influence on the interaction $\mathrm{TiO}_{2}$-IL: the IL density 
inside the nanopores, distances of the ions to the pore walls, as well as the effective pore size, pore shape, surface roughness, and the surface density of electrical charges within the pore walls [135].

Recently, particular interest has been paid to studying the interaction mode between $\mathrm{TiO}_{2}$ and various ILs at the molecular level [136]. Dai et al. studied the role of interfacial hydrogen bonding between the $\mathrm{TiO}_{2}$ slits of different widths and ethylammoinium nitrate (EAN), determining the orientation of nanoconfined IL ions on the (100) rutile surface by combining of MD simulations and vibrational spectroscopy [137]. MD simulations were carried out with the NVT ensemble at $\mathrm{T}=353 \mathrm{~K}$ by using the all-atom FF for the EAN IL, developed by Acevedo and Tirado-Rives [141]. It was found out that $\mathrm{NH}_{3}{ }^{+}$is more likely to adsorb to the $\mathrm{TiO}_{2}$ wall than $\mathrm{NO}_{3}{ }^{-}$. However, both $\mathrm{NH}_{3}{ }^{+}$and $\mathrm{NO}_{3}{ }^{-}$tend to be closer to the surface than $\mathrm{CH}_{3}{ }^{+}$ions, which could be explained by the hydrophilicity of the $\mathrm{TiO}_{2}$ slit. Moreover, the orientation of IL ions was depended on the width of $\mathrm{TiO}_{2}$, which significantly affects the microstructure of the EAN: the smaller is the $\mathrm{TiO}_{2}$ wall, the stronger is hydrogen bonding of $\mathrm{NH}_{3}{ }^{+}$with the $\mathrm{TiO}_{2}$ surface that results in lying down of cations along the $\mathrm{TiO}_{2}$ wall. The increase of the width of the slits leaded to decreasing of the hydrogen bond strength and proportion between IL and $\mathrm{TiO}_{2}$ and, consequently, to the interfacial reorientation of IL ions [137].

Malali and Foroutan have studied the ionic liquid droplets containing 1-butyl-3-methylimidazolium and fluorophosphate on the rutile (110) surface by MD simulations [142]. Using the OPLS-AA FF customized for ionic liquids [141], it was found that the closest surrounding of IL to the nanosurface could be represented by two differently oriented layers of cations. The imidazolium rings are parallel to the surface in the first layer, and they tend to orient perpendicular to the surface in the second region. Such orientation creates some vacancies and empty spaces between these two layers, making the spherical shape gaps, which favors the IL becomes non-wetting at the upper layers of the droplets [142]. Consequently, such non-wetting behavior depends on the covering with a full layer of cations, but not on the density on the $\mathrm{TiO}_{2}$ surface and this effect of the interaction energy of the substrate on ionic liquids leads to a circular configuration of ions in the center of the ionic liquid droplet (Fig. 17).

(a

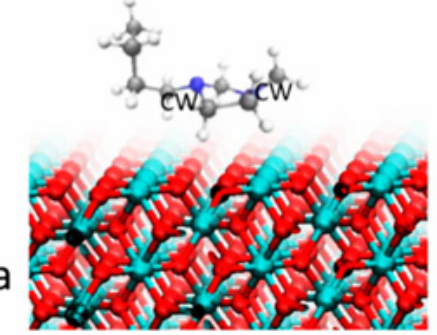

(b

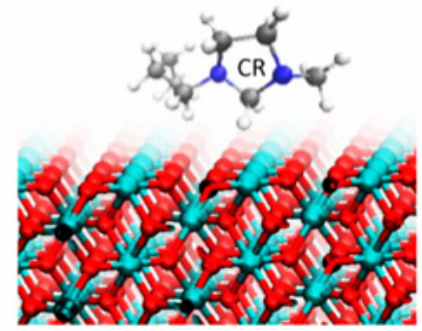

(c

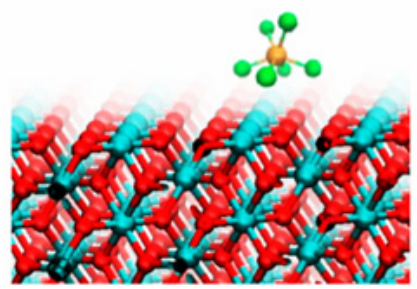

Figure 17. Schematic image of the arrangement of IL ions on the substrate surface: $(a)$ placement of a cation parallel to the surface; $(b)$ placement of a cation perpendicular to the surface; $(c)$ placement of an anion on the surface. Color code is as follows: a fluorine atom is shown in orange, phosphorus atoms in green; hydrogen atoms in white, carbon atoms in light gray, nitrogen atoms in dark blue, oxygen atoms in red, and titanium atoms in light blue. Adapted with permission from [142]. Copyright () 2017 American Chemical Society. (For interpretation of the references to color in this figure legend, the reader is referred to the Web version of this article.)

To investigate the electrostatic potential in the vicinity of the $\mathrm{TiO}_{2}$ surface, Mohammadpour et al . have studied two ILs of the hydrophilic nature, 1-butyl-3-methylimidazolium tetrafluoroborate $\left(\left[\mathrm{C}_{4} \mathrm{mim}\right]\left[\mathrm{BF}_{4}\right]\right)$, 1-butyl-3-methylimidazolium chloride $\left(\left[\mathrm{C}_{4} \mathrm{mim}\right][\mathrm{Cl}]\right)$ and one IL of the hydrophobic nature, 1-butyl-3-methylimidazolium hexafluorophosphate $\left(\left[\mathrm{C}_{4} \mathrm{mim}\right]\left[\mathrm{PF}_{6}\right]\right)$ (Fig. 18a), in the aqueous environment confined between of amorphous slit nanopores [143]. The MD simulations have been performed in an NVT ensemble at $300 \mathrm{~K}$ by using the GROMACS package. The modified OPLS-AA parameters for $\left[\mathrm{C}_{4} \mathrm{mim}\right]\left[\mathrm{BF}_{4}\right],\left[\mathrm{C}_{4} \mathrm{mim}\right][\mathrm{Cl}]$ and $\left[\mathrm{C}_{4} \mathrm{mim}\right]\left[\mathrm{PF}_{6}\right]$ ILs were taken from [141].

The authors have found that the behavior of IL ions inside the nanopores differs significantly from the adsorption behavior at the $\mathrm{TiO}_{2}$ anatase surface so that the extent of an ion-pairing lifetime under such nanoscale confinement is substantially lower than its value found in the bulk solution. The asymmetric distribution of confined IL ions inside amorphous walls was attributed to the formation of ion-pairs (Fig. 18b-f), whereas there is a more homogenous-like distribution of cations and anions inside anatase pores. It has been suggested that the ion-pairing decreases in dilute aqueous mixtures of these ILs [143]. 


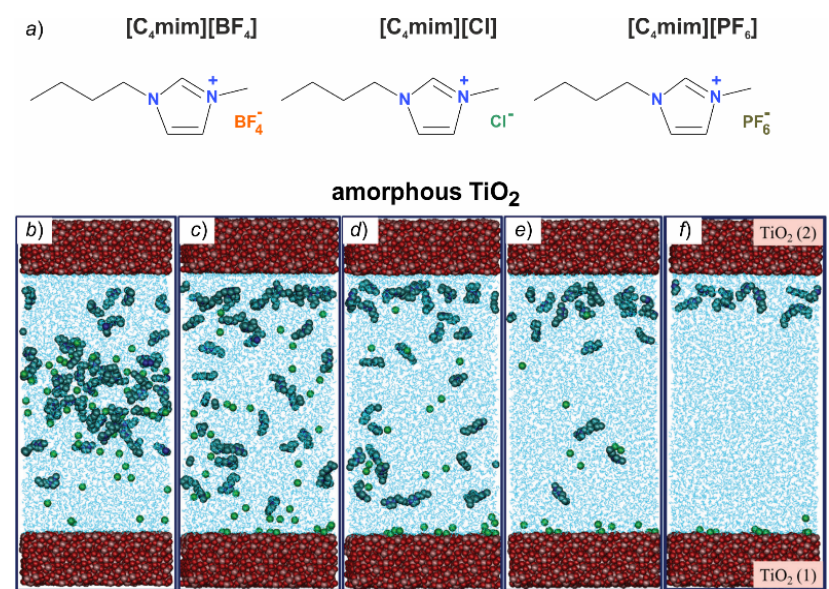

Figure 18. (a) Structures of ILs: $\left[\mathrm{C}_{4} \mathrm{mim}\right]\left[\mathrm{BF}_{4}\right],\left[\mathrm{C}_{4} \mathrm{mim}\right][\mathrm{Cl}]$, and $\left[\mathrm{C}_{4} \mathrm{mim}\right]\left[\mathrm{PF}_{6}\right]$, respectively. Snapshots of the aqueous mixtures of $\left[\mathrm{C}_{4} \mathrm{mim}\right][\mathrm{Cl}]$ with different concentrations confined inside two amorphous $\mathrm{TiO}_{2}$ walls with a $10 \mathrm{~nm}$ size pore after $20 \mathrm{ns:}($ b) 50, (c) 40, (d) 30, (e) 20 and (f) 10 ion-pairs, respectively. Adapted from [143] with permission from The Royal Society of Chemistry.

Considering the fact that a key element of any DSSC devices is the $\mathrm{TiO}_{2} /$ electrolyte interface, Kislenko et al. have studied the influence of different electrolytes (lithium ion $\left(\mathrm{Li}^{+}\right), 1,2$ dimethyl-3propylimidazolium $\left(\mathrm{DMPIM}^{+}\right)$, tetrabutylammonium $\left(\mathrm{TBA}^{+}\right)$as a cation and iodide ion $\left(\mathrm{I}^{-}\right)$as an anion) (Fig. 19) on the formation of the anatase (101) double-layer structure in acetonitrile media [144]. Acetonitrile was described with the model proposed by Nikitin et al. [145]. The Amber94 FF was used for the $\mathrm{TBA}^{+}$cations. FF parameters for $\mathrm{DMPIM}^{+}$were taken from the work of Liu et al. [146], whereas some missing FF parameters were derived by ab initio calculations. Finally, the interaction potentials between $\mathrm{TiO}_{2}$, acetonitrile, and IL ions were adapted from the earlier works of Schiffmann et al. [134].

It has been found that the physicochemical properties of such systems differ significantly, because of different size, symmetry, rigidity, and adsorptive properties of each cation. In the case of $\mathrm{Li}^{+}$, which is prone to adsorption and intercalation, ions in bulk tend to aggregate in pairs, triplets, and larger clusters, representing chains of alternating $\mathrm{Li}^{+}$and $\mathrm{I}^{-}$ions, which leads further to decrease of their diffusion. In the case of DMPIM ${ }^{+}$, the formation of ion pairs and ion clusters of irregular shapes were observed, while the aggregation of $\mathrm{TBA}^{+}$ions in bulk was not frequently occurred, because of its low absorptiveness. The acetonitrile molecules form a self-assembled monolayer on the $\mathrm{TiO}_{2}$ surface, preventing adsorption/desorption phenomena for electrolytes. However, it has been pointed out that the adsorbed $\mathrm{I}^{-}$anions produce local "defects" in the solvent monolayer, which creates adsorption "channels" for $\mathrm{Li}^{+}$and DMPIM${ }^{+}$cations and results in the formation of the adsorbed ion pairs [144].

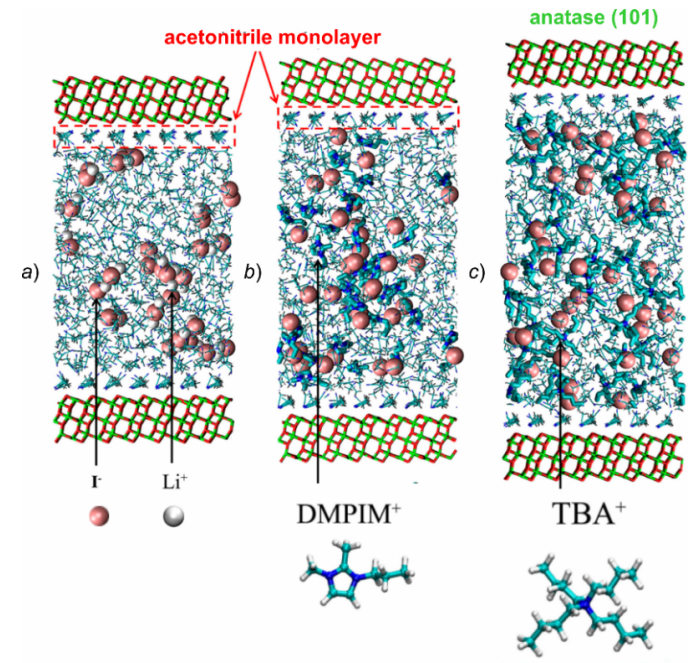

Figure 19. Snapshots of the MD simulation boxes with the electrolytes containing different cations: $\mathrm{Li}^{+}(a)$, $\operatorname{DMPIM}^{+}(b)$, and TBA ${ }^{+}(c)$. Adapted with permission from [144]. Copyright () 2013 American Chemical Society. 


\section{Simulations of $\mathrm{TiO}_{2}$ Nanoparticles}

\section{Amorphous $\mathrm{TiO}_{2}$ Nanoparticles}

Despite many advantages and popularity of the MA force-field of $\mathrm{TiO}_{2}$ in material science modeling, its functional form has rather limited transferability to conventional biomolecular MD simulations. The majority of popular MD packages, such as GROMACS, ABMER, NAMD, etc., have welldocumented FFs and numerous libraries of interaction parameters customized for describing the van der Waals interaction between atoms by the modified Lennard-Jones (LJ) potential (2). To overcome this difficulty, Zhou and co-workers [132] have re-parameterized the MA FF parameters for $\mathrm{TiO}_{2}$ by fitting of the Buckingham potentials for $\mathrm{TiO}_{2}$ with the Lennard-Jones one (Fig. 20 and Table 2).
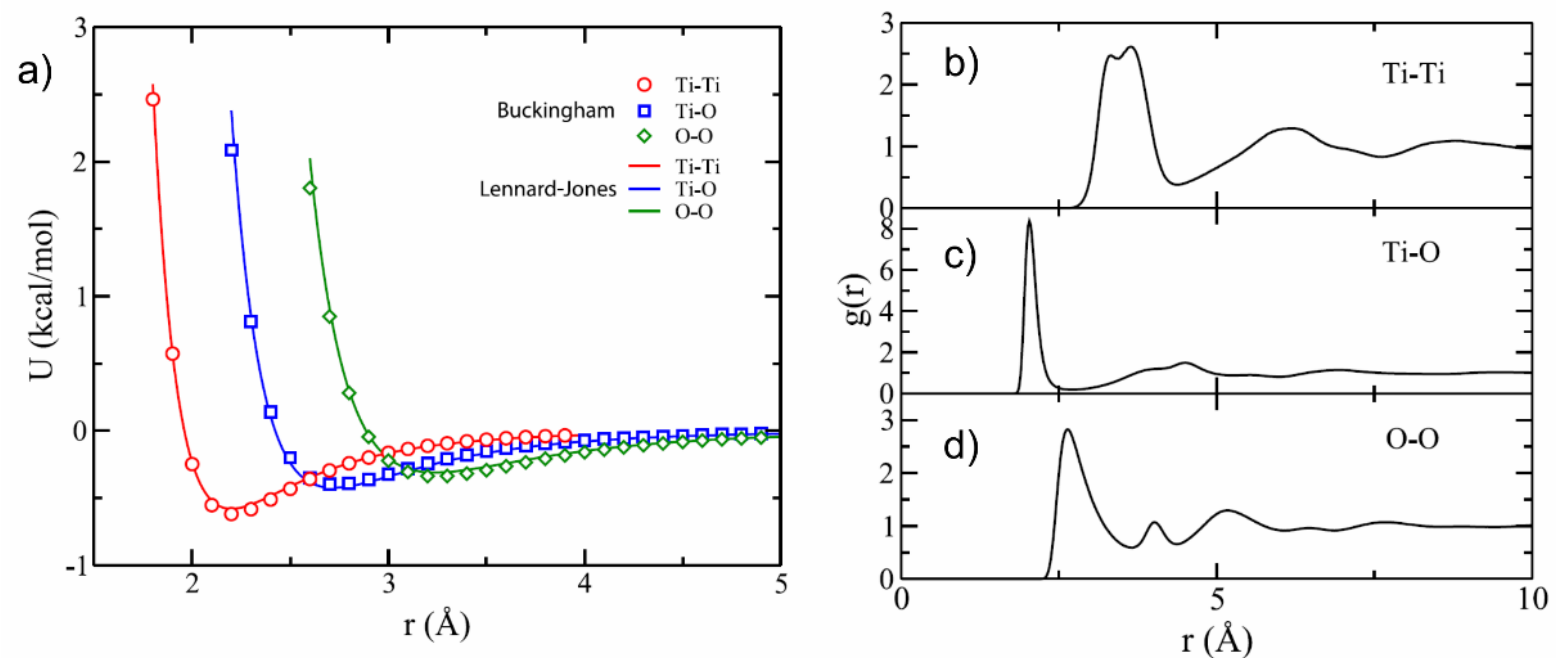

Figure 20. (a) Refitting of the Buckingham potential by the Lennard-Jones potential (2) for van der Waals modeling in the $\mathrm{TiO}_{2}$ solid. (b)-(d) Radial distribution functions $g(r)$ for Ti-Ti $(b)$, Ti-O $(c)$, and $\mathrm{O}-\mathrm{O}(d)$, respectively. Adapted from [132]. Copyright (C) 2015 AIP Publishing LLC.

$$
\begin{array}{ll}
V_{L J}\left(r_{i j}\right)=\varepsilon_{i j}\left(\left(\frac{\sigma_{i j}}{r_{i j}}\right)^{12}-2\left(\frac{\sigma_{i j}}{r_{i j}}\right)^{6}\right) & r<r_{\text {cutoff }} \\
V_{L J}\left(r_{i j}\right)=0 & r>r_{\text {cutoff }}
\end{array}
$$

Table 2. Parameters of the Lennard-Jones potential (2) suitable for modeling of amorphous $\mathrm{TiO}_{2}$ [132].

\begin{tabular}{|c|c|c|}
\hline Interaction & $\varepsilon_{\mathrm{ij}}(\mathrm{kJ} / \mathrm{mol})$ & $\sigma_{\mathrm{ij}}(\mathrm{nm})$ \\
\hline $\mathrm{Ti}-\mathrm{Ti}$ & 2.4244 & 0.220 \\
$\mathrm{Ti}-\mathrm{O}$ & 1.7723 & 0.272 \\
$\mathrm{O}-\mathrm{O}$ & 1.2958 & 0.324 \\
\hline
\end{tabular}

The customized FF parameters, adopted to the LJ form, were tested in MD simulating of the bulk structure of $\mathrm{TiO}_{2}$, water interaction, and the adsorption of the C-terminal (from $\mathrm{Met}_{548}$ to $\mathrm{Glu}_{556}$ ) fragment of the human serum albumin (HSA) at a spherical $\mathrm{TiO}_{2}-\mathrm{NP}$ [132].

\section{Covalently Bound Models of Ti-O Interaction}

A bonded FF, based on $a b$ initio potentials, has been developed for interactions of water molecules with the (110) surface of rutile $\mathrm{TiO}_{2}$ surface slabs [32]. This FF was suitable for atomistic MD simulations of the interfacial structure of the uncharged surface in contact with liquid SPC/E water and negatively charged surfaces in contact with dissolved electrolyte ions $\left(\mathrm{Rb}^{+}, \mathrm{Sr}^{2+}, \mathrm{Zn}^{2+}, \mathrm{Na}^{+}, \mathrm{Ca}^{2+}, \mathrm{Cl}^{-}\right)$ [32-33,147]. 


\section{$\mathrm{TiO}_{2}$ Nanoparticles}

Recent progress and achievement in MD simulations of physicochemical properties of $\mathrm{TiO}_{2}$ nanomaterials have been reviewed elsewhere [6]. Here, we provide the most significant advances and critical examples in this field.

MD simulations of isolated $\mathrm{TiO}_{2}$-NPs in the three characteristic morphology (anatase, brookite, and rutile) have been reported, in which FF parameters were developed based on the MA force-field and fine-tuned with simulated X-ray diffraction data [19]. It has been suggested that the Ti-O bond length was found to be dependent on the coordination environment of Ti and independent of morphology and the size of NPs. The equilibrium Ti-O bond length for a titanium ion was assigned to be $0.186 \mathrm{~nm}$ for a four-coordinated ion, $0.192 \mathrm{~nm}$ for a five-coordinated ion, and $0.194 \mathrm{~nm}$ for an octahedral Ti ion, respectively [19]. Fig. 21 shows MD snapshots of $3 \mathrm{~nm}$ size NPs of quasi-spherical anatase and rutile NPs, respectively.

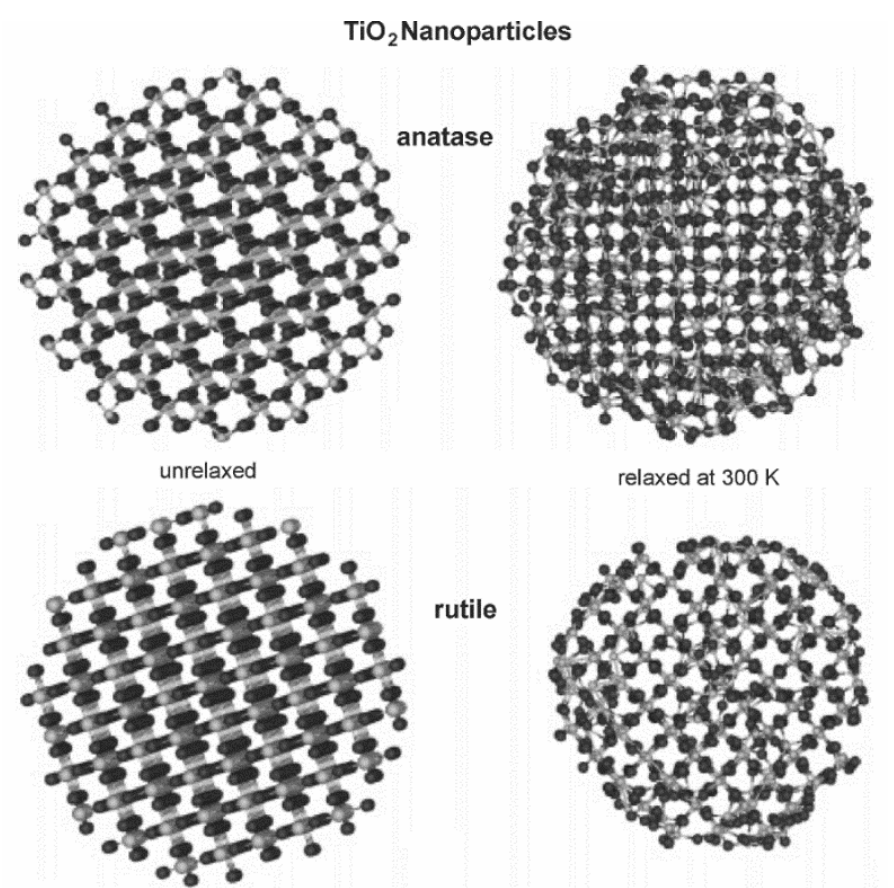

Figure 21. Snapshot of the unrelaxed (left) and relaxed at $300 \mathrm{~K}$ (right) structures of $3 \mathrm{~nm}$ anatase and rutile $\mathrm{TiO}_{2}$-NPs. Adapted with permission from [19]. Copyright (C) 2005 American Chemical Society.

To get a better understanding of the size $\mathrm{TiO}_{2}$ nanoparticles below which anatase NPs become more stable than rutile NPs (crossover diameter), MD simulations of $\mathrm{TiO}_{2}$ nanoparticles were performed based on the MA potential [22]. Sintering-induced phase transformations between various polymorphs, such as anatase and rutile, were considered. It was found that phase transformation between anatase and rutile phases was facilitated by enhanced ionic mobility at temperatures near $1473 \mathrm{~K}$, corresponding to the melting point of the NPs. The final sintering agglomerate transformed to the rutile phase provided one of the sintering NPs was rutile, while sintering of anatase and amorphous nanoparticles resulted in a brookite agglomerate. No such phase transformations were observed at temperatures away from NPs melting temperatures [22].

Alimohammadi and Fichthorn used MD simulations to study the aggregation of various $\mathrm{TiO}_{2}$ (anatase) nanocrystals in vacuum [24]. They found that the aggregation occurred during the picosecond time-scale (Fig. 22). It was not driven by dipole-dipole interactions so that higher-order multipole moments were suggested as the driving force for the preferential alignment of $\mathrm{TiO}_{2}-\mathrm{NPs}$. These highorder multipole moments originate from under-coordinated $\mathrm{O}$ and Ti surface atoms on the edges between nanocrystal facets, which create localized regions of positive and negative charge [24].

MD simulations of the aggregation behavior of amorphous spherical $\mathrm{TiO}_{2}$ of the size $6 \mathrm{~nm}$ were examined at $350 \mathrm{~K}$ and $1400 \mathrm{~K}$ by using the MA force-field [148]. Some localized atomic rearrangements were found to induce preferential crystallization near the surfaces of the NPs. 


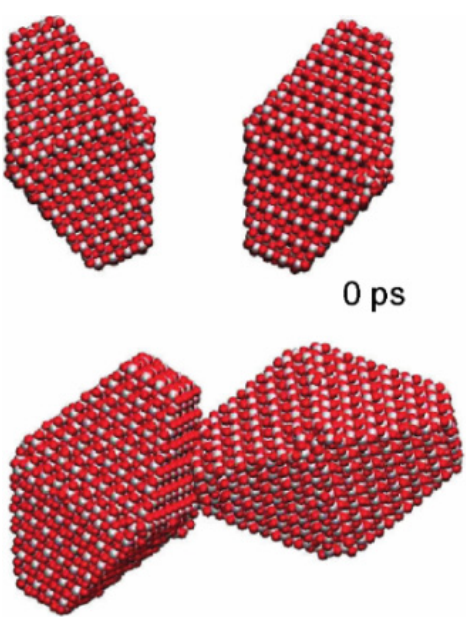

$160 \mathrm{ps}$

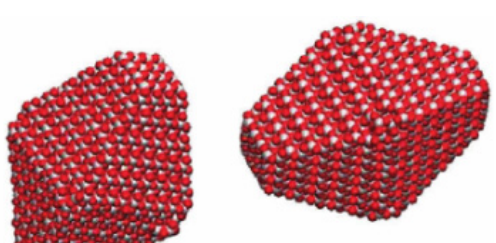

$100 \mathrm{ps}$

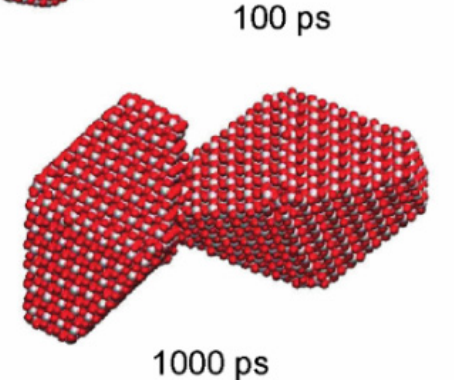

Figure 22. Snapshots of the aggregation of the large symmetric anatase-NPs taken at different simulation times. Adapted with permission from [24]. Copyright @ 2009 American Chemical Society.

The deposition of amorphous $\mathrm{TiO}_{2}-\mathrm{NP}$ of the size $3 \mathrm{~nm}$ onto a flat rigid $\mathrm{TiO}_{2}(\mathrm{~B})$ nanocrystal surface was studied by using spatially resolved pulsed laser deposition combined with MD simulations to gain insight into the binding dynamic and the structural behavior of $\mathrm{TiO}_{2}-\mathrm{NP}$ [149]. The simulations were based on the MA potential and carried out at discrete temperatures of $673 \mathrm{~K}, 873 \mathrm{~K}$, and $1073 \mathrm{~K}$, respectively. MD simulations revealed that an amorphous $\mathrm{TiO}_{2}-\mathrm{NP}$ was attached to the surface within a picosecond time scale, during which some interdiffusion of its atoms into the topmost layer of the $\mathrm{TiO}_{2}$ (B) crystal occurred. Starting from a metastable amorphous nanoparticle with $8 \% \mathrm{TiO}_{6}$ octahedra, the $\mathrm{TiO}_{2}-\mathrm{NP}$ tended to crystallize within the next $2 \mathrm{~ns}$ so that the Ti atoms have formed octahedral oxygen bonds [149].

\section{Quantum-Chemical Calculations of Dye-Sensitized $\mathrm{TiO}_{\mathbf{2}}$}

Dye-sensitized solar cells (DSSC), which are based on dyes adsorbed (or covalently connected) on the surface of $\mathrm{TiO}_{2}$, have been intensively studied in recent years [150]. High efficiency of solar energy conversion, low cost of structural elements, and production of solar cells made them attractive for researchers. Many organic dyes have been studied as constituent elements of DSSC and the relationship between chemical structure and performance of corresponding solar cells has been intensively investigated [150]. In the current section, we present a brief description of the operational principle of DSSC. A more detailed overview can be found elsewhere [151-155].

The main constructive elements of DSSC are an organic dye and a $\mathrm{TiO}_{2}$ semiconductor (Fig. 23). An organic dye (usually $\pi$-conjugated system) contains two structural parts connected by a bridge: a donor and an acceptor. The acceptor moiety is linked to the surface of the semiconductor.

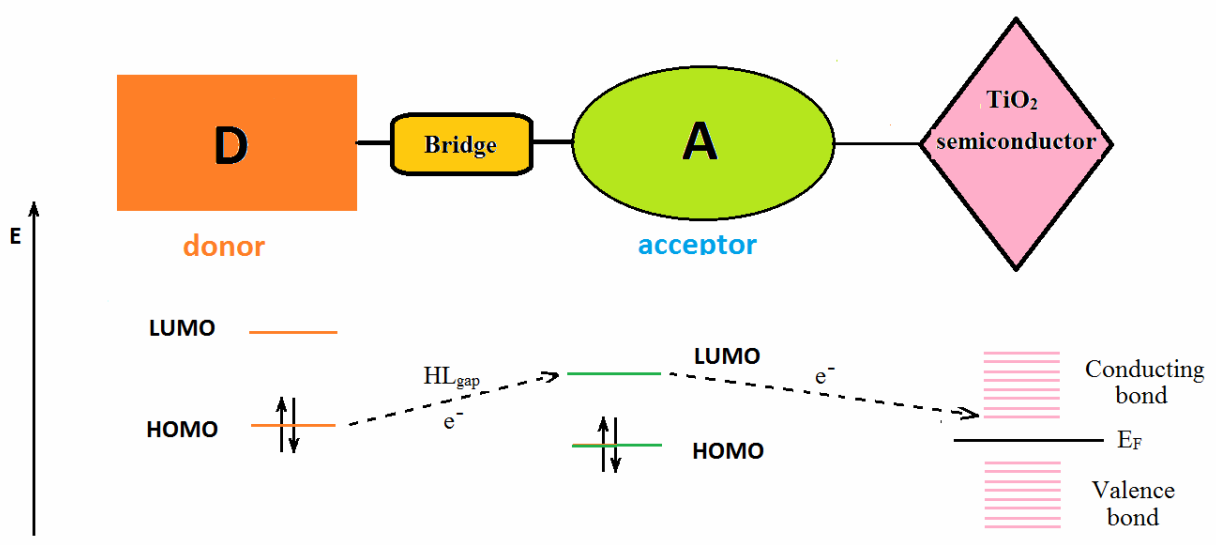

Figure 23. Schematic representation of a donor-acceptor DSSC system. 
The generation of photocurrent in DSSC can be described in the following way. An organic dye in the ground state $(\mathrm{S})$ absorbs the solar radiation and generates an electronically excited state $\left(\mathrm{S}^{*}\right)$.

$$
\mathrm{S}+\mathrm{h} v=\mathrm{S} *
$$

The photoexcited electron is localized at an acceptor part of a dye. After that, the excited state $\mathrm{S}^{*}$ injects the electron into a conduction band of $\mathrm{TiO}_{2}$.

$$
\begin{gathered}
\mathrm{S}^{*} \rightarrow \mathrm{S}^{+}+\mathrm{e}^{-}, \\
\mathrm{e}^{-}+\mathrm{TiO}_{2} \rightarrow \mathrm{e}^{-}\left(\mathrm{TiO}_{2}\right) .
\end{gathered}
$$

The oxidized dye $\left(\mathrm{S}^{+}\right)$regenerates the ground state by $\mathrm{I}^{-}$ion (mediator).

$$
\mathrm{S}^{+}+\mathrm{e}^{-} \rightarrow \mathrm{S} \text {. }
$$

The performance of a DSSC element is characterized by several important parameters. First of all, it is a solar energy-to-electricity conversion yield $(\eta(\%))$

$$
\eta(\%)=\frac{\mathrm{V}_{\mathrm{oc}} \mathrm{J}_{\mathrm{SC}} \mathrm{FF}}{\mathrm{I}_{0}},
$$

where $\mathrm{V}_{\mathrm{oc}}$ is open-circuit voltage of the cell (can be obtained as a difference between the Fermi level of semiconductor and a redox potential of a mediator), $\mathrm{J}_{\mathrm{SC}}$ - photocurrent density at short circuit, $\mathrm{FF}=(0-1)$ is a fill factor, and $\mathrm{I}_{0}$ is the intensity of the incident light.

Another important parameter is IPCE (incident Photon-to-Current conversion efficiency). It is defined as the number of electrons flowing through the external circuit. The IPCE can be calculated in the next way:

$$
\operatorname{IPCE}(\lambda)=\operatorname{LHE}(\lambda) \cdot \Phi_{\text {inj }} \cdot \Phi_{\text {coll }},
$$

where LHE (light-harvesting efficiency) can be obtained using oscillator strength (f) directly from quantum chemistry calculations of electronic spectra. The $\Phi_{\text {inj }}$ and $\Phi_{\text {coll }}$ are measures of the efficiency of electron injection and collection through a photovoltage cycle.

$$
\text { LHE }=1-10^{-\mathrm{f}} \text {. }
$$

In addition, a lifetime of the excited state $\left(\tau_{\mathrm{e}}\right)$ can be an important parameter as soon as long-term stability may lead to more effective charge transfer.

$$
\tau_{\mathrm{e}}=\mathrm{C} / \mathrm{fE}^{2},
$$

where $\mathrm{E}$ - the energy of excitation to the target state and $\mathrm{C}-\mathrm{a}$ constant value.

It is clear that the light conversion efficiency of a DSSC element is heavily influenced by the chemical structure of a dye. It is why quantum chemical calculations play an important role in the investigation and development of high-performance DSSC devices.

During the last decade, the complexes "organic dye- $\mathrm{TiO}_{2}$ " were intensively studied by using different level quantum chemistry ( $a b$ initio) methods. The main problems of such studies are connected, firstly, with the necessity to consider large and "heavy" systems, and secondly, the study of spectral characteristics usually requires rather sophisticated methods. In recent years, many works have been devoted to the study of the electronic structure, geometry, and effects of energy transfer in "organic system- $\mathrm{TiO}_{2}$ " complexes. In the present review, we consider the essential articles only, in which, besides the actual computational data concerned with specific molecular systems, the general theoretic methodological aspects were discussed as well.

$\mathrm{TiO}_{2}$ is one of the most investigated single-crystalline systems. The geometrical structure and properties of rutile and anatase surfaces are described in detail in many reviews (see, for instance, [156]). The results of quantum chemical calculations for $\mathrm{TiO}_{2}$ are presented in a series of articles. Among the most interesting works in this field is the article [157], where the quantum chemical calculations for cluster models $\left(\mathrm{TiO}_{2}\right)_{\mathrm{n}}$ (rutile $\mathrm{n}=20$, and anatase $\left.\mathrm{n}=92\right)$ were performed. Different structural and electronic properties were obtained by using several quantum chemistry approaches. Among them, the semiempirical PM6 method, Hartree-Fock (HF), DFT (BLYP, B3LYP, PBE, PBE0, CAM-B3LYP, and $\omega \mathrm{B} 97$ functionals) approaches. The LANL2DZ basis set was used. The presented data demonstrated significant sensitivity of some critical parameters of the electronic structure to the chosen functional. However, the parameters of the electronic structure demonstrated small sensitivity to the geometrical structure optimization method. For instance, the values of the HOMO-LUMO gap (HL) ob- 
tained using the B3LYP functional vary by only $0.08 \mathrm{eV}$ for differently optimized structures (different DFT functionals were used for optimization). Surprisingly, the HL gap, obtained, for instance, with B3LYP and CAM-B3LYP, differs by as much as $2.91 \mathrm{eV}$ ! Also, the performance of different exchange-correlation functionals for calculations of rutile and anatase was compared in ref [158].

Another structural aspect of anatase $\mathrm{TiO}_{2}$ NPs was discussed [159]. In this study, the nanospheres and nanocrystals of various sizes were compared (Fig. 24). The HSE06 functional, which is considered as the best suited to describe semiconductors, was used. The comparison of HSE06 with the standard B3LYP functional was also presented. Faceted and spherical nanoparticles have been cut from the bulk anatase crystal (Fig. 24a-b). The initial geometry of anatase was derived from DFT calculation. It was shown that the calculated surface energies for NPs higher than for a regular surface. In general, it was demonstrated that these NPs have essentially different structural and electronic properties.

a)

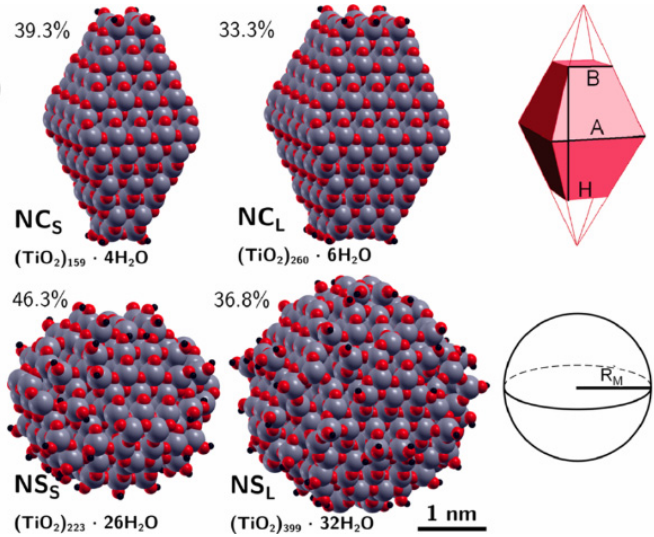

b)
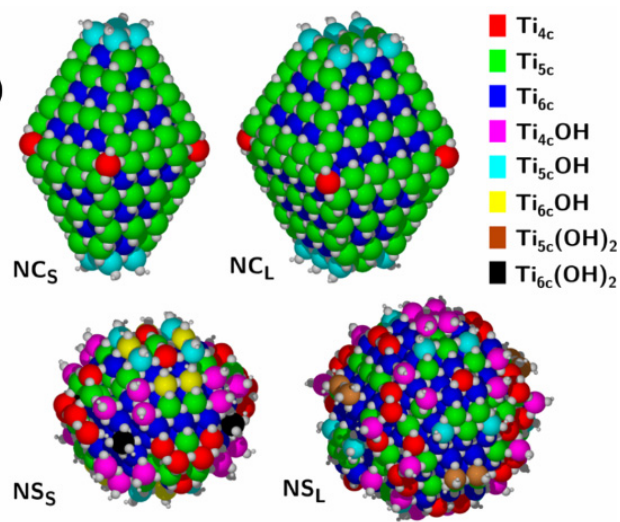

Figure 24. (a) Top: Space-filling representation of the faceted anatase NPs and the corresponding schematic representation of the Wulff-shape decahedron with its parameters A, B, and H. Bottom: Space-filling representation of the spherical anatase NPs and the corresponding schematic representation of the sphere with radius RM. The HSE06 optimized nanostructures are shown. The surface-to-bulk \% ratio and the stoichiometry of each NP are indicated on the side of the model. (b) The position of the Ti atoms with different coordination spheres within the various NPs is visually shown by the color-coding indicated on the right side. Adapted with permission from [159]. Copyright (C) 2015 American Chemical Society.

The electron and geometrical structure of $\mathrm{TiO}_{2}$ nanocrystals with an excess of electrons introduced by defects were investigated in [160]. The spin-polarized variant of the DFT theory and the exchangecorrelation functional HSE06 were used to characterize the electronic properties of the nanocrystals. The various oxygen and titanium atom (interstitial) defects were created by removing an $\mathrm{O}$ atom (for oxygen vacancy), and $\mathrm{Ti}$ was inserted into interstitial location between oxygen atoms ( $\mathrm{Ti}_{\text {int }}$ defect). According to the presented data, the oxygen vacancy demonstrated similar stability at the surface and sub-surface sites, whereas $\mathrm{Ti}_{\text {int }}$ was more stable at sub-surface sites. In general, the result of the study reveals the possibility of tuning the band structure through defects.

A water- $\mathrm{TiO}_{2}$ (anatase) interface was investigated in [161-162]. The calculations were performed by using a semiempirical variant of the DFT theory. Namely, the tide binding model, as an approximate DFT method (DFTB), was used for large cluster calculations. The DFTB method is more than a thousand times faster than the conventional B3LYP approach. Thus, the DFTB method can be used to calculate large clusters composed of thousands of atoms. The test calculations that were performed in [161-162] showed a rather good correspondence between the geometric parameters (water molecules and anatase slab cluster) obtained by the DFTB method and those obtained by the DFT/PBE method. In general, it proved that the DFTB set of parameters was able to reproduce the main features of the $\mathrm{Ti}$ /(water multilayers) interface with the DFT accuracy. However, it was pointed out that the DFT level of theory is still required when the electron excitations and electron transfer were under investigation. The benchmark study of DFTB against DFT is given in [163].

The accuracy of quantum chemical calculations of excited states was recently discussed in [164]. The results of the time-dependent DFT theory (TD-DFT) were compared with the equation of motion coupled-cluster singles and doubles (EOM-CCSD) data for rather small $\left(\mathrm{TiO}_{2}\right)_{n}$ with $n$ varying from 1 up to 13 clusters, respectively. High-quality basis sets were used, such as def2-SV(P), 
def2-TZVP, and def2-TZVPP, respectively. According to the computational data of the TD-DFT (with different functionals used) and EOM-CCSD methods demonstrated qualitatively similar results for excitation energies of $\mathrm{TiO}_{2} \mathrm{NPs}$. However, for systems with a significant charge-transfer character, the standard functionals (e. g. B3LYP) demonstrated a rather poor agreement with the exact EOM-CCSD approach [164]. Such a situation can be illustrated by the data presented in Table 3.

Table 3. Excitation energies (in eV) for the four lowest states ( $\left(\mathrm{TiO}_{2}\right)_{3}$ cluster, $C_{l}$ symmetry) [164].

\begin{tabular}{|c|c|c|c|c|c|}
\hline № & \multicolumn{3}{|c|}{ def2-TZVP } & def2-SV(P) & def2-TZVPP \\
\hline State & B3LYP & CAM- B3LYP & BHLYP & EOM-CCSD & EOM-CCSD \\
\hline 1 & 3.33 & 3.78 & 4.29 & 3.48 & 3.69 \\
2 & 3.49 & 3.91 & 4.41 & 3.59 & 3.80 \\
3 & 3.56 & 4.21 & 4.57 & 3.94 & 4.11 \\
4 & 3.71 & 4.33 & 4.68 & 4.02 & 4.20 \\
\hline
\end{tabular}

One can see from Table 3 that the best quantitative agreement between TD-DFT and EOM-CCSD (with the best basis set def2-TZVPP) was achieved for the CAM-B3LYP functional, while B3LYP demonstrated the rather poor accuracy [164].

The results of quantum chemical calculations of dye-sensitized $\mathrm{TiO}_{2}$ complexes are presented in numerous publications [165-170]. The range of dyes used for DSSC elements is amazing with its variety [171-178]. Some selected studied dyes used in solar cells are shown in Fig. 25. Beyond this list, many dyes are continuously designed as donor-acceptor $\pi$-conjugated systems based on coumarin, polyene, cyanine, thiophene, indoline, xanthene, perylene, porphyrin, and boron dipyrromethenes (BODIPY), etc. The corresponding reviews of organic dyes used for DSSC can be found elsewhere [151,155,165,179-180].

Some essential structural and electronic criteria, which required (but not sufficient) for a dye to generate a photocurrent upon adsorption on a semiconductor surface, have been suggested as following [165]:

- The anchoring group should be positioned on the electron-accepting group.

- The HOMO and LUMO of the dye should be energetically above the valence band edge (VBE) and the conduction band edge (CBE) of the semiconductor, respectively.

- The absorption spectrum should significantly overlap with the solar spectrum.

- The transition involved in the photoconversion phenomenon should have a high intensity.

- The fluorescence lifetime should be sufficiently high (above the nanosecond time scale) to allow an electronic injection to the semiconductor from the excited state of the dye before quenching of the excited state by radiative decay.

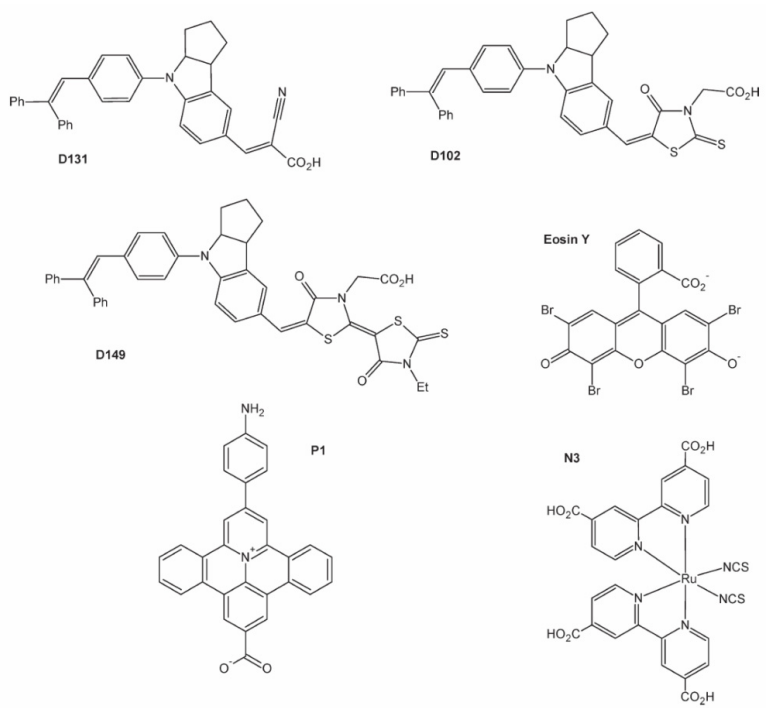

Figure 25. Structures of selected dyes: indolines (D131, D102 [181], and D149) [182], eosin-Y [176], pyridinium-based dye P1 [166], N3 (cis-[Ru-(4,4'-COOH-2,2'-bpy) ( $\left._{2}(\mathrm{NCS})_{2}\right]$ ) [175], respectively. Adapted with permission from [165]. Copyright (C) 2012 American Chemical Society. 
One of the most interesting works concerned dye- $\mathrm{TiO}_{2}$ complex is the article [183]. Herein indicates that even for rather simple $\pi$-systems, the interaction with $\mathrm{TiO}_{2}$ particles may lead to substantial changes in their optical properties. The catechol and dopamine molecules (Fig. 26a) in contact with $\mathrm{TiO}_{2}$-NPs were studied. Three modes of connection with $\mathrm{TiO}_{2}$ were discussed. The bidentate mode corresponds to the connection of the molecule with two Ti sites via two oxygen atoms (Fig. 26b). The chelate mode is a connection of a molecule with a single Ti site via two oxygen sites. The monodentate mode corresponds to the connection of a molecule with a single Ti site, which is realized via a single oxygen site (Fig. 26b). The TD-DFT/CAM-B3LYP/6-311+G* approach was used for an adequate description of charge-transfer excitations. It was demonstrated that the interacting systems show the redshift of the absorption compared to isolated molecules and clusters. The calculation of natural orbits indicates the significant charge-transfer character of the excitations [183].
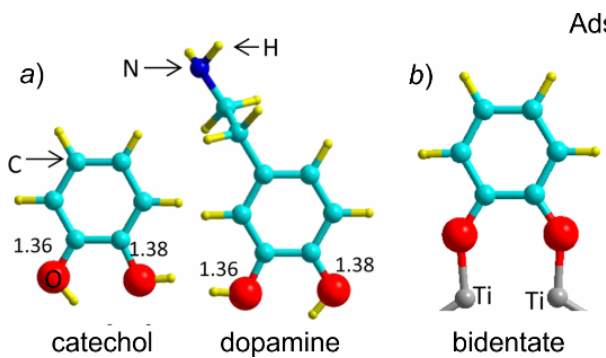

Adsorption modes

Figure 26. (a) Schematic representation of catechol and dopamine. (b) Possible adsorption modes of catechol. Adapted with permission from [183]. Copyright (c) 2016 American Chemical Society.

Based on synthesized polycyclic 9,14-dihydro-4H-dithieno[ $\left[2^{\prime}, 3^{\prime}: 2,3 ; 3^{\prime}, 2^{\prime}: 10,11\right]$-piceno[1,14,13,12bcdefgh]carbazole (DTPC) the in silico analysis and design for suitable electron withdrawing structures was performed [184]. The electronic structure calculations have been performed by using the B3LYP and MPW1K functionals with the $6-311 \mathrm{G}(\mathrm{d}, \mathrm{p})$ basis set. The molecular structure of investigated systems is typical for a dye used in DSSC elements (Fig. 27). Here the main part of a molecule is electron donor fragment, while $\mathbf{X}$ is an electron acceptor. The carboxylic acid that was attached to acceptor group $\mathbf{X}$ is an anchoring group since this group can provide strong dye- $\mathrm{TiO}_{2}$ adsorption [184]. Geometry and electronic structure of the ground and excited states for systems with different $\mathbf{X}$ (Fig. 27) was predicted by means of the DFT method. The calculated by using functional B3LYP maximum absorption wavelength for parent dye $\left(\lambda_{\max }=596 \mathrm{~nm}\right)$ agreed well with known experimental data $\left(\lambda_{\max }=609 \mathrm{~nm}\right)[184]$.

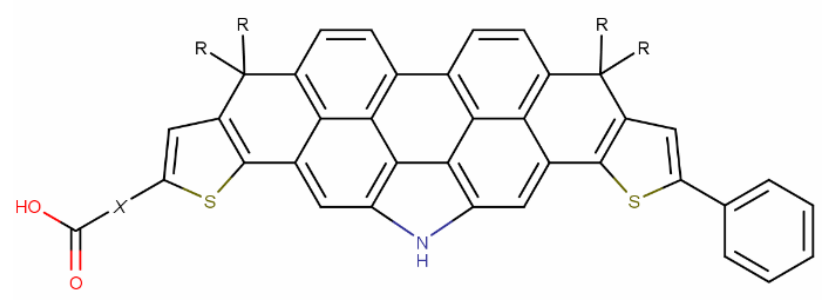

Figure 27. The molecular structure of the parent dye studied in [184].

The most critical parameters that influence the DSSC device performance were calculated. Among them, the LHE (light-harvesting efficiency), the number of injected electrons, the electron-injection lifetime, and the quantum-energy alignment of the adsorbed dye molecule to $\mathrm{TiO}_{2}$ components. The results of work demonstrated that by modifying the acceptor group $(\mathbf{X})$ the optical properties of dyes and the energy alignment of dye- $\mathrm{TiO}_{2}$ structure could be tuned [184].

The effects of electron donor group on electronic and optical properties of arylamine-based dyes for DSSC were investigated in [185] (Fig. 28). DFTB optimized geometries of a dye and dye-TiO ${ }_{2}$ conjugates were used for TD-DFT excited states calculations. The following functionals were used: CAM-B3LYP/3-21G(d), LC- $\omega P B E / 6-31+G(d)$, and mPWDandHPW91/6-31G(d), respectively. The results show that the functional $\omega \mathrm{PBE} / 6-31+\mathrm{G}(\mathrm{d})$ with the damping parameter of $0.175 \mathrm{au}^{-1}$ provides the best agreement with experimental values. New rigid triarylamine based dyes were designed. Some 
critical parameters, such as $\eta(\%)$ and LHE, as well as other characteristics, were calculated. It was demonstrated that the investigated optical properties of new systems match with the requirement of an effective sensitizer [185].

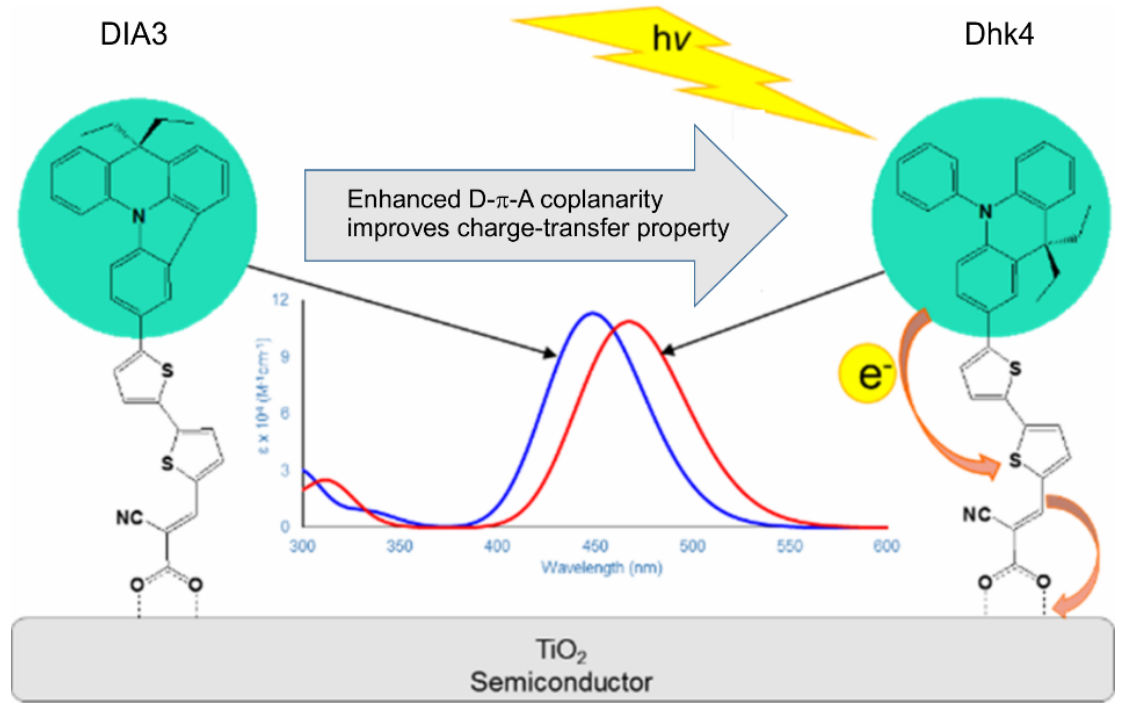

Figure 28. Schematic illustration demonstrating that new dye Dhk4 was designed by modifying the rigidity of its donor moiety via altering the type and position of binding in the donor group. This structure modification leads to distinct planarity of the dyes, which significantly affects its properties so that Dhk4 dye showed more redshifted and broadened absorption spectra owing to the enhanced coplanarity between its donor and $\pi$-bridge moiety, as compared with a parent dye DIA3. Adapted with permission from [185]. Copyright (C) 2016 American Chemical Society.

In the ref. [186], the effects of various anchoring groups on the electronic coupling of dye-to- $\mathrm{TiO}_{2}$ were investigated by means of $a b$ initio and molecular dynamics simulations. The set of anchoring groups includes the following structures: carboxylic acid $(-\mathrm{COOH})$, biscarbodithiolic acid $(-\mathrm{CSSH})$, phosphonic acid $\left(-\mathrm{PO}(\mathrm{OH})_{2}\right)$, sulfonic acid $\left(-\mathrm{SO}_{3} \mathrm{H}\right)$ and hydrixamic acid $(-\mathrm{CONHOH})$, respectively (Fig. 29a). The TD-DFT/PBE0/6-31G(d,p) with the PCM model for tetrahydrofurane solvent was used for excited-state calculations. It was shown that different anchoring groups give noticeably different contributions to LUMO. For instance, the contribution of a CSSH group is more significant than that of the $\mathrm{COOH}$ moiety. Hence, the CSSH group is favorable for electron injection from a dye to $\mathrm{TiO}_{2}$. Also, the effect of anchoring groups on an aggregation of a dye was investigated by MD simulations (Fig. 29b).

a)

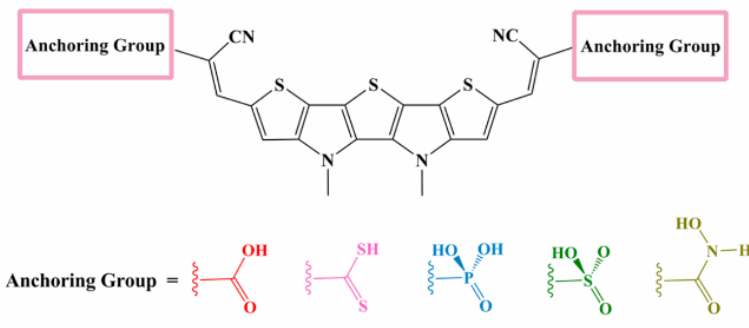

b)

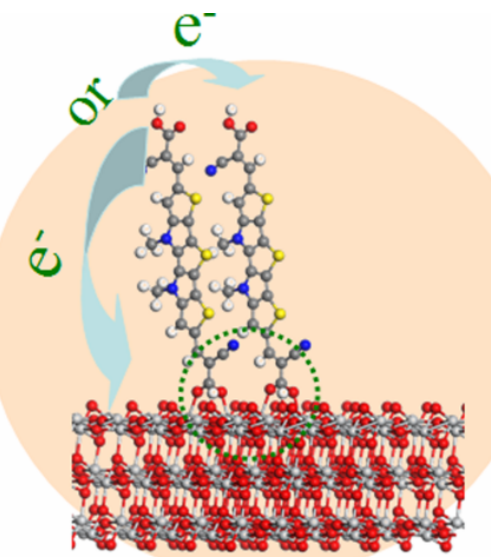

Figure 29. (a) Sketch structures of investigated dyes and corresponding anchoring groups. (b) A graph of the adsorption configuration of a head-to-head stacking dimer of the dye with the anchoring moiety $\mathrm{COOH}$ onto the $\mathrm{TiO}_{2}(101)$ surface, indicating two possible routes for electron transfer: (i) electron injection from a dye to $\mathrm{TiO}_{2}$ and (ii) dye-to-dye electron migration, respectively. Adapted with permission from [186]. Copyright (C) 2017 American Chemical Society. 
In addition, the role of anchoring modes in adsorption of retinoic acid (RA) Fig. 30a on $\mathrm{TiO}_{2}$ was studied by DFT calculations [187]. Three anchoring modes of RA, which contains a carboxylic acid group, were considered, as shown in Fig. $30 b$.

a)
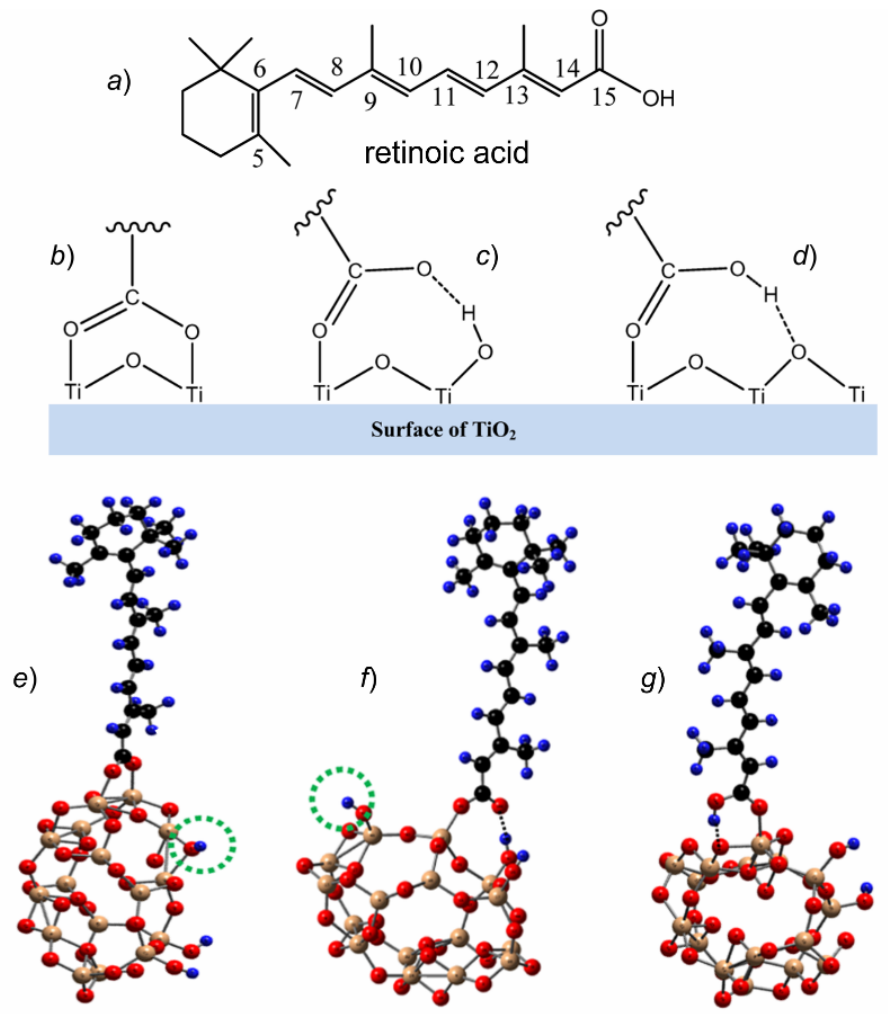

Figure 30. (a) Structure of retinoic acid (RA). (b- $d$ ) Three anchoring modes of a carboxylic acid group of RA on the surface of $\mathrm{TiO}_{2}$ : $(b)$ the carboxylic acid group loses a proton and forms two coordination bonds with two surface $\mathrm{Ti}$ atoms of $\mathrm{TiO}_{2} ;(c)$ the carboxylic acid group loses a proton and forms one coordination bond with one surface $\mathrm{Ti}$ atom of $\mathrm{TiO}_{2}$ and one hydrogen bond (H-bond) with a Ti-OH group on the surface of $\mathrm{TiO}_{2} ;(d)$ the carboxylic acid group does not lose a proton and forms one coordination bond with one surface $\mathrm{Ti}$ atom of $\mathrm{TiO}_{2}$ and one $\mathrm{H}$-bond due to the interaction between the $\mathrm{OH}$ group of the carboxylic acid group and the bridging oxygen atom on the surface of $\mathrm{TiO}_{2}$. Optimized structures of $\mathrm{RA}$ adsorbed onto a $\left(\mathrm{TiO}_{2}\right)_{16}$ cluster by various anchoring modes: $(e)$ anchoring mode $b$, $(f)$ anchoring mode $c$, and $(g)$ anchoring mode $d$, respectively. Adapted with permission from [187]. Copyright (C) 2019 American Chemical Society.

The analysis of the B3LYP/6-31G(d) optimized structures revealed (Fig. 30b) that among the three anchoring modes, the mode $c$ involving surface $\mathrm{Ti}-\mathrm{OH}$ groups was suggested to have the highest driving force for photo-induced electron transfer. In this bound geometry, the mixing between the RA's LUMO and the conduction band states of $\mathrm{TiO}_{2}$ was also the highest. The calculated results were supported by EPR measurements, which showed enhanced light-driven charge separation upon increasing the density of the $\mathrm{Ti}-\mathrm{OH}$ groups on the surface of $\mathrm{TiO}_{2}$. It was found that the anchoring modes affected the bond length, degree of conjugation, energies of the HOMO and LUMO, and the mixing of the dye's excited states with the conduction band states of a semiconductor (Fig. 30e-g).

The influence of the chemical environment at the electrolyte/dye $/ \mathrm{TiO}_{2}$ interface on the adsorption geometries and electronic properties of a dye adsorbed on $\mathrm{TiO}_{2}$ was considered by first-principles calculations [188]. Various adsorption modes of a series of organic dyes (Fig. 31a-b) on the (101) surface of anatase $\mathrm{TiO}_{2}$ were examined in the absence and the presence of explicitly coadsorbed solvent (water or acetonitrile) molecules. Periodic DFT calculations were carried out within the generalized gradient approximation (GGA) using the PBE exchange-correlation functional [188]. It was found that coadsorbed solvent molecules introduced important modifications on the dye adsorption geometry with respect to the geometry calculated in vacuo (Fig. 31c-f). In particular, the bonding distance of the dye from the Ti anchoring atoms increased, whereas the adsorption energy decreased. Moreover, the adsorbed solvent induces the deprotonation of the dye due to the changing the acid/base 
properties of the system. Analysis of the electronic properties for the dye-sensitized $\mathrm{TiO}_{2}$ structures in the presence of coadsorbed solvent molecules revealed an upward shift in the $\mathrm{TiO}_{2}$ conduction band from 0.5 up to $0.8 \mathrm{eV}$ in acetonitrile [188]. It should also be noticed that a similar shift of the $\mathrm{TiO}_{2}$ conduction band was estimated for a solvent monolayer on unsensitized $\mathrm{TiO}_{2}$.

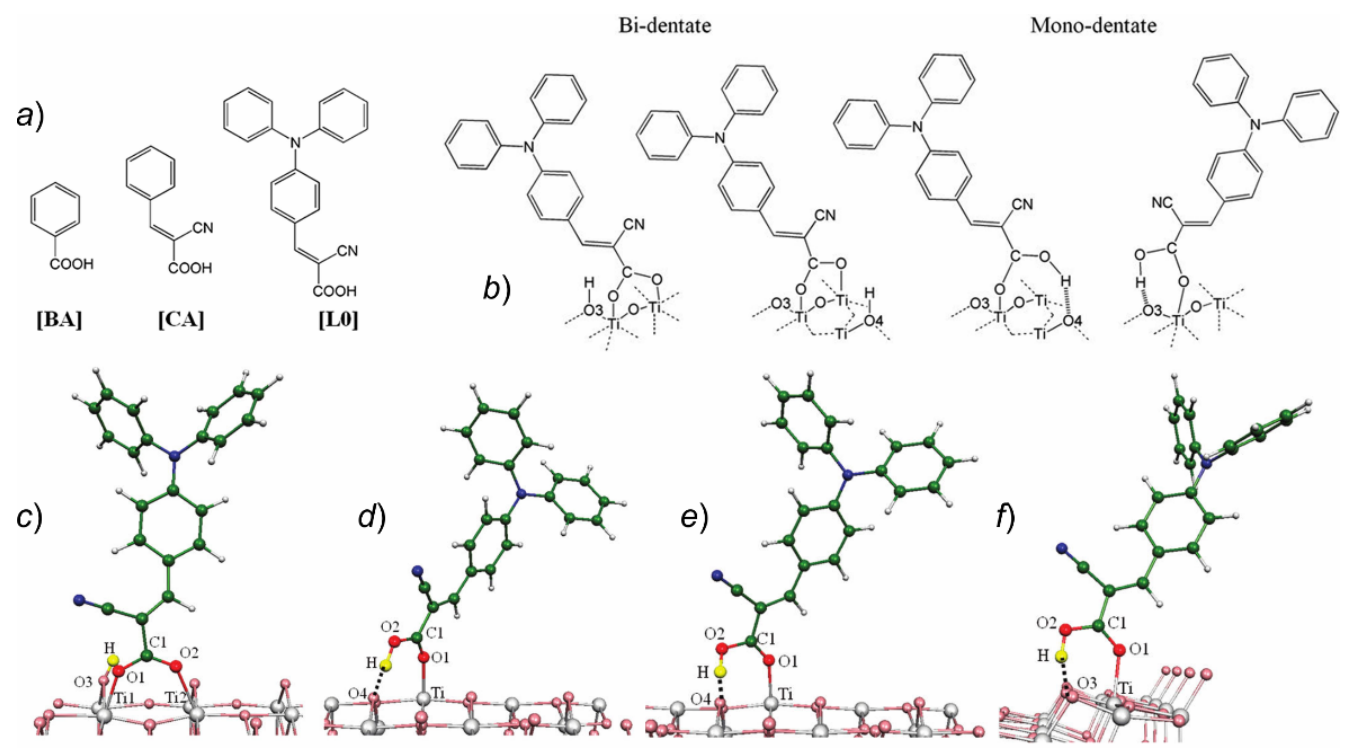

Figure 31. (a) Chemical formulae of the investigated molecules: benzoic acid [BA], 2-cyano-3-phenyl-acrylic acid ([CA]), and 4-(diphenylamino)phenylcyanoacrylic acid [L0]. (b) Schematic representation of the considered adsorption modes of [L0] on a $\mathrm{TiO}_{2}$ anatase (101) surface. (c-f) DFT optimized adsorption structures of [L0]: bidentate $(c)$; molecular monodentate $(d-f)$. Adapted with permission from [188]. Copyright (C) 2012, American Chemical Society.

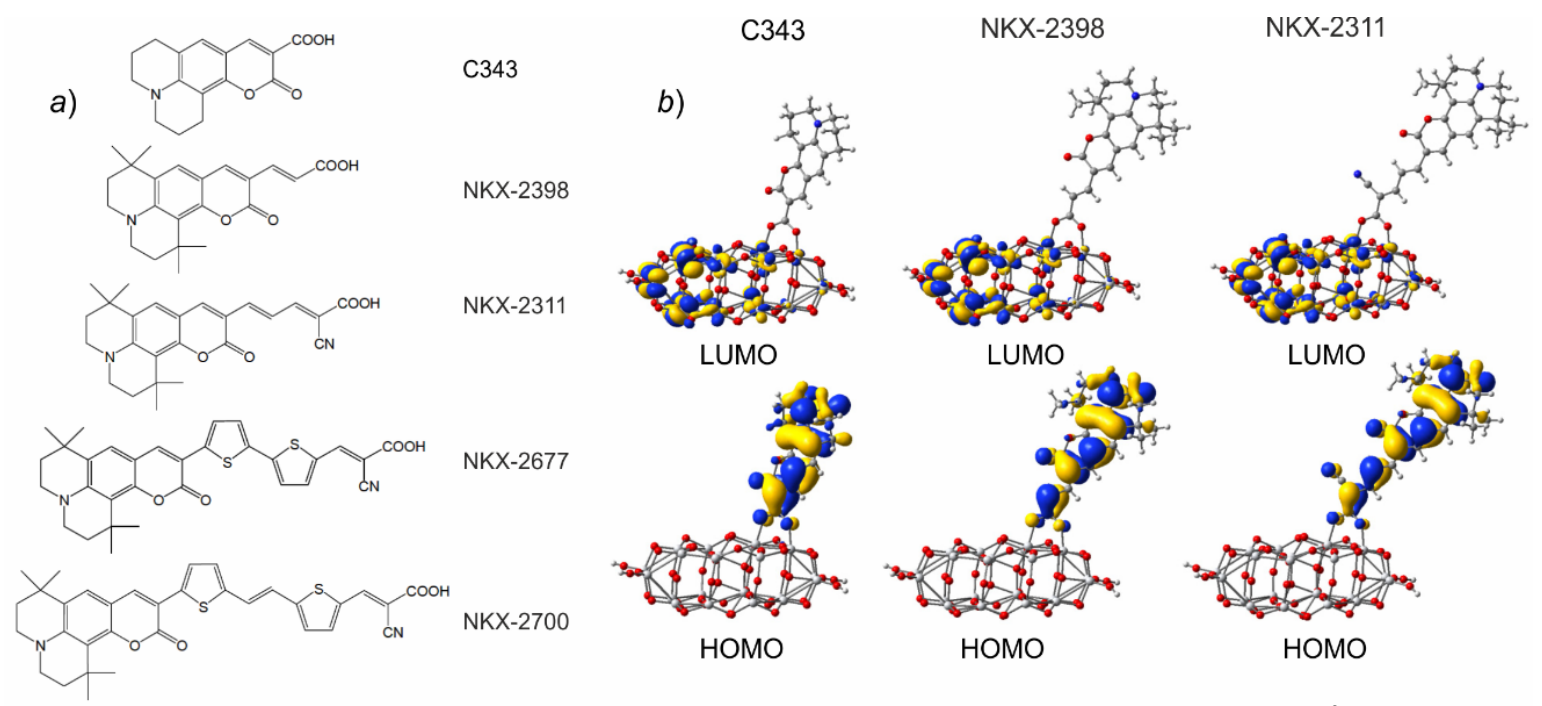

Figure 32. (a) Molecular structures of coumarin-based dyes. (b) Isodensity surfaces $\left(0.02 \mathrm{e} / \mathrm{bohr}^{3}\right)$ of the HOMO and LUMO orbitals of the dyes adsorbed on the $\mathrm{TiO}_{2}$ nanocluster $\left(\mathrm{Ti}_{24} \mathrm{O}_{50} \mathrm{H}_{4}\right)$ calculated with the B3LYP functional and a combined basis DZVP/LANL2DZ and modeled in PCM-water. Adapted from [169]. Copyright (C) 2013 MDPI (Basel, Switzerland).

A joint experimental and computational study of the optical and charge transfer properties of D102 dye in the presence of Li-TFSI and EMIM-TFSI additives, as well as at the dye-sensitized TiO2 interface, was reported [181]. Experimental UV adsorption spectra showed that the spectral shifts of D102 are negligible for the dye in solution. However, upon moving to the $\mathrm{TiO}_{2}$ film these additives resulted in some slight red-shifts in spectra, accompanied with the appearance of a lower-energy shoulder in the absorption spectrum. B3LYP/6-311G** and PBE0/6-311G** calculations showed the formation of weak dye/additive complexes in solution and also predicted spectral red-shifts. Moreover, the strong 
effect of these additives on the electronic coupling between the dye's LUMO and the $\mathrm{TiO}_{2}$ conduction band states, approximated by $\left(\mathrm{TiO}_{2}\right)_{82}(101)$ two-layer anatase slab [181].

The systematical theoretical study of seven $\mathrm{D}-\mathrm{A}-\pi-\mathrm{A}$-based indoline (IND) dyes (Fig. 33a) was comprehensively investigated via quantitative-structure-property relationships to evaluate their prospect of application in DSSCs [195].

a)
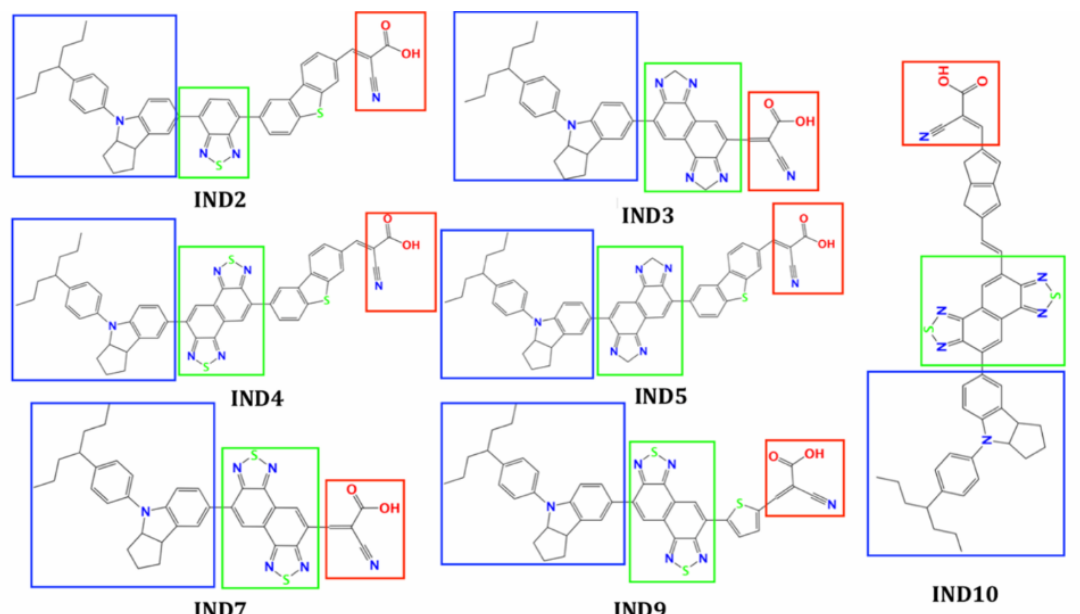

b)

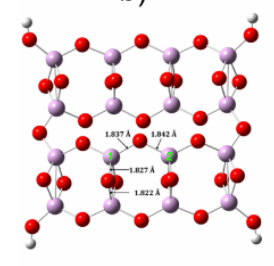

c)

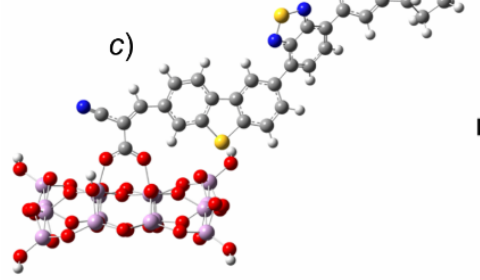

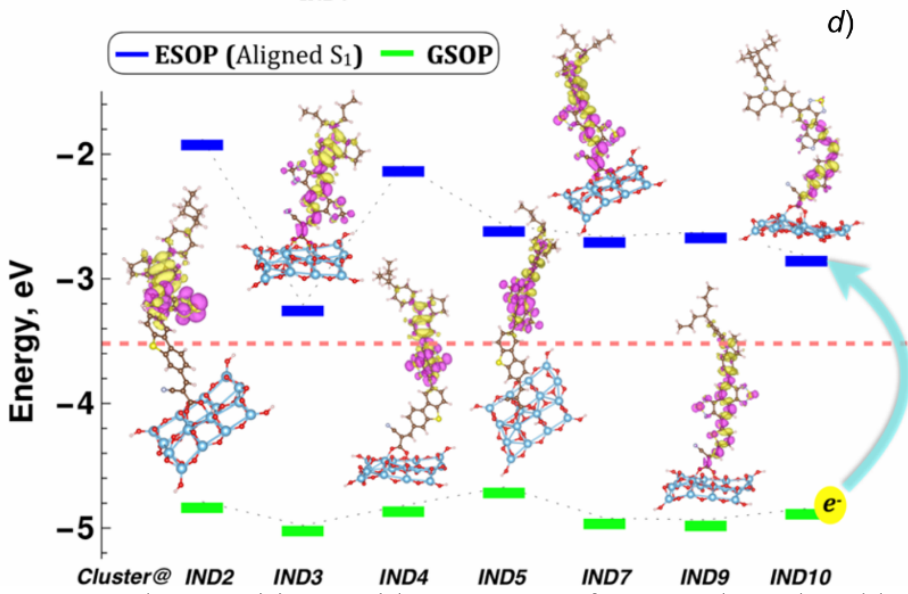

Figure 33. (a) Chemical structures of seven IND dye-sensitizers with $\mathrm{D}-\mathrm{A}-\pi-\mathrm{A}$ framework. Colored boxes are indicating constituents of the framework. Blue (D), green (A or internal acceptor), red (A or cyanoacrylic acid), and the fragment in between red and green box is the $\pi$-spacer, $(b-c)$ Fully relaxed optimized geometry of the model $\mathrm{TiO}_{2}$ cluster $\left(\mathrm{Ti}_{16} \mathrm{O}_{34} \mathrm{H}_{4}\right)$ and the IND2/ $\mathrm{TiO}_{2}$-cluster with bridged bidentate mode, $(d)$ Energy alignment of the IND dyes with respect to $\mathrm{TiO}_{2}$ along with the $\mathrm{CDD}$ of the dyes/ $/ \mathrm{TiO}_{2}$-cluster complex and $\mathrm{CB}$ of $\mathrm{TiO}_{2}$. Adapted with permission from [195]. Copyright (c) 2019 American Chemical Society. (For interpretation of the references to color in this figure legend, the reader is referred to the Web version of this article.)

Optoelectronic properties of the isolated dye and dyes adsorbed on a $\mathrm{TiO}_{2}$ cluster were explored by DFT (B3LYP and CAM-B3LYP with a combined 6-31G(d,p)/LANL2DZ basis set) and TD-DFT methods (Fig. 33b-c). Light absorption spectra, vertical dipole moment, shift of the conduction band of the semiconductor, excited-state lifetime, a driving force of electron injection, the photostability of the excited state, and exciton binding energy were computed. The authors showed that the presence of an internal acceptor such as pyrido[3,4-b]pyrazine would influence greater the open-circuit voltage $\left(\mathrm{V}_{\mathrm{OC}}\right)$, compared to the benzothiadiazole moiety (Fig. 33d). Considering the balance between the $\mathrm{V}_{\mathrm{OC}}$ and $\mathrm{J}_{\mathrm{SC}}$ (short circuit current), the IND3, IND5, and IND10 dyes were suggested as the most suited to be utilized as potential candidates for DSSC [195].

Different mechanisms for electron injection in DSSC are discussed in ref. [196]. The aim of work was to investigate structural aspects of a dye, which lead to specific electron injection to $\mathrm{TiO}_{2}$ mechanism. The classification of sensitizers was proposed. Type I of sensitizers corresponds to the indirect mechanism. For these systems, the orbitals involved in excitations mainly localized in the molecule. Type II is characterized by virtual orbitals mostly localized on a dye that appears well into the conduc- 
tion band of the semiconductor. These orbitals are formed via the interaction of $\mathrm{d}_{\mathrm{z} 2}$ orbitals of Ti atom and $p$-orbitals of the oxygen atom of the dye [196].

A series of Ru(II)-based dyes, labeled as $N$ dyes, such as N3 (Fig. 25), N719, N749, etc. have become prototypical benchmark systems for ab initio calculations sensitizing effect to $\mathrm{TiO}_{2}$ [197-199]. Earlier computational investigations of the absorption spectrum and the alignment of the ground and excited state energies for an $\mathrm{N} 719$ dye, adsorbed on an extended $\mathrm{TiO}_{2}$ anatase slab exposing the majority (101) surface, were carried out by DFT/TDDFT calculations (Fig. 34a) [198]. The geometry of the dye- $\mathrm{TiO}_{2}$ conjugate was optimized by using the PBE exchange-correlation functional together with a plane wave basis set and ultrasoft pseudopotentials [199]. TDDFT calculations were performed on the optimized geometries, employing the hybrid B3LYP functional with a $3-21 \mathrm{G}^{*}$ basis set. A polarizable continuum model of solvation (C-PCM) was employed to treat the effect of the surrounding water solvent. It was found that the calculated and experimental absorption spectra for the dye- $\mathrm{TiO}_{2}$ conjugate were in excellent agreement with an absorption maximum deviation below $0.1 \mathrm{eV}$ (Fig. 34b). The lowest optically active excited state was found to lie ca. $0.3 \mathrm{eV}$ above the lowest $\mathrm{TiO}_{2}$ state. The latter was characterized with a sizable contribution from the dye $\pi^{*}$ orbitals, strongly mixed with unoccupied $\mathrm{TiO}_{2}$ states (Fig. 34c). Therefore, an ultrafast electron injection component was predicted on the basis of the strong coupling and of the matching of the visible absorption spectrum and density of $\mathrm{TiO}_{2}$ unoccupied states (Fig. 34d).
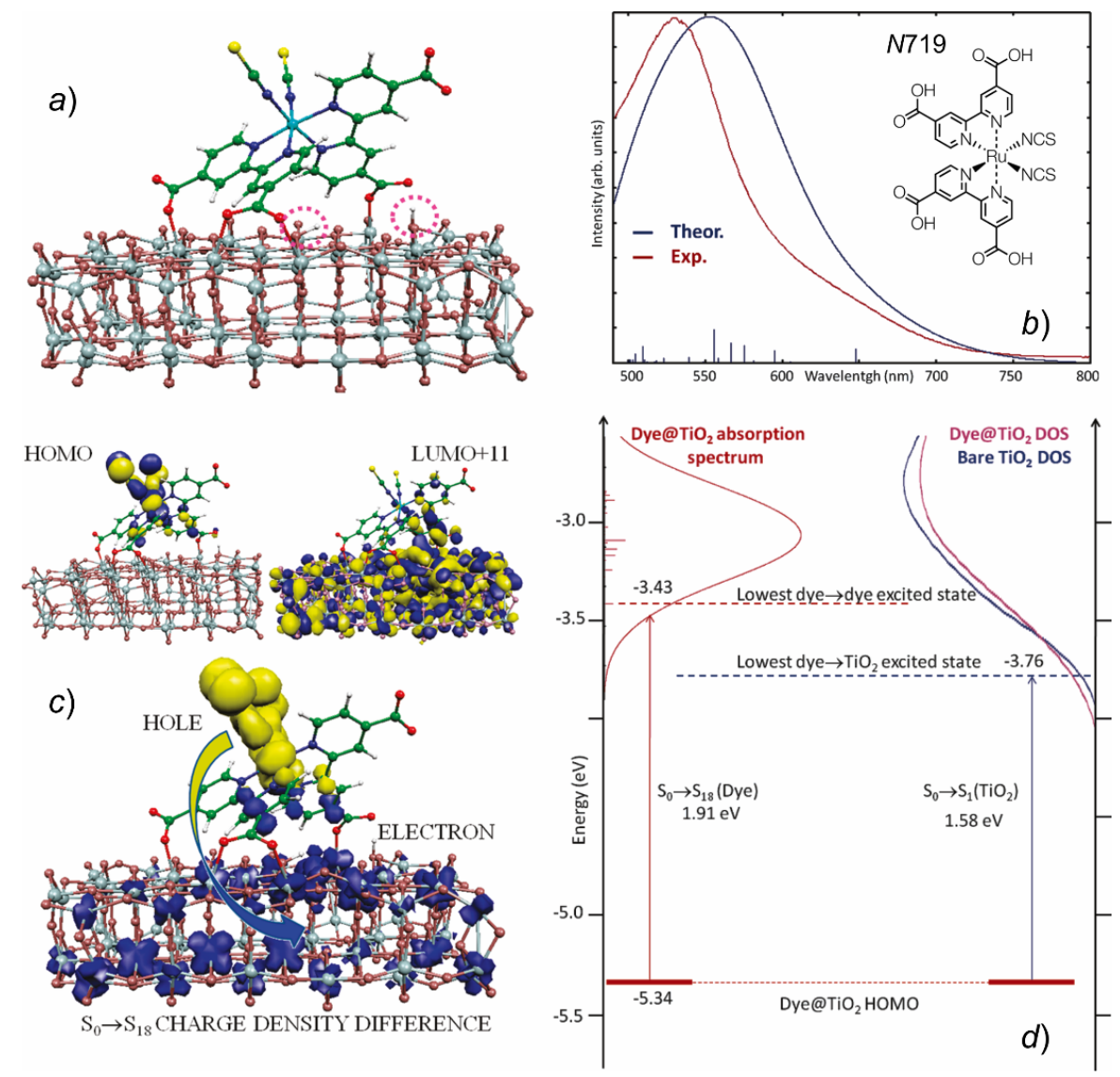

Figure 34. (a) Optimized structure of the N719 dye with two protons and no counterions adsorbed on the $\left(\mathrm{TiO}_{2}\right)_{82}$ slab. The position of the two protons is denoted by the dotted circles. (b) Comparison between the experimental (red) and calculated (blue) absorption spectra of $\mathrm{N} 719$ on $\mathrm{TiO}_{2}$. For clarity, the experimental spectrum intensity has been normalized to the calculated absorption maxima. Blue vertical lines represent unbroadened transition wavelengths and oscillator strengths. (c) Isodensity plots of the HOMO and LUMO+11 of the $\mathrm{N} 719-\mathrm{TiO}_{2}$ conjugate. Bottom: Charge density difference between the ground state $\left(\mathrm{S}_{0}\right)$ and the $\mathrm{S}_{18}$ excited state. A blue (yellow) color signifies and increases (decrease) of charge density upon electron excitation. (d) Left: alignment of the ground and excited-state energy levels for the $\mathrm{N}^{2} 19-\mathrm{TiO}_{2}$ conjugate. Right: the calculated density of unoccupied $\mathrm{TiO}_{2}$ states, aligned to the energy of the lowest $\mathrm{TiO}_{2}$ state in the conjugate. Adapted with permission from [198]. Copyright $(\mathcal{C} 2011$ American Chemical Society. (For interpretation of the references to color in this figure legend, the reader is referred to the Web version of this article.) 
Successes, failures, and challenges of quantum chemical calculations of excited states and alignment of energy levels in dye-sensitized solar cells were critically analyzed in the context of the potential and limitations of current DFT and TDDFT computational methods to model DSCs [197]. Pastore, Fantacci, and De Angelis considered the ground and excited-state properties of both isolated and $\mathrm{TiO}_{2}-$ adsorbed metallorganic and fully organic dyes, relevant to modeling the dye $\rightarrow$ semiconductor electron injection process. By reviewing previous data from their laboratory, combined with new calculations (Fig. 35a-b), they suggested that ruthenium dyes are typically accurately described by standard DFT approaches [165,197-198]. However, in the case of highly conjugated organic dyes, which are often characterized by strong charge-transfer excited states, some specifically tailored exchange-correlation functionals, such as CAM-B3LYP, are required. It was shown that for donor-acceptor organic dyes, a simple picture based on the dye lowest unoccupied molecular orbital (LUMO) broadening accounts for the different interfacial electronic coupling exhibited by dyes with different anchoring groups. It was also concluded that the explored DFT/TDDFT functionals, such as B3LYP, MPW1K, and CAM-B3LYP, estimate a balanced description of the dye- $\mathrm{TiO}_{2}$ excited states and of the alignment of the dye excited states with the semiconductor manifold of unoccupied states with different accuracy (Fig. 35c) [197].

a)
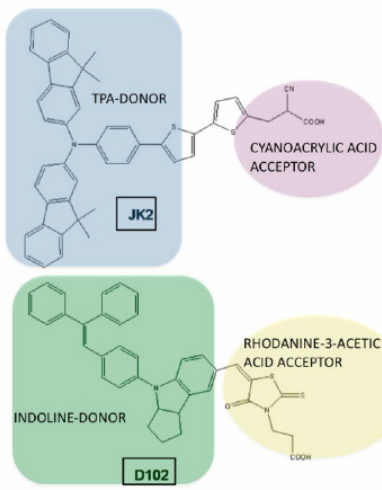
RHODANINE-3-ACETIC RHODANINE-3-ACE
ACID ACCEPTOR

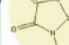

$$
\text { E (eV) }
$$

c)

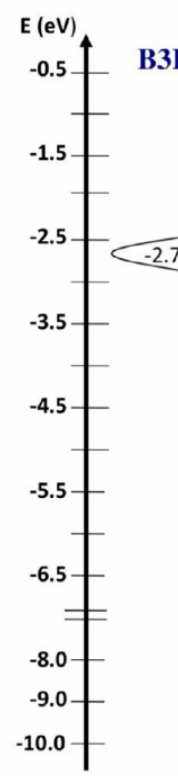

b)
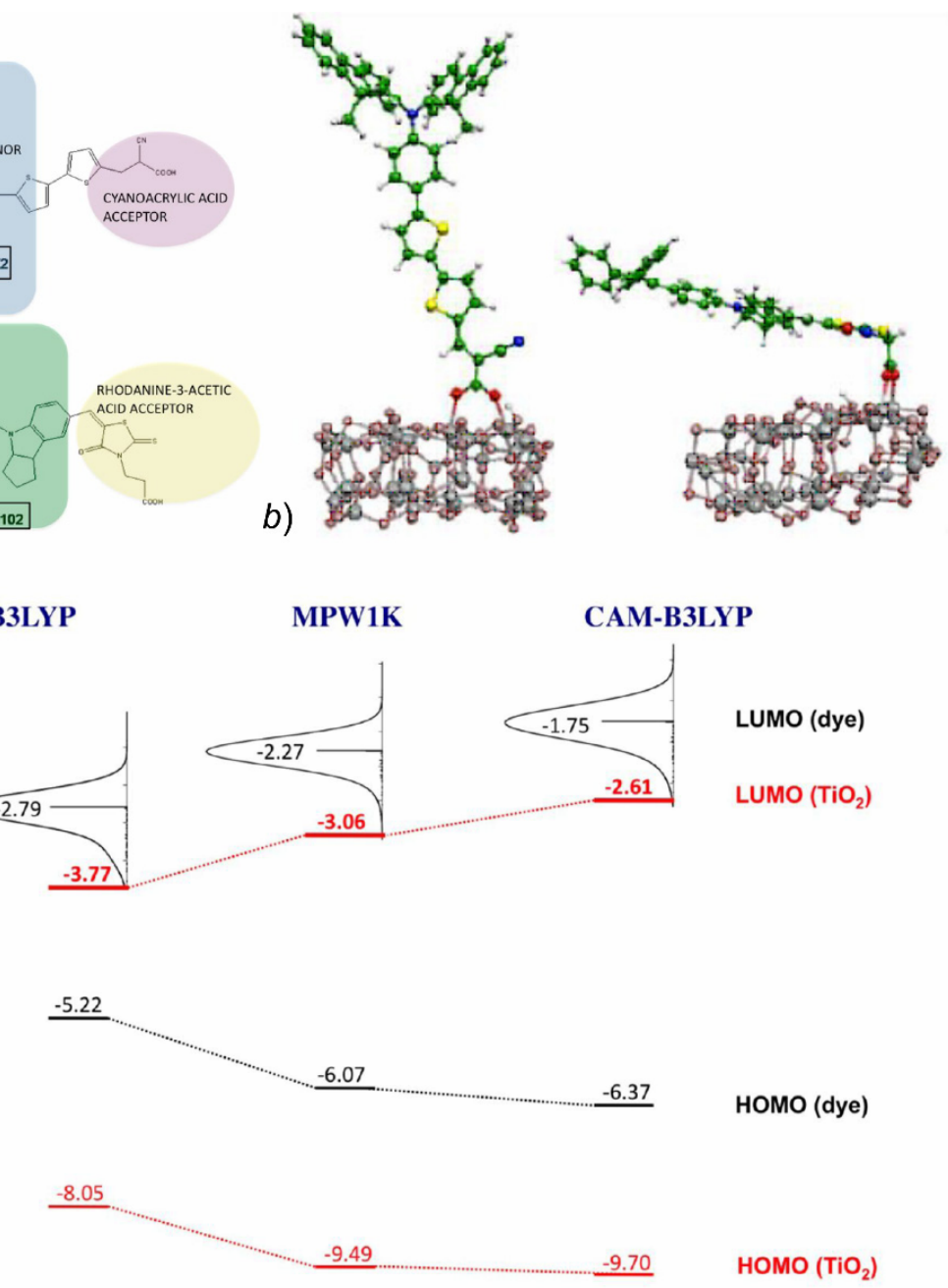

HOMO $\left(\mathrm{TiO}_{2}\right)$

Figure 35. (a) Molecular structures of a JK2 dye, containing a triphenylamine(TPA)-like donor ( $N, N$-bis(9,9-dimethylfluorene-2-yl)phenyl) with a cyanoacrylic acid as an anchoring unit, and a D102 dye, containing indoline and rhodanine-3-acetic acid as electron donor and acceptor groups. $(b)$ Optimized geometries of JK2- $\left(\mathrm{TiO}_{2}\right)_{38}$ and D102- $\left(\mathrm{TiO}_{2}\right)_{38}$. (c) Scheme of the energy levels of the D102- $\mathrm{TiO}_{2}$ system calculated by the B3LYP, MPW1K, and CAM-B3LYP functionals in the PCM water solution. The dye's LUMO is represented through the dye's projected density of states (PDOS). Adapted with permission from [197]. Copyright (C) 2013 American Chemical Society. 
A fully atomistic computational approach was suggested to capture the differences between direct (type-I) and indirect (type-II) photoinjection mechanisms by a time-dependent density functional tightbinding (TD-DFTB) approach [200-203]. The type-I photoinjection involves two steps (Fig. 36a): (i) an excitation from the ground state to the excited state of the dye, which is produced by the absorption of a photon, (ii) an electron transfer to the conduction band of the semiconductor nanoparticle (NP). Whereas the type-II photoinjection is referred to as the one-step electron injection from the ground state of the dye to the conduction band of the semiconductor upon photoabsorption. It should be noted that, in the type-II mechanism, a new charge-transfer band appears, which characterizes the direct electron excitation into the conduction band and can be observed in the UV-vis absorption spectrum. On the opposite, in the type-I mechanism, no new bands are expected in the UV-vis spectra. A model anatase $\mathrm{TiO}_{2} \mathrm{NP}$ (a 270 atom $\left(90 \mathrm{TiO}_{2}\right.$ units)) functionalized with different dyes, such as alizarin, coumarin $\mathrm{C} 343$ (C343), catechol, cresol, [Ti(Ph-tetra- $t$-Bu)(catechol- $\left.\left.\mathrm{CO}_{2} \mathrm{H}\right)\right]$, aniline derivative, and naphthalenediol, was considered. The equilibrium structure of the anatase $\mathrm{TiO}_{2} \mathrm{NP}$ was taken from an equilibrated MD simulation at $300 \mathrm{~K}$ by using the MA FF parameters [200-201,203]. It was shown that the nature of the photoabsorption process in the dye- $\mathrm{TiO}_{2} \mathrm{NP}$ can be understood in terms of orbital population dynamics occurring during photoabsorption (Fig. 36b) [200]. Fig. 36c-d shows that alizarin and coumarin C343 exhibited an indirect (type-I) mechanism for electron injection because no new absorption band was observed in the visible region upon adsorbing the dye onto the $\mathrm{TiO}_{2} \mathrm{NP}$. The lowest-energy band suffers a redshift for the alizarin-NP, while coumarin C343 shows a slight shift to higher energies. The lack of energy shift in the case of C343 might be understood in terms of the weak electronic coupling between the excited states of the dye and the anatase NP [200].

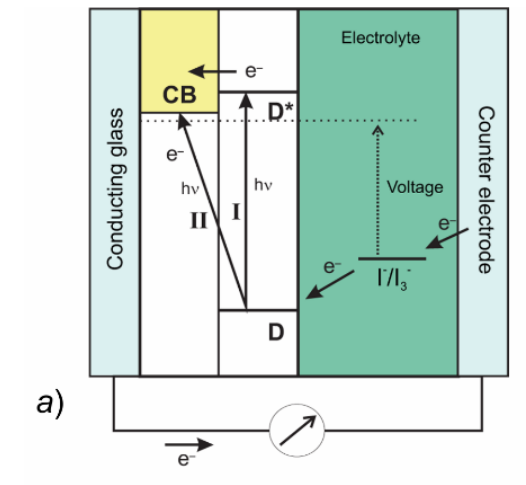

b)
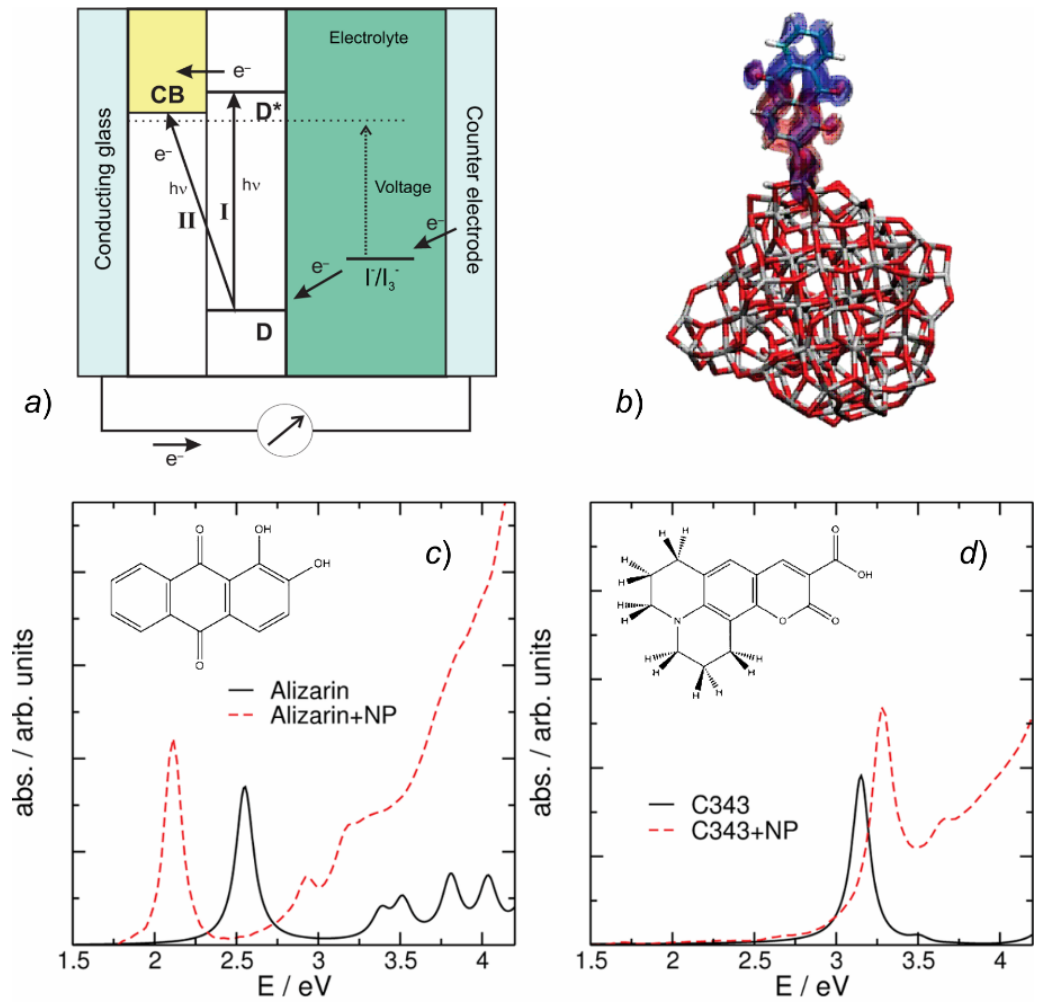

Figure 36. (a) Electron injection mechanisms type-I and type-II in a DSSC, where CB is a conduction band of the semiconductor and D is a dye. (b) A plot of the HOMO (red) and the LUMO (blue) of the alizarin- $\mathrm{TiO}_{2}$ conjugate superimposed on the respective atomic structures. $(c-d)$ Superposition of the optical spectra of the free dyes (black lines) and dyes anchored to the $\mathrm{TiO}_{2} \mathrm{NP}$ (red lines): alizarin (c), coumarin C343 (C343) (d). Adapted with permission from [200]. Copyright $\mathbb{C} 2012$ American Chemical Society. (For interpretation of the references to color in this figure legend, the reader is referred to the Web version of this article.)

The proton transfer at a dopamine-functionalized $\mathrm{TiO}_{2}$ interface was investigated by using dispersion-corrected hybrid DFT calculations and DFT tight-binding (DFTB) MD simulations [204]. The adsorption modes, patterns of growth, and configurations of dopamine on the anatase (101) $\mathrm{TiO}_{2}$ surface were considered with reference to the binding archetype of catechol. It was found that at low cov- 
erage, the isolated dopamine molecule prefers to bend toward the surface, coordinating the $\mathrm{NH}_{2}$ group to a $\mathrm{Ti}_{5 \mathrm{c}}$ ion. Whereas, at high coverage, the packed molecules were succeeded in bending toward the surface only in some monolayer configurations so that a proton transfer from the surface to the ethylamino group occurred. It was suggested that improving the probability of dopamine molecules being free to bend toward the surface through thermodynamic versus kinetic growth conditions should lead to the formation of a monolayer of fully protonated dopamine molecules [204].

Self-assembly of organic molecules on semiconductor surfaces is of crucial importance in the performance of DSSC devices. Several computational works were focused on a strong tendency of organic dyes to form molecular aggregates on the $\mathrm{TiO}_{2}$ surface [204-206].

The optical and electronic properties of dye aggregates of $p$-methyl red on a $\mathrm{TiO}_{2}$ anatase (101) surface were considered as a function of aggregation order varying from a monomer up to pentameric dyes (Fig. 37) by using dispersion-corrected DFT calculations (PBE functional and ultrasoft pseudopotentials) [205]. A progressive red-shifting accompanied by the intensity increase toward the visible region in UV-vis absorption spectra were observed from monomeric-to-tetrameric dyes. The calculated density of states (DOS) and partial DOS spectra reveal similar dye ${ }^{\cdots} \mathrm{TiO}_{2}$ nanocomposite conduction band characteristics; however, different valence band features were revealed. Associated molecular orbital distributions demonstrated dye-to- $\mathrm{TiO}_{2}$ interfacial charge transfer in all studied aggregates.

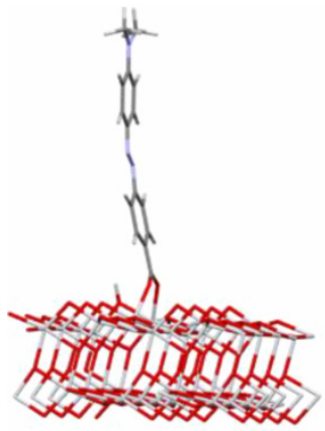

monomer

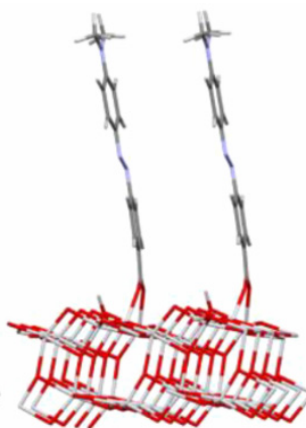

dimer

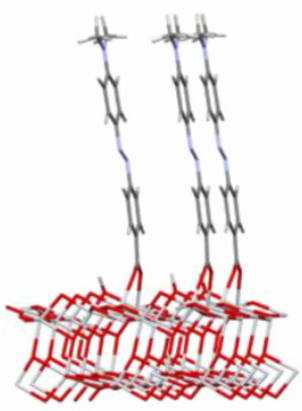

trimer

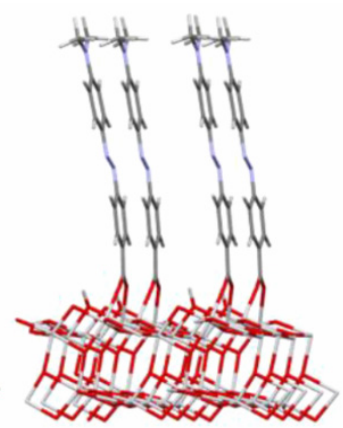

tetramer

Figure 37. Optimized structural geometries of different adsorbed dye aggregates. Adapted with permission from [205]. Copyright (C) 2014 American Chemical Society.

Adsorption modes, dynamics, self-aggregation, and optical properties of an indoline D102 dye adsorbed on $\mathrm{TiO}_{2}$ anatase (101) substrates were studied by reactive MD (ReaxFF) simulations combined with TD-DFT calculations [206]. The morphology and electronic properties of dye-sensitized heterogeneous interfaces were examined at an atomistic level. Extensive MD simulations of the adsorption of $\mathrm{D} 102$ dyes on medium/large size $\mathrm{TiO}_{2}$ anatase slabs allowed to monitor a variety of dye binding modes. It was suggested that the main driving forces toward the formation of ordered surface aggregates of D102 dyes are $\pi$ stacking and T-shaped interactions between the aromatic rings of the donor moiety of the dyes, as well as the tendency to maximize the anchoring points with the surface. The dye aggregates were found to be organized in domains, which are characterized by a different orientation of the packing units with a certain degree of short-to-medium range order [206].

Finally, at the end of this section, we suggest a few methodological conclusions from the results described above:

1) The results of the electronic structure calculations are insensitive to the geometry optimization method. The tight-binding DFT approach (DFTB) can be a realistic low-cost alternative to regular DFT geometry optimization.

2) The results of calculations are insensitive to the choice of basis set. Probably most of medium size contemporary basis sets (valence double-, triple $\zeta$ ) can lead to similar results.

3) The results of electronic property calculations are sensitive to the choice of the DFT functional.

4) The TDDFT excited states calculations by using standard exchange-correlation functional (B3LYP) perform well only for local excitations. However, for the excitations with a significant charge-transfer character the CAM-B3LYP (or M06-2X, etc.) is preferable. 


\section{$A b$ initio MD Investigations}

In the current section, we are briefly discussing the most interesting papers where ab initio MD simulation methods were predominately used for the theoretical investigation of the pristine $\mathrm{TiO}_{2}$ fragments or $\mathrm{TiO}_{2}$-based functional materials in the last two decades.

Ab initio (quantum or first principles) MD is the most powerful molecular modeling method for investigating the structure and dynamics of many-body systems in the framework of the condensed matter physics and computation quantum chemistry. The main idea underlying in any first principle MD method is to compute the true forces acting on the nuclei from proper electronic structure calculations that are performed "on the fly" as the MD trajectory is generated [207]. The three basic techniques are traditionally distinguished among an ab initio MD simulations: The first one is the conventional MD of nuclei using the quantum chemistry predicted Born-Oppenheimer (BO) potential energy surface (BOMD method). In the second MD technique, that was proposed by Car and Parrinello (CP), instead of solving the electronic structure problem at each new nuclear configuration, the so-called fictitious dynamics for the electronic orbitals (wave functions) is introduced that, as before, allows adiabatic motion of the nuclei (CPMD method) [208-209]. Both mentioned approaches deal with the ground state of an electronic sub-system. The third specific ab initio MD technique was designed for the solution of the more complicated non-adiabatic (NA) problems, such as electronic excitation and relaxation or particle collision and scattering (NA or Ehrenfest MD method) [210].

Earlier investigations of the photoinduced electron transfer from a molecular donor to the $\mathrm{TiO}_{2}$ semiconductor acceptor, using the NAMD simulation method, were carried out in a series of works by Stier and Prezhdo [211-213]. The small systems under study are typically composed of dye-sensitized semiconductor nanomaterials, used in solar cells, photocatalysis, and photoelectrolysis. The electronic structure of a dye-semiconductor system and the adiabatic dynamics were simulated using BOMD, while the NA effects were incorporated by the quantum-classical mean-field approach that neglects the quantum effects of the ionic motion, in particular, the zero-point energy and decoherence effects. A novel procedure separating the NA and adiabatic electron transfer pathways (Fig. 38) was also developed. The simulation provided a detailed picture of the ET process.

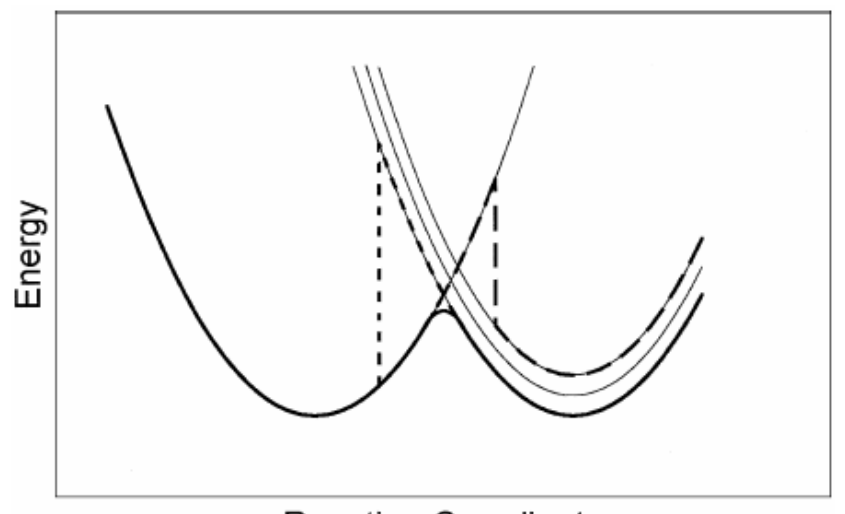

Reaction Coordinate

Figure 38. Adiabatic and NA pathways of electron transfer. In adiabatic electron transfer (solid bold line) the electron remains in the same adiabatic state throughout the reaction proceeding from the reactant state to the product state through the transition state. In NA electron transfer, the electron proceeds from the reactant state to the product state via a direct transition (bold dotted and dashed lines). Adapted from [211]. Copyright (C) 2002 WILEY-VCH Verlag GmbH \& Co. KGaA, Weinheim.

It was initially assumed that ground and excited state ion dynamics are similar. So, the change in the quantum force due to the electronic photoexcitation could be neglected and the following analysis might be greatly simplified. An important result was that thermally driven adiabatic transfer is the dominant electron transfer mechanism. Compared to the earlier simulation at $50 \mathrm{~K}$, the rate of NA transfer at $350 \mathrm{~K}$ remained almost unchanged, whereas the rate of adiabatic electron transfer increased substantially [211].

In the next two publications, the ultrafast dynamics of the photoinduced electron transfer process occurring between a model organic sensitizer molecule (isonicotinic acid) and a $\mathrm{TiO}_{2}$ semiconductor surface was simulated and discussed in details (Fig. 39). The model used in simulation exhibited the 
key features of the larger real systems studied before experimentally while providing a detailed simulation picture of the electron transfer mechanism [212-213].

Finally, the authors indicated that the NA electron transfer entirely dominated at short times and could occur due to the presence of the strong localized avoided crossing region, as well as the extended region of weaker NA coupling. Although the adiabatic electron transfer contribution accumulated more slowly, it approached that of the NA transfer pathway asymptotically. As a result, the simulation predicted a complex non-single-exponential time dependence of the electron transfer process [213].

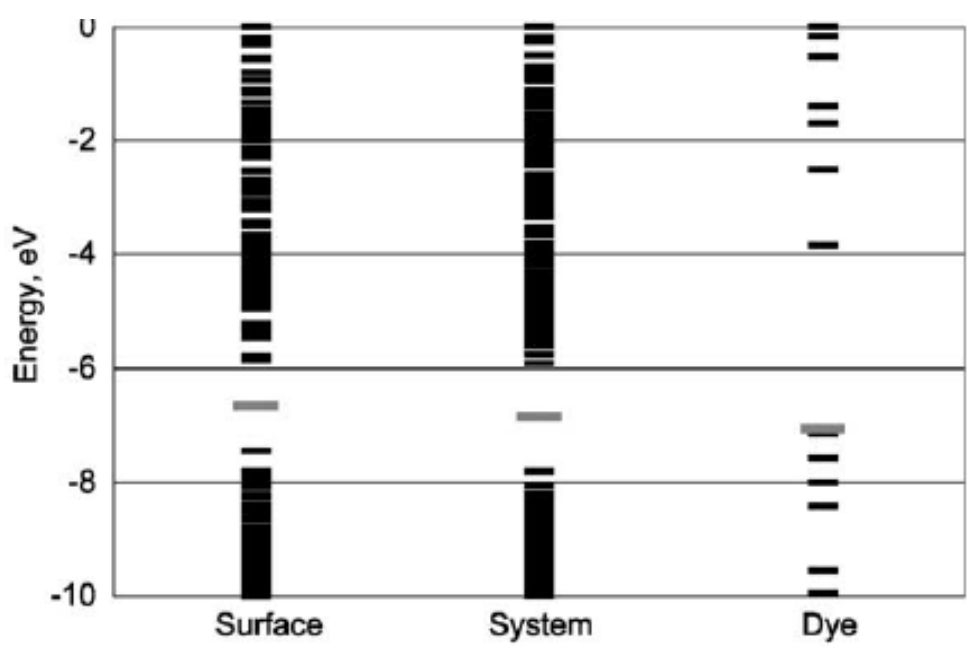

Figure 39. The Kohn-Sham orbital energies of the $\mathrm{TiO}_{2}$ surface, the isolated dye, and the combined system. The longer gray line indicates the Fermi energy. The HOMO-LUMO gap of the dye equals $3.2 \mathrm{eV}$ and is close to the $3.4 \mathrm{eV}$ energy of the first excited state calculated by the TD-DFT calculations. Adapted from [213]. Copyright (C) 2003 Elsevier B.V. All rights reserved.

An interesting theoretical investigation in the field of phase transformation mechanisms from anatase to the $\mathrm{TiO}_{2}$ nanosheets was carried out by Alvarez-Ramirez and Ruiz-Morales [214]. Several $a b$ initio MD simulations with the non-self-consistent Harris functional (so-called non-self-consistent BOMD) including $(i)$ the $\Gamma$-point approximation and (ii) the k-points were performed [214]. The three different size wire models of anatase with the periodic conditions along the $(0,1,0)$ direction were used and also several different environmental conditions were investigated.

It was found the titanate-type structures are energetically favorable. The transformation (Fig. 40) was followed by monitoring the formation of four-coordinated oxygen atoms, which constituted the characteristic sequence of edge-sharing $\mathrm{TiO}_{6}$ octahedrons of titanates. In addition, it was shown that the titanate-type structure could be transformed to anatase in a reversed mechanism. An essential factor in the transformation of the anatase-type sections to the $\mathrm{TiO}_{6}$ octahedrons was the interaction of the $(0,0, \pm 1)$ surfaces of the anatase with positive counter ions, which stressed the surface, deforming it and promoting the transformation [214].

Outstanding NAMD investigation of the so-called "wet-electrons" on the $\mathrm{TiO}_{2}$ surface was carried out by Prezhdo and coworkers [215]. Simulations directly mimicked real time-resolved experiments and revealed the nature of electron transfer in the "wet-electron" system. Earlier, the experimental and theoretical studies were done on the $\mathrm{TiO}_{2}(110) / \mathrm{H}_{2} \mathrm{O}$ interface have shown a short-lived state around $2.4 \mathrm{eV}$ above the Fermi level. The electron in this state was localized on the surface and was partially hydrated (Fig. 41). Therefore, it was named the "wet-electron". The time-resolved studies of the "wetelectrons" provide a fundamental understanding of the solvent role in the DSSC processes. The "wetelectron" state is higher in energy than the excited states of the majority of chromophores used in DSSC devices. Therefore, pristine "wet-electron" states are not directly involved in the photovoltaic processes [215]. 


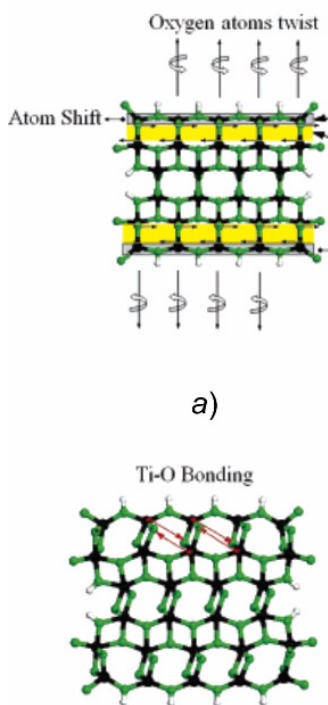

c)

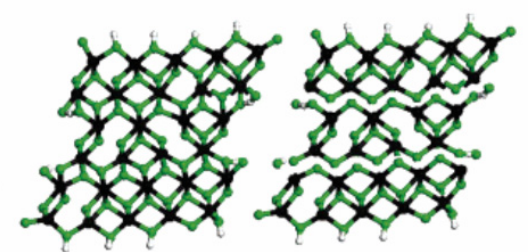

d)

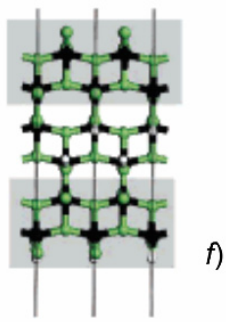

b)

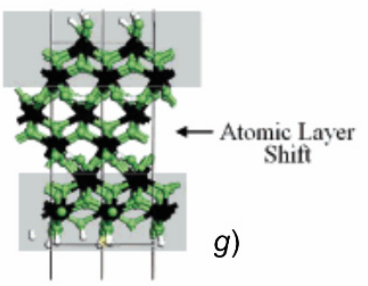

Figure 40. Schematic representation of the different stages in the mechanism of the phase transformation of anatase-to-lepidocrocite-type titanate. Panels $a$ and $b$ are initial configurations, where the initial atomic shifts and oxygen atom twisting are indicated. Panel $b$ is a slightly rotated view of crystal shown in Panel $a$. (c) This panel shows the structure shifted and twisted, where the formation of tetra coordinated $\left(T_{h}\right)$ oxygen atoms is indicated. (d) The crystal structure shown after the formation of the $T_{h}$ oxygen atoms is distorted. Panel $e$ is the same as Panel $d$, where the internal bonds were deleted to show that lepidocrocite-type titanate layers are formed. Panels $f$ and $g$ correspond to side views of the initial anatase structure and the final lepidocrocite structure, respectively. The internal layer dislocation can be observed In Panel $g$. Adapted with permission from [214]. Copyright (C) 2007, American Chemical Society.

It was shown that thermal phonon motions induced a large fluctuation of the "wet-electron" state energy, generated frequent crossings of the donor and acceptor states, and drove the adiabatic mechanism. The rapid phonon-assisted NA tunneling from the "wet-electron" state to the $\mathrm{TiO}_{2}$ surface was facilitated by the strong water- $\mathrm{TiO}_{2}$ electronic interaction. Besides, it was demonstrated that the motions of $\mathrm{H}_{2} \mathrm{O}$ molecules had a greater effect on the electron transfer dynamics than the hydroxyl vibrations [215].

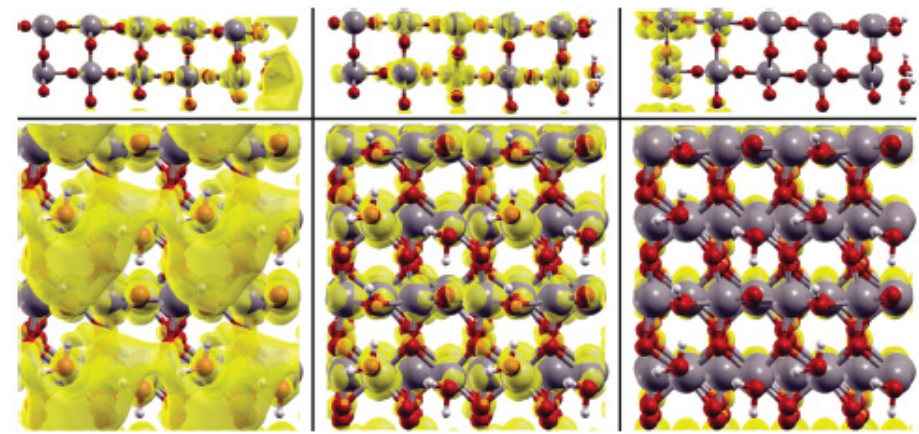

Figure 41. Charge densities for the "wet-electron" state (left), the surface state (middle), and the bulk state (right) of the "wet-electron" system. The charge is transferred sequentially from the "wet-electron" state through the surface state to the bulk state. The large delocalization of charge around the water molecules in the "wetelectron" state is shown, which is due to the dangling hydrogen atoms that help stabilize the electron. Adapted with permission from [215]. Copyright (C) 2009, American Chemical Society

In order to better understand the electron-hole relaxation of nano-scale $\mathrm{TiO}_{2}$ structures, it was important to start with an understanding of $\mathrm{TiO}_{2}$ synthesis building blocks. Such investigation was carried out by Vogel and Kilin [216], in which the $\mathrm{Ti}(\mathrm{OH})_{4}$ complex with tetrahedral coordination was examined. To simulate the electronic properties of the $\mathrm{Ti}^{\mathrm{IV}}$ ion in solution, the model was surrounded with explicit $27 \mathrm{H}_{2} \mathrm{O}$ molecules (Fig. 42). The model was explored by means of standard DFT BOMD 
followed by NA electron dynamics computed with a reduced density matrix approach combined with "on-the-fly coupling" [216].

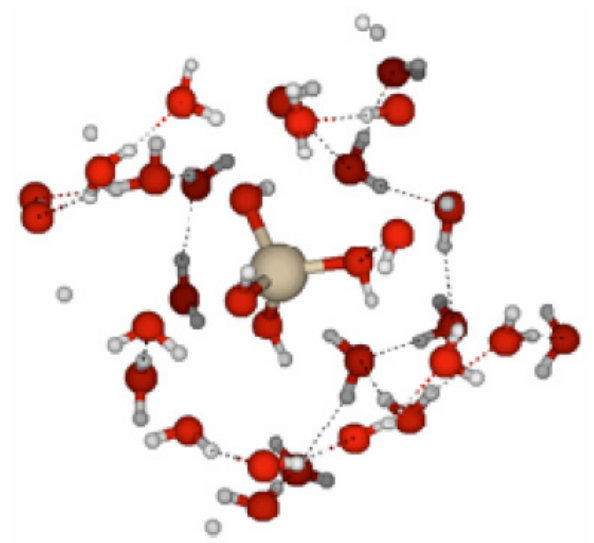

Figure 42. The optimized geometry of the studied $\mathrm{Ti}(\mathrm{OH})_{4}$ model placed in a periodic box of water molecules. The model consists of three elements represented by colored spheres: titanium (large and gray), hydrogens (small and white), and oxygens (small and dark). The black dotted lines represent the occurrence of hydrogen bonds. Adopted from [216]. Copyright (C): Materials Research Society 2014. (For interpretation of the references to color in this figure legend, the reader is referred to the Web version of this article.)

According to the MD simulation results [216], the titanium ion is affected by coordination to hydroxyl groups and an explicitly modeled water environment in three ways: First, the crystal field environment stabilizes the oxidation state. Second, the crystal field provides splitting of the titanium ion $d$ orbitals, which is responsible for the density of states in the conduction band range of energies. Third, thermal motion of near hydroxyl ligands and water coordination sphere are responsible for the nonradiative relaxation mechanisms: a photoexcitation in the solvated titanium ion is followed by the energy dissipation from electronic degrees of freedom to thermal motion. Thus, it was found that electrons dissipate energy slower than holes [216].

Chemical and physical adsorption of water on small-sized wet $\mathrm{TiO}_{2}$ nanoparticles was investigated by ab initio MD simulations [217]. The wetting behavior of $\left(\mathrm{TiO}_{2}\right)_{24} \cdot \mathrm{nH}_{2} \mathrm{O}(\mathrm{n}=0,1,3,8,15,30)$ was studied as a function of water content, ranging from dry nanoparticles to wet nanoparticles with monolayer coverage of water. The simulations were performed with the mixed Gaussian and planewave (GPW) method, as implemented in the CP2K code. It was found that the surface reactivity was shown to be a concave function of water content and driven by surface defects [217]. It was suggested that the local coordination number at the defect of $\mathrm{TiO}_{2} \mathrm{NPs}$ was identified as the key factor in deciding whether water adsorption proceeds through dissociation or physisorption on the surface.

\section{Hybrid QM-MD Simulations}

In the last decade, hydride QM-MM calculations utilizing the DFTB approximation have become an attractive alternative to conventional non-empirical first principle ab initio MD simulations. Several examples of such studied are summarized below.

Small $\mathrm{TiO}_{2}$ NPs (anatase, rutile, brookite) have been studied by ab initio MD simulations to elucidate chemical and physical adsorption of water molecules on the $\mathrm{TiO}_{2}$-water interface, ranging from dry NPs up to monolayer solvated NPs [217]. QM-MM simulations have been used to model the adsorption of insulin on $\mathrm{TiO}_{2}$ (100) surfaces [218]. Recently, a multistep and multiscale investigation based on hybrid DFT, DFT tight-binding (DFTB), and QM-MM calculations have been applied to consider solvation behavior of curved $\mathrm{TiO}_{2}-\mathrm{NPs}$, ranging from vacuum, multilayered solvation and up to the bulk water environment, resulting in an overall stoichiometry of $\left(\mathrm{TiO}_{2}\right)_{223} \cdot 8958 \mathrm{H}_{2} \mathrm{O}$ (Fig. 43 ) [219].

Recently, DFT-based BOMD was carried out by Byrne and English to investigate the effect with which the choice of exchange-correlational functional has on the structural properties of a $[\mathrm{BMIM}]^{+}\left[\mathrm{NTF}_{2}\right]^{-}$RTIL solvating an N719 sensitizing dye, adsorbed onto the anatase $\mathrm{TiO}_{2}(101)$ surface [220]. The systematic study of an N719 dye, non-solvated and solvated by RTILs, was performed 
by comparing the widely used BLYP and PBE functionals, which were utilized with and without D3 dispersion corrections by Grimme [220].

a)

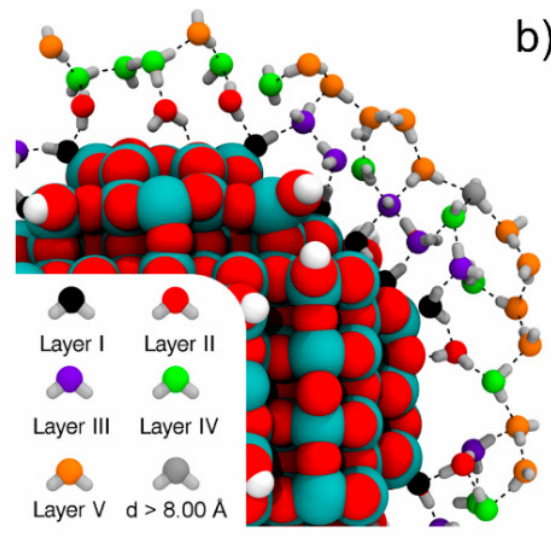

b)

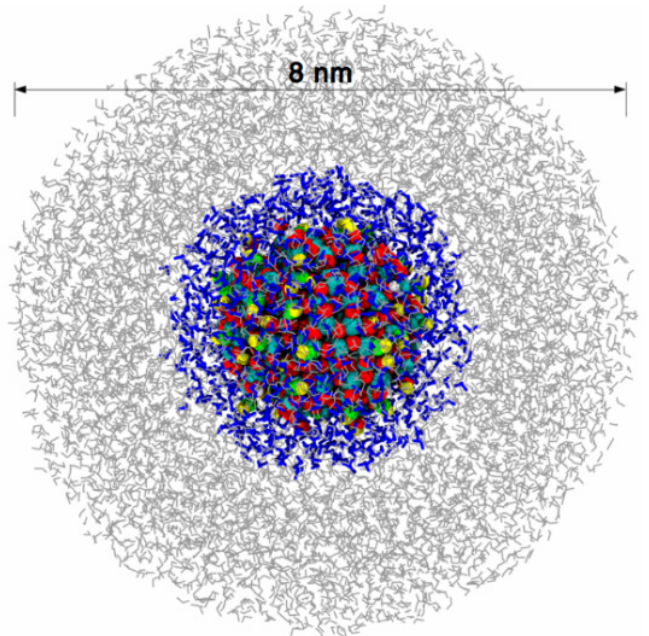

Figure 43. (a) A snapshot of the water multilayer on $\mathrm{TiO}_{2}-\mathrm{NP}$, as obtained from the DFTB MD simulation. (b) Representation of $\mathrm{TiO}_{2}$-NP solvated with a DFTB water multilayer (in blue) enclosed in a water droplet flexible (SPC/Fw model) (in gray). Adapted with permission from [219]. Copyright (C) 2018 American Chemical Society. (For interpretation of the references to color in this figure legend, the reader is referred to the Web version of this article.)

The above results show that neither the addition of dispersion corrections nor solvation by the strongly ionic solvent has any noticeable effect on the anatase surface structure. The structure of the surface was stable throughout the MD simulations, as is the carbon backbone of an N719 dye with neither group showing any real differences in their structure upon change of the DFT functional. However, the pair distribution functions (PDFs) for some of the carboxylate oxygens showed that the results obtained with the PBE functional led to some structural peaks shifts by $0.01 \mathrm{~nm}$ closer than their position derived by the BLYP functional [220]. The metal complex at the center of the dye was also largely unaffected by utilization of the dispersion correction, variations in the functionals or the presence of the solvent. The structure of the dye was found to be essentially unaffected by solvation with the bipyridine rings and anchoring groups retained their rigid geometry. A comparison of the PDFs, derived from the BLYP and PBE functionals, showed the structure of the anions and cations to be quite similar. On the other hand, some deviation was found between the results of the BLYP-D3 and the PBE-D3 so that the cations and anions are seen to be slightly closer to each other in the case of the PBE-D3 calculation by about $0.02 \mathrm{~nm}$. Moreover, it was suggested that the dispersion corrections also introduced the pronounced effect of an orientational alignment in the liquid, the phenomenon which would be expected for a real liquid [220].

Stable structures and photoexcitation character of adsorption of an $\mathrm{N} 749$ dye to $\mathrm{TiO}_{2}$ anatase (101) interface, solvated by explicit acetonitrile (ACN) molecules were considered by DFT-MD simulations [221]. It was found that the adsorption of an N749 dye via its deprotonated carboxylate two anchors (type $d 2$ ) was the most stable at the interface (Fig. 44a). However, the adsorption mode with the one protonated carboxyl anchor (type $p l$ ) was observed to be at the average energy only slightly higher than that of type $d 2$ (Fig. $44 b$ ).

Other possible anchoring modes, shown schematically in Fig. $44 c-e$ were all higher in energy as compared to those of $p 1$ and $d 2$, respectively. It was suggested that, under equilibrium, the mode $p 1$ might still coexist with the mode $d 2$ [221]. These findings were in contrast with the high stability calculated for the mode $\mathrm{p} 1$ in vacuo. It was proposed that some stabilization of the mode $d 2$ could be caused by inhomogeneous charge distribution and anchor fluctuation enhanced by ACN solution (Fig. $44 f-g$ ). The calculated projected densities of states and the photoabsorption spectra supported the conclusions that the mode $d 2$ has the larger driving force of the electron injection from an N749 dye into the $\mathrm{TiO}_{2}$, whereas the characteristic sensitizer photoabsorption in the wavelength region over $800 \mathrm{~nm}$, was mainly attributed to the mode $p l$ even in the bulk ACN solution. It was concluded that the better 
performance of a N749 dye in DSSC devices can be regionalized in terms of the co-sensitizer framework of the adsorption modes $d 2$ and $p 1$, respectively [197-198,221].
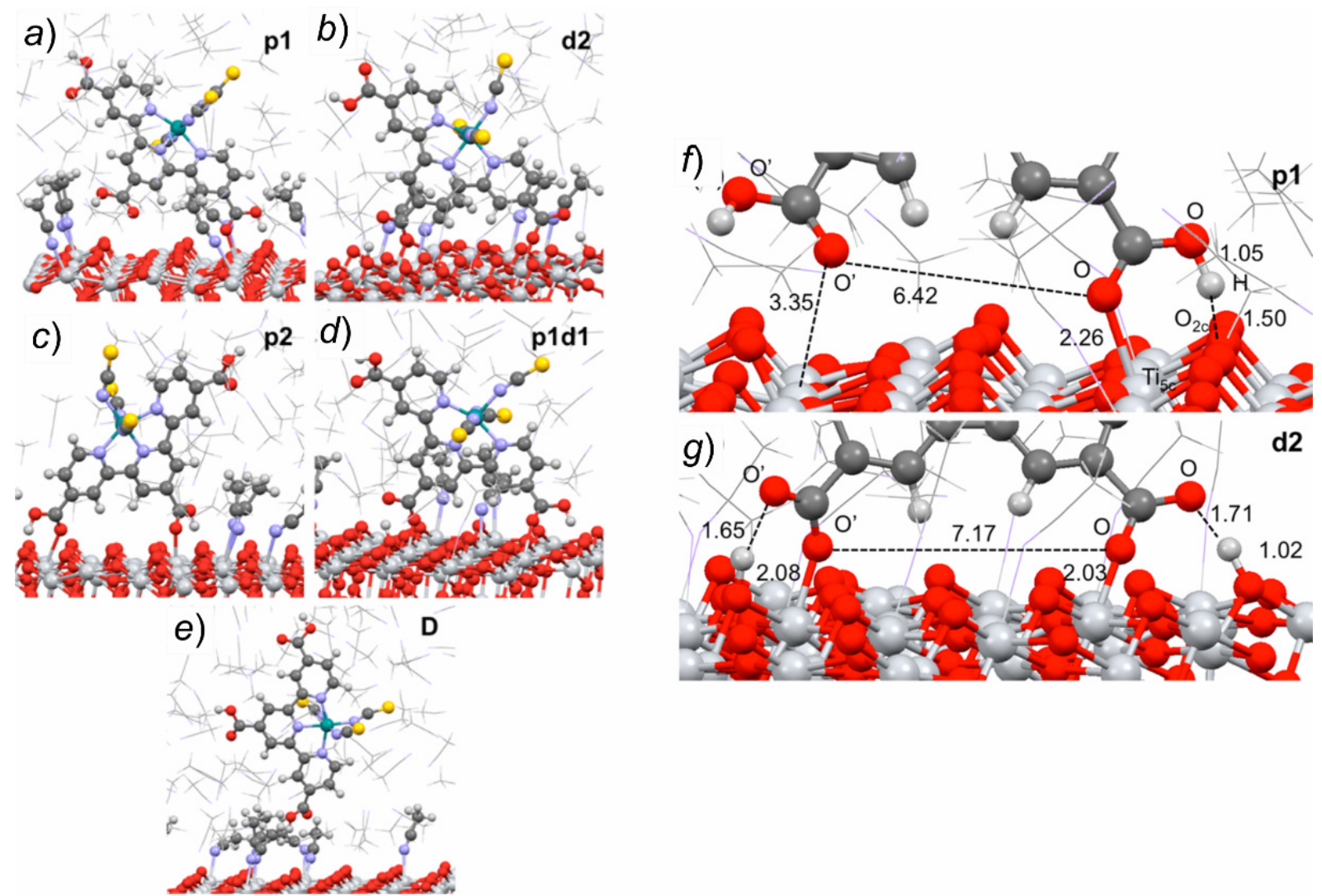

Figure 44. Representative snapshots of the equilibrium trajectories of adsorption of a $\mathrm{N} 749$ dye to $\mathrm{TiO}_{2}$ anatase (101)/acetonitrile (ACN) interfaces: $(a)$ adsorption with one protonated carboxyl anchor $(-\mathrm{COOH})$, labeled as $p 1$, (b) adsorption with two deprotonated $\left(-\mathrm{COO}^{-}\right)$anchors, labeled as $d 2$, (c) adsorption with two protonated anchors (label $p 2$ ), (d) adsorption with one protonated and one deprotonated anchors (label pld1), and (e) the desorbed state, assigned as $D$. Each trajectory was obtained with DFT-MD simulation with different initial configuration of the dye, which was optimized on the vacuum surface, in advance. $(f-g)$ Average structures and distances (in angstroms) of the characteristic atoms near the interface in $(f)$ the $p l$ equilibrium state and $(g)$ the $d 2$ state, respectively. Adapted with permission from [221]. Copyright (C) 2014, American Chemical Society.

Small $\mathrm{TiO}_{2} \mathrm{NPs}$, functionalized with a supramolecular complex consisting of an entirely organic naphthalene-diimide (NDI) dye covalently bound to a mononuclear Ru-based water oxidation catalyst (Fig. 45a) were studied by ab initio MD simulations to elucidate the mechanistic insight and microscopic details of water oxidation at the photoanode induced by visible light absorption [222]. The MD nuclear trajectory was calculated through ab initio MD by using the Car-Parrinello MD (CPMD) code. The orthorhombic cell, containing a two-layer anatase slab $\left(\mathrm{TiO}_{2}\right)_{32}$ functionalized with the NDI1 chromophore, was used together with periodic boundary conditions to model the $\mathrm{TiO}_{2}$ surface. The fast photoinduced electron injection from the NDI into the semiconductor was observed, which provided the driving force for the activation of the Ru catalyst (Fig. 45b). The explicit description of the water environment was utilized to elucidate the sub-picosecond time-scale and the nature of the proton-coupled electron transfer of the catalytic reaction path. It was suggested that the explicit water treatment was essential to determine the proton diffusion channel and the free energy change along with the reaction [222].

The above photochemical reaction simulations are a promising example for the computational design and DSSC device optimization with an aim to explore the effect of different anchoring groups, which allow tuning the driving force for the subsequent steps of the catalytic water photo-oxidation cycle and reducing the charge recombination rate [223-225]. 

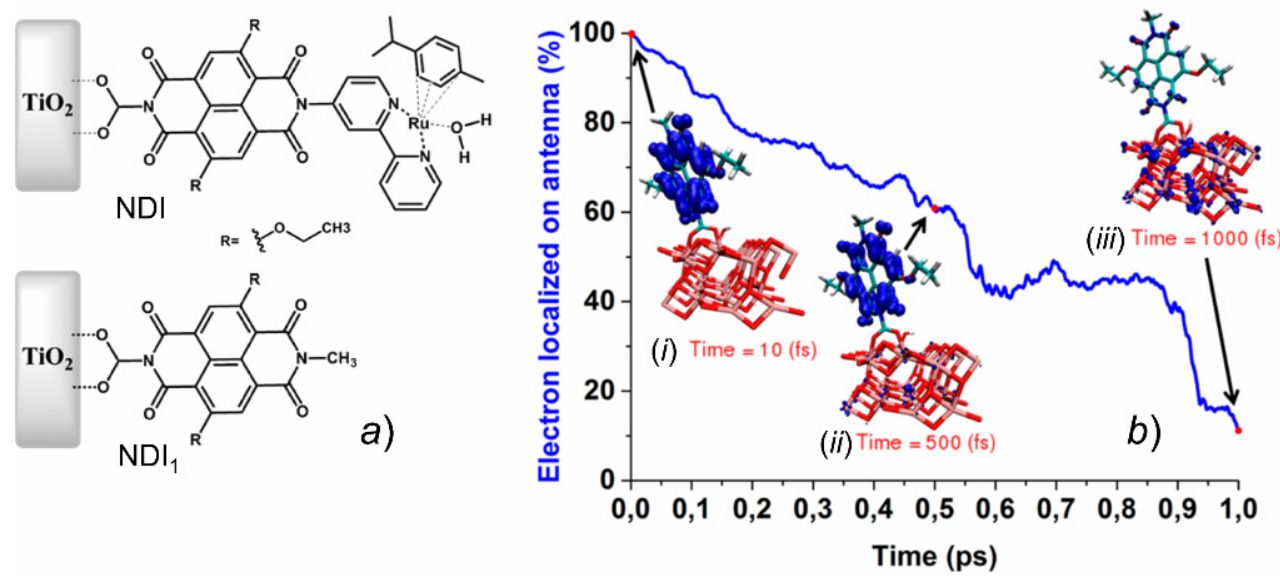

Figure 45. (a) Schematic representation of the studied photoanode (NDI) composed of the acceptor semiconductor $\left(\mathrm{TiO}_{2}\right)$, the molecular chromophore NDI, and the Ru-based water oxidation catalyst; $\left(\mathrm{NDI}_{1}\right)$ chromophoresemiconductor subsystem employed for the photoinduced electron injection MD simulation. (b) Electron injection profile obtained through the time-dependent population analysis of the wavepacket projected only over the dye- $\mathrm{TiO}_{2}$ conjugate (solid line). The insets show the distribution of the total wavepacket after initialization $(i)$, and along with the time evolution of the MD trajectory ( $i i$ and iii). Adapted with permission from [222]. Copyright (C) 2016, American Chemical Society.

\section{Conclusions and Outlook}

The review describes recent advances in theoretical studies of $\mathrm{TiO}_{2}$ nanomaterials. Particular attention is focused on the MD simulation approaches that are essential for the modeling of bulk $\mathrm{TiO}_{2}$, its interfaces with aqueous and non-aqueous environments, as well as large-scale nanoparticles and their aggregates. Starting from the earlier FF model by Matsui and Akaogi (MA) [14], rapid progress in computational modeling of $\mathrm{TiO}_{2}$ nanomaterials resulted in the development of well-validated $\mathrm{FFs}$ for a broad range of $\mathrm{TiO}_{2}$ nanomaterials, ranging from small perfect clusters and up to water/ $/ \mathrm{TiO}_{2}$ interfaces. The applicability of MD simulation tools has currently extended up to about $100 \mathrm{~nm}$ size and microseconds, and can further be scaled up by coarse-grain and finite element models to the range of micrometers. However, the critical overview of recent computational models suggested for modeling partially hydroxylated $\mathrm{TiO}_{2}$ surfaces reveals that the existing MA approach still requires further improvements and validation. The main limitation of the MA force-field, developed originally for bulk $\mathrm{TiO}_{2}$, is that it utilizes only two types of atoms, such as $\mathrm{Ti}$ and $\mathrm{O}$. However, in realistic $\mathrm{TiO}_{2}$ nanostructures, these atoms are characterized by different coordination numbers so that they can be classified into inner-bulk and outer-surface-exposed atoms. The latter can be further divided into subgroups of corner, edge, or side atoms. Recent ab initio MD studies demonstrated that indeed these atoms bear different partial charges and, hence, they should be represented by different atom types in an empirical force field [217]. The different atoms types for $\mathrm{Ti}$ and $\mathrm{O}$ have already been implemented in some MD simulation studies of $\mathrm{TiO}_{2}$ nanostructures [19,32,84]. Moreover, the development of computational models for some realistic systems with the simultaneous presence of several crystalline facets $(100,110,111)$ or different phases, such as rutile and anatase, will enable modeling the adsorption phenomena that may take place at the grain boundary and at their common interface with the outer environment [226].

The understanding of the mechanisms that govern the interaction of biological systems with inorganic materials remains a challenge for both fundamental and applied material science [227-228]. The protein adsorption modulates the formation of biofilms onto surfaces, which is essential for medical implants and dental technologies. The interaction of $\mathrm{TiO}_{2}$ nanomaterials with biomacromolecules is crucial to further response of cells to foreign inorganic materials, such as engineered implants or accidentally entrapped inorganic nanoparticles. Therefore, detailed knowledge of the $\mathrm{TiO}_{2} /$ biological interfaces is required for the design of new biocompatible materials. MD simulations of conformation equilibria of biomolecules at perfect, defect-free, and curved interfaces have provided insight into the mechanism, specific recognition, and sequence-relation suggestions to understand their adsorption, binding, and assembly. However, due to the complexity of the configuration space, it remains challenging to explore because of the large number of possible conformations of biomacromolecules. 
Therefore, the critical review of MD studies in this field reveals that free, unbiased MD sampling of protein binding and adsorption onto $\mathrm{TiO}_{2}$ may not guarantee finding of proper binding modes so that the development of some innovative sampling techniques is required. Some recent studies report new promising approaches in this direction, such as the potential mean-force calculations, free-energy umbrella sampling, and replica-exchange MD simulations [229].

In the last decade, significant progress has been achieved in quantum chemical calculations of the structural, electronic, and optical properties of $\mathrm{TiO}_{2}$ materials in the context of their use as components of dye-sensitized solar cells (DSSC). Successes, failures, and challenges of quantum chemical, DFT, and TDDFT computational methods of dye- $\mathrm{TiO}_{2}$ conjugates have been critically analyzed elsewhere $[1,197,230]$. To summarize, we found that the electronic structure calculations are little sensitive to the basis set and DFT functionals used for geometry optimization. Moreover, the tight-binding DFT approach (DFTB) can provide a low-cost alternative to regular CPU-expensive DFT geometry optimization. However, it was found that the results of electronic property calculations are crucially sensitive to the choice of the DFT functional $[165,197]$. The presented DFT/TDDFT computational models, employing conventional hybrid (B3LYP) and range-separated functional and based on the use of large $\mathrm{TiO}_{2}$ clusters, PCM-continuum solvation models, allows one to reproduce to a reasonable degree of accuracy the electronic and optical properties of dye- $\mathrm{TiO}_{2}$ systems. However, for highly conjugated organic dyes, which are often characterized by a high degree of charge-transfer excited states, specifically tailored exchange-correlation functionals, such as CAM-B3LYP or M06-2X, are required [197]. Some efforts have already devoted to solving the shortcomings of current TDDFT methodologies for dye- $\mathrm{TiO}_{2}$ systems [231].

Finally, our review sheds light on the progress and development of modern computational tools, combining classical FF modeling and high-level ab initio MD simulations, which may assist the molecular engineering and rational design of more efficient dye sensitizers and deeper understanding of the electron transfer dynamics in dye-sensitized solar cells.

\section{Acknowledgments}

The authors acknowledge Grant 0119U002532 of the Ministry of Education and Science of Ukraine. This research was also performed within the Joint Ukraine-France R\&D project "High-performance photovoltaic solar cells based on new dye-sensitizers. Molecular design and optimization of photoinduced process."

\section{References}

1. Bai Y., Mora-Seró I., De Angelis F., Bisquert J., Wang P. Titanium dioxide nanomaterials for photovoltaic applications. Chem. Rev. 2014, 114 (19), 10095-10130.

2. Kapilashrami M., Zhang Y., Liu Y.-S., Hagfeldt A., Guo J. Probing the optical property and electronic structure of $\mathrm{TiO}_{2}$ nanomaterials for renewable energy applications. Chem. Rev. 2014, 114 (19), 9662-9707.

3. Zhang H., Banfield J. F. Structural characteristics and mechanical and thermodynamic properties of nanocrystalline $\mathrm{TiO}_{2}$. Chem. Rev. 2014, 114 (19), 9613-9644.

4. Fattakhova-Rohlfing D., Zaleska A., Bein T. Three-dimensional titanium dioxide nanomaterials. Chem. Rev. 2014, 114 (19), 9487-9558.

5. Momma K., Izumi F. VESTA 3 for three-dimensional visualization of crystal, volumetric and morphology data. J. Appl. Crystall. 2011, 44 (6), 1272-1276.

6. YazdanYar A., Aschauer U., Bowen P. Interaction of biologically relevant ions and organic molecules with titanium oxide (rutile) surfaces: A review on molecular dynamics studies. Colloids Surf. B 2018, 161, 563-577.

7. Liu X., Chu P. K., Ding C. Surface modification of titanium, titanium alloys, and related materials for biomedical applications. Mater. Sci. Engineer. Reports 2004, 47 (3), 49-121.

8. Silva-Bermudez P., Rodil S. E. An overview of protein adsorption on metal oxide coatings for biomedical implants. Surf. Coatings Technol. 2013, 233, 147-158.

9. Liu K., Cao M., Fujishima A., Jiang L. Bio-inspired titanium dioxide materials with special wettability and their applications. Chem. Rev. 2014, 114 (19), 10044-10094. 
10. Casalini T., Limongelli V., Schmutz M., Som C., Jordan O., Wick P., Borchard G., Perale G. Molecular modeling for nanomaterial-biology interactions: Opportunities, challenges, and perspectives. Frontiers Bioengineer. Biotech. 2019, 7, art. no. 268.

11. Rajh T., Dimitrijevic N. M., Bissonnette M., Koritarov T., Konda V. Titanium dioxide in the service of the biomedical revolution. Chem. Rev. 2014, 114 (19), 10177-10216.

12. Akimov A. V., Neukirch A. J., Prezhdo O. V. Theoretical insights into photoinduced charge transfer and catalysis at oxide interfaces. Chem. Rev. 2013, 113 (6), 4496-4565.

13. Wang Q., Wang M.-h., Wang K.-f., Liu Y., Zhang H.-p., Lu X., Zhang X.-D. Computer simulation of biomolecule-biomaterial interactions at surfaces and interfaces. Biomedical Materials 2015, 10 (3), art. no. 032001.

14. Matsui M., Akaogi M. Molecular dynamics simulation of the structural and physical properties of the four polymorphs of $\mathrm{TiO}_{2}$. Mol. Simul. 1991, 6 (4-6), 239-244.

15. Limo M. J., Sola-Rabada A., Boix E., Thota V., Westcott Z. C., Puddu V., Perry C. C. Interactions between metal oxides and biomolecules: From fundamental understanding to applications. Chem. Rev. 2018, 118 (22), 11118-11193.

16. Mao Q., Ren Y., Luo K. H., Li S. Sintering-induced phase transformation of nanoparticles: A molecular dynamics study. J. Phys. Chem. C 2015, 119 (51), 28631-28639.

17. Collins D. R., Smith W., Harrison N. M., Forester T. R. Molecular dynamics study of $\mathrm{TiO}_{2}$ microclusters. J. Mater. Chem. 1996, 6 (8), 1385-1390.

18. R. Collins D., Smith W., M. Harrison N., R. Forester T. Molecular dynamics study of the high temperature fusion of $\mathrm{TiO}_{2}$ nanoclusters. J. Mater. Chem. 1997, 7 (12), 2543-2546.

19. Naicker P. K., Cummings P. T., Zhang H., Banfield J. F. Characterization of titanium dioxide nanoparticles using molecular dynamics simulations. J. Phys. Chem. B 2005, 109 (32), 15243 15249 .

20. Koparde V. N., Cummings P. T. Molecular dynamics simulation of titanium dioxide nanoparticle sintering. J. Phys. Chem. B 2005, 109 (51), 24280-24287.

21. De Angelis F., Di Valentin C., Fantacci S., Vittadini A., Selloni A. Theoretical studies on anatase and less common $\mathrm{TiO}_{2}$ phases: Bulk, surfaces, and nanomaterials. Chem. Rev. 2014, 114 (19), 9708-9753.

22. Koparde V. N., Cummings P. T. Phase transformations during sintering of titania nanoparticles. ACS Nano 2008, 2 (8), 1620-1624.

23. Buesser B., Gröhn A. J., Pratsinis S. E. Sintering rate and mechanism of $\mathrm{TiO}_{2}$ nanoparticles by molecular dynamics. J. Phys. Chem. C 2011, 115 (22), 11030-11035.

24. Alimohammadi M., Fichthorn K. A. Molecular dynamics simulation of the aggregation of titanium dioxide nanocrystals: Preferential alignment. Nano Lett. 2009, 9 (12), 4198-4203.

25. Filyukov D. V., Brodskaya E. N., Piotrovskaya E. M., de Leeuw S. W. Molecular-dynamics simulation of nanoclusters of crystal modifications of titanium dioxide. Rus. J. Gen. Chem. 2007, 77 (1), 10-16.

26. Oliver P., Watson G., Kelsey E., Parker S. Atomistic simulation of the surface structure of $\mathrm{TiO}_{2}$ polymorphs rutile and anatase. J. Mater. Chem. 1997, 7 563-568.

27. Swamy V., Gale J. D., Dubrovinsky L. S. Atomistic simulation of the crystal structures and bulk moduli of $\mathrm{TiO}_{2}$ polymorphs. J. Phys. Chem. Solids 2001, 62 (5), 887-895.

28. Bandura A. V., Kubicki J. D. Derivation of force field parameters for $\mathrm{TiO}_{2}-\mathrm{H}_{2} \mathrm{O}$ systems from ab initio calculations. J. Phys. Chem. B 2003, 107 (40), 11072-11081.

29. Bandura A. V., Sykes D. G., Shapovalov V., Troung T. N., Kubicki J. D., Evarestov R. A. Adsorption of water on the $\mathrm{TiO}_{2}$ (rutile) (110) surface: A comparison of periodic and embedded cluster calculations. J. Phys. Chem. B 2004, 108 (23), 7844-7853.

30. Carravetta V., Monti S. Peptide- $-\mathrm{TiO}_{2}$ surface interaction in solution by ab initio and molecular dynamics simulations. J. Phys. Chem. B 2006, 110 (12), 6160-6169.

31. Skelton A. A., Liang T., Walsh T. R. Interplay of sequence, conformation, and binding at the peptide-titania interface as mediated by water. ACS Appl. Mater. Interfaces. 2009, 1 (7), 1482-1491.

32. Předota M., Bandura A. V., Cummings P. T., Kubicki J. D., Wesolowski D. J., Chialvo A. A., Machesky M. L. Electric double layer at the rutile (110) surface. 1. Structure of surfaces and 
interfacial water from molecular dynamics by use of ab initio potentials. J. Phys. Chem. B 2004, 108 (32), 12049-12060.

33. Předota M., Zhang Z., Fenter P., Wesolowski D. J., Cummings P. T. Electric double layer at the rutile (110) surface. 2. Adsorption of ions from molecular dynamics and X-ray experiments. $J$. Phys. Chem. B 2004, 108 (32), 12061-12072.

34. Alimohammadi M., Fichthorn K. A. A force field for the interaction of water with $\mathrm{TiO}_{2}$ surfaces. J. Phys. Chem. C 2011, 115 (49), 24206-24214.

35. Foroutan M., Darvishi M., Mahmood Fatemi S., Hamideh Babazadeh K. Water chain formation on rutile $\mathrm{TiO}_{2}(110)$ nanocrystal: A molecular dynamics simulation approach. J. Mol. Liq. 2018, 250, 344-352.

36. Jorgensen W. L., Chandrasekhar J., Madura J. D., Impey R. W., Klein M. L. Comparison of simple potential functions for simulating liquid water. J. Chem. Phys. 1983, 79 (2), 926-935.

37. Schneider J., Ciacchi L. C. A classical potential to model the adsorption of biological molecules on oxidized titanium surfaces. J. Chem. Theory Comput. 2011, 7 (2), 473-484.

38. Skelton A. A., Walsh T. R. Interaction of liquid water with the rutile $\mathrm{TiO}_{2}$ (110) surface. Mol. Simul. 2007, 33 (4-5), 379-389.

39. Kavathekar R. S., Dev P., English N. J., MacElroy J. M. D. Molecular dynamics study of water in contact with the $\mathrm{TiO}_{2}$ rutile-110, 100, 101, 001 and anatase-101, 001 surface. Mol. Phys. 2011, 109 (13), 1649-1656.

40. Kavathekar R. S., English N. J., MacElroy J. M. D. Spatial distribution of adsorbed water layers at the $\mathrm{TiO}_{2}$ rutile and anatase interfaces. Chem. Phys. Lett. 2012, 554, 102-106.

41. English N. J. Dynamical properties of physically adsorbed water molecules at the $\mathrm{TiO}_{2}$ rutile(110) surface. Chem. Phys. Lett. 2013, 583, 125-130.

42. Köppen S., Langel W. Simulation of the interface of (100) rutile with aqueous ionic solution. Surf. Sci. 2006, 600 (10), 2040-2050.

43. Senftle T. P., Hong S., Islam M. M., Kylasa S. B., Zheng Y., Shin Y. K., Junkermeier C., EngelHerbert R., Janik M. J., Aktulga H. M., Verstraelen T., Grama A., van Duin A. C. T. The ReaxFF reactive force-field: Development, applications and future directions. NPJ: Comput. Mater. 2016, 2 (1), art. no. 15011.

44. Monti S., Li C., Ågren H., Carravetta V. Dropping a droplet of cysteine molecules on a rutile (110) interface: Reactive versus nonreactive classical molecular dynamics simulations. J. Phys. Chem. C 2015, 119 (12), 6703-6712.

45. Futera Z., English N. J. Exploring rutile (110) and anatase (101) $\mathrm{TiO}_{2}$ water interfaces by reactive force-field simulations. J. Phys. Chem. C 2017, 121 (12), 6701-6711.

46. Kim S.-Y., Kumar N., Persson P., Sofo J., van Duin A. C. T., Kubicki J. D. Development of a ReaxFF reactive force field for titanium dioxide/water systems. Langmuir 2013, 29 (25), 78387846.

47. Nakamura H., Ohto T., Nagata Y. Polarizable site charge model at liquid/solid interfaces for describing surface polarity: Application to structure and molecular dynamics of water/rutile $\mathrm{TiO}_{2}$ (110) interface. J. Chem. Theory Comput. 2013, 9 (2), 1193-1201.

48. Morita A., Kato S. Ab initio molecular orbital theory on intramolecular charge polarization: Effect of hydrogen abstraction on the charge sensitivity of aromatic and nonaromatic species. $J$. Am. Chem. Soc. 1997, 119 (17), 4021-4032.

49. Morita A., Kato S. Molecular dynamics simulation with the charge response kernel: Diffusion dynamics of pyrazine and pyrazinyl radical in methanol. J. Chem. Phys. 1998, 108 (16), 68096818.

50. Isegawa M., Kato S. Polarizable force field for protein with charge response kernel. J. Chem. Theory Comput. 2009, 5 (10), 2809-2821.

51. Ohto T., Mishra A., Yoshimune S., Nakamura H., Bonn M., Nagata Y. Influence of surface polarity on water dynamics at the water/rutile $\mathrm{TiO}_{2}(110)$ interface. J. Phys.: Condens. Matter 2014, 26 (24), art. no. 244102.

52. Hosseinpour S., Tang F., Wang F., Livingstone R. A., Schlegel S. J., Ohto T., Bonn M., Nagata Y., Backus E. H. G. Chemisorbed and physisorbed water at the $\mathrm{TiO}_{2} /$ water interface. J. Phys. Chem. Lett. 2017, 8 (10), 2195-2199. 
53. Solute ions at ice/water interface. In Ionic soft matter: Modern Trends in Theory and Applications, Henderson, D.; Holovko, M.; Trokhymchuk, A., Eds. Springer Netherlands: Dordrecht, 2005; 418 p.

54. Bryk T., Haymet A. D. J. Ice 1h/water interface of the SPC/E model: Molecular dynamics simulations of the equilibrium basal and prism interfaces. J. Chem. Phys. 2002, 117 (22), 10258-10268.

55. Seitsonen A. P., Bryk T. Melting temperature of water: DFT-based molecular dynamics simulations with D3 dispersion correction. Phys. Rev. B 2016, 94 (18), art. no. 184111.

56. González Solveyra E., de la Llave E., Molinero V., Soler-Illia G. J. A. A., Scherlis D. A. Structure, dynamics, and phase behavior of water in $\mathrm{TiO}_{2}$ nanopores. J. Phys. Chem. C 2013, 117 (7), 3330-3342.

57. Wei M.-J., Zhou J., Lu X., Zhu Y., Liu W., Lu L., Zhang L. Diffusion of water molecules confined in slits of rutile $\mathrm{TiO}_{2}(110)$ and graphite(0001). Fluid Phase Equilibria 2011, 302 (1), 316-320.

58. Zhu Y., Zhang Y., Shi Y., Lu X., Li J., Lu L. Lubrication behavior of water molecules confined in $\mathrm{TiO}_{2}$ nanoslits: A molecular dynamics study. J. Chem. Eng. Data 2016, 61 (12), 4023-4030.

59. Cao W., Lu L., Huang L., Dong Y., Lu X. Molecular behavior of water on titanium dioxide nanotubes: A molecular dynamics simulation study. J. Chem. Eng. Data 2016, 61 (12), 41314138.

60. Zeydabadi-Nejad I., Zolfaghari N., Mosavi-Mashhadi M., Baniassadi M. Exceptional behavior of anatase $\mathrm{TiO}_{2}$ nanotubes in axial loading: A molecular dynamics study of the effect of surface wrinkles. Comput. Mater. Sci. 2019, 158, 307-314.

61. Papavasileiou K. D., Makrodimitri Z. A., Peristeras L. D., Chen J., van der Laan G. P., Rudra I., Kalantar A., Economou I. G. Molecular simulation of $n$-octacosane-water mixture in titania nanopores at elevated temperature and pressure. J. Phys. Chem. C 2016, 120 (43), 24743-24753.

62. Utesch T., Daminelli G., Mroginski M. A. Molecular dynamics simulations of the adsorption of bone morphogenetic protein-2 on surfaces with medical relevance. Langmuir 2011, 27 (21), 13144-13153.

63. Mancardi G., Hernandez Tamargo C., Terranova U., de Leeuw N. H. Calcium phosphate deposition on planar and stepped (101) surfaces of anatase $\mathrm{TiO}_{2}$ : Introducing an interatomic potential for the $\mathrm{TiO}_{2} / \mathrm{Ca}-\mathrm{PO}_{4} /$ water interface. Langmuir 2018, 34 (34), 10144-10152.

64. Zheng T., Wu C., Zhang Y., Chen M., Cummings P. T. Molecular investigation of the initial nucleation of calcium phosphate on $\mathrm{TiO}_{2}$ substrate: The effects of surface nanotopographies. Cryst. Growth Des. 2018, 18 (6), 3283-3290.

65. Zheng T., Wu C., Chen M., Zhang Y., Cummings P. T. Molecular mechanics of the cooperative adsorption of a Pro-Hyp-Gly tripeptide on a hydroxylated rutile $\mathrm{TiO}_{2}(110)$ surface mediated by calcium ions. Phys. Chem. Chem. Phys. 2016, 18 (29), 19757-19764.

66. Monti S., Walsh T. R. Free energy calculations of the adsorption of amino acid analogues at the aqueous titania interface. J. Phys. Chem. C 2010, 114 (50), 22197-22206.

67. Sushko M. L., Gal A. Y., Shluger A. L. Interaction of organic molecules with the $\mathrm{TiO}_{2}(110)$ surface: Ab inito calculations and classical force fields. J. Phys. Chem. B 2006, 110 (10), 4853 4862.

68. Yang L., Tunega D., Xu L., Govind N., Sun R., Taylor R., Lischka H., DeJong W. A., Hase W. L. Comparison of cluster, slab, and analytic potential models for the dimethyl methylphosphonate (DMMP)/TiO $2(110)$ intermolecular interaction. J. Phys. Chem. C 2013, 117 (34), 17613-17622.

69. Hamad S., Sánchez-Valencia J. R., Barranco A., Mejías J. A., González-Elipe A. R. Molecular dynamics simulation of the effect of $\mathrm{pH}$ on the adsorption of rhodamine laser dyes on $\mathrm{TiO}_{2}$ hydroxylated surfaces. Mol. Simul. 2009, 35 (12-13), 1140-1151.

70. Fortunelli A., Monti S. Simulations of lipid adsorption on $\mathrm{TiO}_{2}$ surfaces in solution. Langmuir 2008, 24 (18), 10145-10154.

71. Předota M., Vlček L. Comment on parts 1 and 2 of the series "electric double layer at the rutile (110) surface". J. Phys. Chem. B 2007, 111 (5), 1245-1247. 
72. Předota M., Cummings P. T., Wesolowski D. J. Electric double layer at the rutile (110) surface. 3. Inhomogeneous viscosity and diffusivity measurement by computer simulations. J. Phys. Chem. C 2007, 111 (7), 3071-3079.

73. Předota M., Machesky M. L., Wesolowski D. J., Cummings P. T. Electric double layer at the rutile (110) surface. 4 . Effect of temperature and $\mathrm{pH}$ on the adsorption and dynamics of ions. $J$. Phys. Chem. C 2013, 117 (44), 22852-22866.

74. Předota M., Machesky M. L., Wesolowski D. J. Molecular origins of the Zeta potential. Langmuir 2016, 32 (40), 10189-10198.

75. Biriukov D., Kroutil O., Předota M. Modeling of solid-liquid interfaces using scaled charges: Rutile (110) surfaces. Phys. Chem. Chem. Phys. 2018, 20 (37), 23954-23966.

76. Biriukov D., Kroutil O., Kabeláč M., Ridley M. K., Machesky M. L., Předota M. Oxalic acid adsorption on rutile: Molecular dynamics and ab initio calculations. Langmuir 2019, 35 (24), 7617-7630.

77. Machesky M. L., Ridley M. K., Biriukov D., Kroutil O., Předota M. Oxalic acid adsorption on rutile: Experiments and surface complexation modeling to $150{ }^{\circ} \mathrm{C}$. Langmuir 2019, 35 (24), 7631-7640.

78. Nada H., Kobayashi M., Kakihana M. Anisotropy in conformation and dynamics of a glycolate ion near the surface of a $\mathrm{TiO}_{2}$ rutile crystal between its $\{001\}$ and $\{110\}$ planes: A molecular dynamics study. J. Phys. Chem. C 2016, 120 (12), 6502-6514.

79. Nada H., Kobayashi M., Kakihana M. Anisotropy in stable conformations of hydroxylate ions between the $\{001\}$ and $\{110\}$ planes of $\mathrm{TiO}_{2}$ rutile crystals for glycolate, lactate, and 2hydroxybutyrate ions studied by metadynamics method. ACS Omega 2019, 4 (6), 11014-11024.

80. Costa D., Garrain P.-A., Baaden M. Understanding small biomolecule-biomaterial interactions: A review of fundamental theoretical and experimental approaches for biomolecule interactions with inorganic surfaces. J. Biomed. Mater. Res. 2013, 101 A (4), 1210-1222.

81. Schwaminger S., Blank-Shim S. A., Borkowska-Panek M., Anand P., Fraga-García P., Fink K., Wenzel W., Berensmeier S. Experimental characterization and simulation of amino acid and peptide interactions with inorganic materials. Engineer. Life Sci. 2018, 18 (2), 84-100.

82. Kyrychenko A. NANOGOLD decorated by pHLIP peptide: Comparative force field study. Phys. Chem. Chem. Phys. 2015, 17 (19), 12648-12660.

83. Kyrychenko A., Blazhynska M. M., Kalugin O. N. Protonation-dependent adsorption of polyarginine onto silver nanoparticles. J. Appl. Phys. 2020, 127 (7), art. no. 075502.

84. Brandt E. G., Lyubartsev A. P. Systematic optimization of a force field for classical simulations of $\mathrm{TiO}_{2}$-water interfaces. J. Phys. Chem. C 2015, 119 (32), 18110-18125.

85. Brandt E. G., Lyubartsev A. P. Molecular dynamics simulations of adsorption of amino acid side chain analogues and a titanium binding peptide on the $\mathrm{TiO}_{2}(100)$ surface. J. Phys. Chem. C 2015, 119 (32), 18126-18139.

86. Monti S., Walsh T. R. Molecular dynamics simulations of the adsorption and dynamical behavior of single DNA components on $\mathrm{TiO}_{2}$. J. Phys. Chem. C 2011, 115 (49), 24238-24246.

87. Neria E., Fischer S., Karplus M. Simulation of activation free energies in molecular systems. $J$. Chem. Phys. 1996, 105 (5), 1902-1921.

88. Sultan A. M., Hughes Z. E., Walsh T. R. Binding affinities of amino acid analogues at the charged aqueous titania interface: Implications for titania-binding peptides. Langmuir 2014, 30 (44), 13321-13329.

89. Shchelokov A., Palko N., Potemkin V., Grishina M., Morozov R., Korina E., Uchaev D., Krivtsov I., Bol'shakov O. Adsorption of native amino acids on nanocrystalline $\mathrm{TiO}_{2}$ : Physical chemistry, QSPR, and theoretical modeling. Langmuir 2019, 35 (2), 538-550.

90. Monti S., Carravetta V., Zhang W., Yang J. Effects due to interadsorbate interactions on the dipeptide $/ \mathrm{TiO}_{2}$ surface binding mechanism investigated by molecular dynamics simulations. $J$. Phys. Chem. C 2007, 111 (21), 7765-7771.

91. Tirrell M., Kokkoli E., Biesalski M. The role of surface science in bioengineered materials. Surf. Sci. 2002, 500 (1), 61-83.

92. Wu C., Chen M., Guo C., Zhao X., Yuan C. Peptide- $-\mathrm{TiO}_{2}$ interaction in aqueous solution: Conformational dynamics of RGD using different water models. J. Phys. Chem. B 2010, 114 (13), 4692-4701. 
93. Song D.-P., Chen M.-J., Liang Y.-C., Bai Q.-S., Chen J.-X., Zheng X.-F. Adsorption of tripeptide RGD on rutile $\mathrm{TiO}_{2}$ nanotopography surface in aqueous solution. Acta Biomater. 2010, 6 (2), 684-694.

94. Wu C., Skelton A. A., Chen M., Vlček L., Cummings P. T. Modeling the interaction between integrin-binding peptide (RGD) and rutile surface: The effect of $\mathrm{Na}^{+}$on peptide adsorption. $J$. Phys. Chem. C 2011, 115 (45), 22375-22386.

95. Wu C., Skelton A. A., Chen M., Vlček L., Cummings P. T. Modeling the interaction between integrin-binding peptide (RGD) and rutile surface: The effect of cation mediation on Asp adsorption. Langmuir 2012, 28 (5), 2799-2811.

96. Wagstaffe M., Hussain H., Taylor M., Murphy M., Silikas N., Thomas A. G. Interaction of a tripeptide with titania surfaces: RGD adsorption on rutile $\mathrm{TiO}_{2}(110)$ and model dental implant surfaces. Mater. Sci. Eng. C 2019, 105, art. no. 110030.

97. Wu C., Chen M., Skelton A. A., Cummings P. T., Zheng T. Adsorption of arginine-glycineaspartate tripeptide onto negatively charged rutile (110) mediated by cations: The effect of surface hydroxylation. ACS Appl. Mater. Interfaces 2013, 5 (7), 2567-2579.

98. Zhang H.-p., Lu X., Leng Y., Watari F., Weng J., Feng B., Qu S. Effects of aqueous environment and surface defects on Arg-Gly-Asp peptide adsorption on titanium oxide surfaces investigated by molecular dynamics simulation. J. Biomed. Mater. Res., Part A 2011, 96 A (2), 466-476.

99. Liang Y.-C., Song D.-P., Chen M.-J., Bai Q.-S. Adsorption mechanism of Arg-Gly-Asp on rutile $\mathrm{TiO}_{2}$ (110) surface in aqueous solution. J. Vac. Sci. Technol. B 2009, 27 (3), 1548-1554.

100. Sultan A. M., Westcott Z. C., Hughes Z. E., Palafox-Hernandez J. P., Giesa T., Puddu V., Buehler M. J., Perry C. C., Walsh T. R. Aqueous peptide- $-\mathrm{TiO}_{2}$ interfaces: Isoenergetic binding via either entropically or enthalpically driven mechanisms. ACS Appl. Mater. Interfaces 2016, 8 (28), 18620-18630.

101. Walsh T. R. Pathways to structure-property relationships of peptide-materials interfaces: Challenges in predicting molecular structures. Acc. Chem. Res. 2017, 50 (7), 1617-1624.

102. Mao C. M., Sampath J., Sprenger K. G., Drobny G., Pfaendtner J. Molecular driving forces in peptide adsorption to metal oxide surfaces. Langmuir 2019, 35 (17), 5911-5920.

103. Kang Y., Li X., Tu Y., Wang Q., Ågren H. On the mechanism of protein adsorption onto hydroxylated and nonhydroxylated $\mathrm{TiO}_{2}$ surfaces. J. Phys. Chem. C 2010, 114 (34), 1449614502.

104. Puddu V., Slocik J. M., Naik R. R., Perry C. C. Titania binding peptides as templates in the biomimetic synthesis of stable titania nanosols: Insight into the role of buffers in peptidemediated mineralization. Langmuir 2013, 29 (30), 9464-9472.

105. Sultan A. M., Hughes Z. E., Walsh T. R. Effect of calcium ions on peptide adsorption at the aqueous rutile titania (110) interface. Biointerphases 2018, 13 (6), art. no. 06D403.

106. Polimeni M., Petridis L., Smith J. C., Arcangeli C. Dynamics at a peptide- $\mathrm{TiO}_{2}$ anatase (101) interface. J. Phys. Chem. B 2017, 121 (38), 8869-8877.

107. Hogan B. L. M. Bone morphogenetic proteins in development. Curr. Opin. Gen. Develop. 1996, $6(4), 432-438$.

108. Yang C., Peng C., Zhao D., Liao C., Zhou J., Lu X. Molecular simulations of myoglobin adsorbed on rutile (110) and (001) surfaces. Fluid Phase Equilibria 2014, 362, 349-354.

109. Keefe A. D., Pai S., Ellington A. Aptamers as therapeutics. Nat. Rev. Drug Discovery 2010, 9 (7), 537-550.

110. Habibzadeh Mashatooki M., Rastkar Ebrahimzadeh A., Jahanbin Sardroodi J., Abbasi A. Investigation of $\mathrm{TiO}_{2}$ anatase (101), (100) and (110) facets as immobilizer for a potential anticancer rna aptamer: A classical molecular dynamics simulation. Mol. Simul. 2019, 45 (11), 849-858.

111. Cölfen H. A crystal-clear view. Nat. Mater. 2010, 9 (12), 960-961.

112. Nudelman F., Pieterse K., George A., Bomans P. H. H., Friedrich H., Brylka L. J., Hilbers P. A. J., de With G., Sommerdijk N. A. J. M. The role of collagen in bone apatite formation in the presence of hydroxyapatite nucleation inhibitors. Nat. Mater. 2010, 9 (12), 1004-1009.

113. Zheng T., Wu C., Chen M. Early adsorption of collagen on the reduced rutile (110) surface mediated by water: A molecular dynamics study. Surf. Sci. 2013, 616, 51-59. 
114. Chen M., Zheng T., Wu C., Xing C. Molecular dynamics simulations of collagen adsorption onto grooved rutile surface: The effects of groove width. Colloids Surf. B 2014, 121, 150-157.

115. Alamdari S., Pfaendtner J. Impact of glutamate carboxylation in the adsorption of the $\alpha-1$ domain of osteocalcin to hydroxyapatite and titania. Mol. Syst. Des. Eng. 2020, 5 (3), 620-631.

116. Pierschbacher M. D., Ruoslahti E. Cell attachment activity of fibronectin can be duplicated by small synthetic fragments of the molecule. Nature 1984, 309 (5963), 30-33.

117. Guo C., Wu C., Chen M., Zheng T., Chen N., Cummings P. T. Molecular modeling of fibronectin adsorption on topographically nanostructured rutile (110) surfaces. Appl. Surf. Sci. 2016, 384, 36-44.

118. Gamucci O., Bertero A., Gagliardi M., Bardi G. Biomedical nanoparticles: Overview of their surface immune-compatibility. Coatings 2014, 4 (1), 139-159.

119. Kyrychenko A., Korsun O. M., Gubin I. I., Kovalenko S. M., Kalugin O. N. Atomistic simulations of coating of silver nanoparticles with poly(vinylpyrrolidone) oligomers: Effect of oligomer chain length. J. Phys. Chem. C 2015, 119 (14), 7888-7899.

120. Kyrychenko A., Pasko D. A., Kalugin O. N. Poly(vinyl alcohol) as a water protecting agent for silver nanoparticles: The role of polymer size and structure. Phys. Chem. Chem. Phys. 2017, 19 (13), 8742-8756.

121. Blazhynska M. M., Kyrychenko A., Kalugin O. N. Molecular dynamics simulation of the sizedependent morphological stability of cubic shape silver nanoparticles. Mol. Simul. 2018, 44 (12), 981-991.

122. Kyrychenko A., Blazhynska M. M., Slavgorodska M. V., Kalugin O. N. Stimuli-responsive adsorption of poly(acrylic acid) onto silver nanoparticles: Role of polymer chain length and degree of ionization. J. Mol. Liq. 2019, 276 243-254.

123. Borodin O., Smith G. D., Bandyopadhyaya R., Byutner O. Molecular dynamics study of the influence of solid interfaces on poly(ethylene oxide) structure and dynamics. Macromolecules 2003, 36 (20), 7873-7883.

124. Melis C., Mattoni A., Colombo L. Atomistic investigation of poly(3-hexylthiophene) adhesion on nanostructured titania. J. Phys. Chem. C 2010, 114 (8), 3401-3406.

125. Jokerst J. V., Lobovkina T., Zare R. N., Gambhir S. S. Nanoparticle pegylation for imaging and therapy. Nanomedicine 2011, 6 (4), 715-728.

126. Mano S. S., Kanehira K., Sonezaki S., Taniguchi A. Effect of polyethylene glycol modification of $\mathrm{TiO}_{2}$ nanoparticles on cytotoxicity and gene expressions in human cell lines. Int. J. Mol. Sci. 2012, 13 (3), 3703-3717.

127. Sun J., Petersen E. J., Watson S. S., Sims C. M., Kassman A., Frukhtbeyn S., Skrtic D., Ok M. T., Jacobs D. S., Reipa V., Ye Q., Nelson B. C. Biophysical characterization of functionalized titania nanoparticles and their application in dental adhesives. Acta Biomaterialia 2017, 53, 585597.

128. Lee Y.-G., Park S., Cho W., Son T., Sudhagar P., Jung J. H., Wooh S., Char K., Kang Y. S. Effective passivation of nanostructured $\mathrm{TiO}_{2}$ interfaces with PEG-based oligomeric coadsorbents to improve the performance of dye-sensitized solar cells. J. Phys. Chem. C 2012, $116(11), 6770-6777$.

129. Jung M.-H., Ko K. C., Lee J. Y. Single crystalline-like $\mathrm{TiO}_{2}$ nanotube fabrication with dominant (001) facets using poly(vinylpyrrolidone) for high efficiency solar cells. J. Phys. Chem. C 2014, 118 (31), 17306-17317.

130. Selli D., Valentin C. D. Ab initio investigation of polyethylene glycol coating of $\mathrm{TiO}_{2}$ surfaces. J. Phys. Chem. C 2016, 120 (51), 29190-29201.

131. Selli D., Tawfilas M., Mauri M., Simonutti R., Di Valentin C. Optimizing pegylation of $\mathrm{TiO}_{2}$ nanocrystals through a combined experimental and computational study. Chem. Mater. 2019, 31 (18), 7531-7546.

132. Luan B., Huynh T., Zhou R. Simplified $\mathrm{TiO}_{2}$ force fields for studies of its interaction with biomolecules. J. Chem. Phys. 2015, 142 (23), art. no. 234102.

133. Gindri I. M., Frizzo C. P., Bender C. R., Tier A. Z., Martins M. A. P., Villetti M. A., Machado G., Rodriguez L. C., Rodrigues D. C. Preparation of $\mathrm{TiO}_{2}$ nanoparticles coated with ionic liquids: A supramolecular approach. ACS Appl. Mater. Interfaces 2014, 6 (14), 11536-11543. 
134. Schiffmann F., Hutter J., VandeVondele J. Atomistic simulations of a solid/liquid interface: A combined force field and first principles approach to the structure and dynamics of acetonitrile near an anatase surface. J. Phys.: Cond. Mat. 2008, 20 (6), art. no. 064206.

135. Singh R., Rajput N. N., He X., Monk J., Hung F. R. Molecular dynamics simulations of the ionic liquid $\left[\mathrm{EMIM}^{+}\right]\left[\mathrm{TFMSI}^{-}\right]$confined inside rutile (110) slit nanopores. Phys. Chem. Chem. Phys. 2013, 15 (38), 16090-16103.

136. Yan T., Wang S., Zhou Y., Cao Z., Li G. Adsorption of $\mathrm{CO}_{2}$ on the rutile (110) surface in ionic liquid. A molecular dynamics simulation. J. Phys. Chem. C 2009, 113 (45), 19389-19392.

137. Dai Z., Shi L., Lu L., Sun Y., Lu X. Unique structures and vibrational spectra of protic ionic liquids confined in $\mathrm{TiO}_{2}$ slits: The role of interfacial hydrogen bonds. Langmuir 2018, 34 (44), $13449-13458$.

138. Weber H., Salanne M., Kirchner B. Toward an accurate modeling of ionic liquid- $\mathrm{TiO}_{2}$ interfaces. J. Phys. Chem. C 2015, 119 (45), 25260-25267.

139. Weber H., Bredow T., Kirchner B. Adsorption behavior of the 1,3-dimethylimidazolium thiocyanate and tetracyanoborate ionic liquids at anatase (101) surface. J. Phys. Chem. C 2015, 119 (27), 15137-15149.

140. Kelkar M. S., Maginn E. J. Effect of temperature and water content on the shear viscosity of the ionic liquid 1-ethyl-3-methylimidazolium bis(trifluoromethanesulfonyl)imide as studied by atomistic simulations. J. Phys. Chem. B 2007, 111 (18), 4867-4876.

141. Sambasivarao S. V., Acevedo O. Development of OPLS-AA force field parameters for 68 unique ionic liquids. J. Chem. Theory Comput. 2009, 5 (4), 1038-1050.

142. Malali S., Foroutan M. Study of wetting behavior of $\mathrm{BMIM}^{+} / \mathrm{PF}_{6}^{-}$ionic liquid on $\mathrm{TiO}_{2}(110)$ surface by molecular dynamics simulation. J. Phys. Chem. C 2017, 121 (21), 11226-11233.

143. Mohammadpour F., Heydari Dokoohaki M., Zolghadr A. R., Ghatee M. H., Moradi M. Confinement of aqueous mixtures of ionic liquids between amorphous $\mathrm{TiO}_{2}$ slit nanopores: Electrostatic field induction. Phys. Chem. Chem. Phys. 2018, 20 (46), 29493-29502.

144. Kislenko S. A., Amirov R. H., Samoylov I. S. Effect of cations on the $\mathrm{TiO}_{2}$ /acetonitrile interface structure: A molecular dynamics study. J. Phys. Chem. C 2013, 117 (20), 10589-10596.

145. Nikitin A. M., Lyubartsev A. P. New six-site acetonitrile model for simulations of liquid acetonitrile and its aqueous mixtures. J. Comput. Chem. 2007, 28 (12), 2020-2026.

146. Liu Z., Huang S., Wang W. A refined force field for molecular simulation of imidazolium-based ionic liquids. J. Phys. Chem. B 2004, 108 (34), 12978-12989.

147. Zhang Z., Fenter P., Cheng L., Sturchio N. C., Bedzyk M. J., Předota M., Bandura A., Kubicki J. D., Lvov S. N., Cummings P. T., Chialvo A. A., Ridley M. K., Bénézeth P., Anovitz L., Palmer D. A., Machesky M. L., Wesolowski D. J. Ion adsorption at the rutile-water interface: Linking molecular and macroscopic properties. Langmuir 2004, 20 (12), 4954-4969.

148. Yildirim H., Greeley J. P., Sankaranarayanan S. K. R. S. Localized order-disorder transitions induced by Li segregation in amorphous $\mathrm{TiO}_{2}$ nanoparticles. ACS Appl. Mater. Interfaces 2014, $6(21), 18962-18970$.

149. Mahjouri-Samani M., Tian M., Puretzky A. A., Chi M., Wang K., Duscher G., Rouleau C. M., Eres G., Yoon M., Lasseter J., Xiao K., Geohegan D. B. Nonequilibrium synthesis of $\mathrm{TiO}_{2}$ nanoparticle "building blocks" for crystal growth by sequential attachment in pulsed laser deposition. Nano Lett. 2017, 17 (8), 4624-4633.

150. Hagfeldt A., Boschloo G., Sun L., Kloo L., Pettersson H. Dye-sensitized solar cells. Chem. Rev. 2010, 110 (11), 6595-6663.

151. Ooyama Y., Harima Y. Molecular designs and syntheses of organic dyes for dye-sensitized solar cells. Eur. J. Org. Chem. 2009, 2009 (18), 2903-2934.

152. Beljonne D., Cornil J. Multiscale modelling of organic and hybrid photovoltaics. Springer Berlin Heidelberg: Berlin, Heidelberg, 2014; Vol. 352, 394 p.

153. Würfel P. Physics of solar cells. From principles to new concepts. Wiley-VCH Verlag: London, $2005 ; 186 \mathrm{p}$.

154. Luque A., Hegedus S. Handbook of photovoltaic science and engineering. John Wiley \& Sons, Ltd: London, 2003; 1138 p.

155. Sharma K., Sharma V., Sharma S. S. Dye-sensitized solar cells: Fundamentals and current status. Nanoscale Res. Lett. 2018, 13 (1), art. no. 381. 
156. Diebold U. The surface science of titanium dioxide. Surf. Sci. Rep. 2003, 48 (5), 53-229.

157. Gałyńska M., Persson P. Quantum chemical calculations of the structural influence on electronic properties in $\mathrm{TiO}_{2}$ nanocrystals. Mol. Phys. 2017, 115 (17-18), 2209-2217.

158. Labat F., Baranek P., Domain C., Minot C., Adamo C. Density functional theory analysis of the structural and electronic properties of $\mathrm{TiO}_{2}$ rutile and anatase polytypes: Performances of different exchange-correlation functionals. J. Chem. Phys. 2007, 126 (15), 154703.

159. Fazio G., Ferrighi L., Di Valentin C. Spherical versus faceted anatase $\mathrm{TiO}_{2}$ nanoparticles: A model study of structural and electronic properties. J. Phys. Chem. C 2015, 119 (35), 2073520746.

160. Morita K., Yasuoka K. Density functional theory study of atomic and electronic properties of defects in reduced anatase $\mathrm{TiO}_{2}$ nanocrystals. AIP Advances 2018, 8 (3), art. no. 035119.

161. Selli D., Fazio G., Seifert G., Di Valentin C. Water multilayers on $\mathrm{TiO}_{2}(101)$ anatase surface: Assessment of a DFTB-based method. J. Chem. Theory Comput. 2017, 13 (8), 3862-3873.

162. Selli D., Fazio G., Di Valentin C. Using density functional theory to model realistic $\mathrm{TiO}_{2}$ nanoparticles, their photoactivation and interaction with water. Catalysts 2017, 7 (12), art. no. 357.

163. Selli D., Fazio G., Di Valentin C. Modelling realistic $\mathrm{TiO}_{2}$ nanospheres: A benchmark study of SCC-DFTB against hybrid DFT. J. Chem. Phys. 2017, 147 (16), 164701.

164. Berardo E., Hu H.-S., Shevlin S. A., Woodley S. M., Kowalski K., Zwijnenburg M. A. Modeling excited states in $\mathrm{TiO}_{2}$ nanoparticles: On the accuracy of a TD-DFT based description. J. Chem. Theory Comput. 2014, 10 (3), 1189-1199.

165. Labat F., Le Bahers T., Ciofini I., Adamo C. First-principles modeling of dye-sensitized solar cells: Challenges and perspectives. Acc. Chem. Res. 2012, 45 (8), 1268-1277.

166. Le Bahers T., Labat F., Pauporté T., Lainé P. P., Ciofini I. Theoretical procedure for optimizing dye-sensitized solar cells: From electronic structure to photovoltaic efficiency. J. Am. Chem. Soc. 2011, 133 (20), 8005-8013.

167. Duncan W. R., Prezhdo O. V. Theoretical studies of photoinduced electron transfer in dyesensitized $\mathrm{TiO}_{2}$. Ann. Rev. Phys. Chem. 2007, 58 (1), 143-184.

168. Oprea I. C., Gîrțu A. M. Structure and electronic properties of $\mathrm{TiO}_{2}$ nanoclusters and dyenanocluster systems appropriate to model hybrid photovoltaic or photocatalytic applications. Nanomaterials 2019, 9 (3), art. no. 357.

169. Oprea I. C., Panait P., Cimpoesu F., Ferbinteanu M., Gîrţu A. M. Density functional theory (DFT) study of coumarin-based dyes adsorbed on $\mathrm{TiO}_{2}$ nanoclusters - applications to dyesensitized solar cells. Materials 2013, 6 (6), 2372-2392.

170. O'Rourke C., Bowler D. R. DSSC anchoring groups: A surface dependent decision. J. Phys.: Condens. Matter. 2014, 26 (19), art. no. 195302.

171. Mowbray D. J., Migani A. Optical absorption spectra and excitons of dye-substrate interfaces: Catechol on $\mathrm{TiO}_{2}(110)$. J. Chem. Theory Comput. 2016, 12 (6), 2843-2852.

172. Feng J., Jiao Y., Ma W., Nazeeruddin M. K., Grätzel M., Meng S. First principles design of dye molecules with ullazine donor for dye sensitized solar cells. J. Phys. Chem. C 2013, 117 (8), 3772-3778.

173. De Angelis F., Fantacci S., Selloni A., Nazeeruddin M. K., Grätzel M. Time-dependent density functional theory investigations on the excited states of $\mathrm{Ru}(\mathrm{II})$-dye-sensitized $\mathrm{TiO}_{2}$ nanoparticles: The role of sensitizer protonation. J. Am. Chem. Soc. 2007, 129 (46), 1415614157.

174. Labat F., Adamo C. Bi-isonicotinic acid on anatase (101): Insights from theory. J. Phys. Chem. C 2007, 111 (41), 15034-15042.

175. Labat F., Ciofini I., Hratchian H. P., Frisch M. J., Raghavachari K., Adamo C. Insights into working principles of ruthenium polypyridyl dye-sensitized solar cells from first principles modeling. J. Phys. Chem. C 2011, 115 (10), 4297-4306.

176. Labat F., Ciofini I., Hratchian H. P., Frisch M., Raghavachari K., Adamo C. First principles modeling of eosin-loaded $\mathrm{ZnO}$ films: A step toward the understanding of dye-sensitized solar cell performances. J. Am. Chem. Soc. 2009, 131 (40), 14290-14298.

177. Jungsuttiwong S., Tarsang R., Sudyoadsuk T., Promarak V., Khongpracha P., Namuangruk S. Theoretical study on novel double donor-based dyes used in high efficient dye-sensitized solar 
cells: The application of TDDFT study to the electron injection process. Org. Electron. 2013, 14 (3), 711-722.

178. Zheng J., Zhang K., Fang Y., Zuo Y., Duan Y., Zhuo Z., Chen X., Yang W., Lin Y., Wong M. S., Pan F. How to optimize the interface between photosensitizers and $\mathrm{TiO}_{2}$ nanocrystals with molecular engineering to enhance performances of dye-sensitized solar cells? ACS Appl. Mater. Interfaces 2015, 7 (45), 25341-25351.

179. Hara K., Sato T., Katoh R., Furube A., Ohga Y., Shinpo A., Suga S., Sayama K., Sugihara H., Arakawa $\mathrm{H}$. Molecular design of coumarin dyes for efficient dye-sensitized solar cells. J. Phys. Chem. B 2003, 107 (2), 597-606.

180. Liu H., Li B., Xue B., Liu E. Theoretical design of high-performance boron dipyrromethenes dyes by introducing heterocyclics to tune photoelectric properties. J. Phys. Chem. C 2019, 123 (43), 26047-26056.

181. Agrawal S., Leijtens T., Ronca E., Pastore M., Snaith H., De Angelis F. Modeling the effect of ionic additives on the optical and electronic properties of a dye-sensitized $\mathrm{TiO}_{2}$ heterointerface: Absorption, charge injection and aggregation. J. Mater. Chem. A 2013, 1 (46), 14675-14685.

182. Le Bahers T., Pauporté T., Scalmani G., Adamo C., Ciofini I. A TD-DFT investigation of ground and excited state properties in indoline dyes used for dye-sensitized solar cells. Phys. Chem. Chem. Phys. 2009, 11 (47), 11276-11284.

183. Luppi E., Urdaneta I., Calatayud M. Photoactivity of molecule- $\mathrm{TiO}_{2}$ clusters with timedependent density-functional theory. J. Phys. Chem. A 2016, 120 (27), 5115-5124.

184. Yang Z., Liu C., Li K., Cole J. M., Shao C., Cao D. Rational design of dithienopicenocarbazolebased dyes and a prediction of their energy-conversion efficiency characteristics for dyesensitized solar cells. ACS Appl. Mater. Interfaces 2018, 1 (4), 1435-1444.

185. Estrella L. L., Balanay M. P., Kim D. H. The effect of donor group rigidification on the electronic and optical properties of arylamine-based metal-free dyes for dye-sensitized solar cells: A computational study. J. Phys. Chem. A 2016, 120 (29), 5917-5927.

186. Wen Y., Yang H., Zheng D., Sun K., Wang L., Zhang J. First-principles and molecular dynamics on A-D $(\pi)-\mathrm{A}$ type sensitizers for dye-sensitized solar cells: Effects of various anchoring groups on electronic coupling and dye aggregation. J. Phys. Chem. C 2017, 121 (26), 14019-14026.

187. Gao Y., Lockart M., Kispert L. D., Bowman M. K. Photoinduced charge separation in retinoic acid on $\mathrm{TiO}_{2}$ : Comparison of three anchoring modes. J. Phys. Chem. C 2019, 123 (40), 2463424642.

188. Mosconi E., Selloni A., De Angelis F. Solvent effects on the adsorption geometry and electronic structure of dye-sensitized tio ${ }_{2}$ : A first-principles investigation. J. Phys. Chem. C 2012, 116 (9), 5932-5940.

189. Seo K. D., Choi I. T., Park Y. G., Kang S., Lee J. Y., Kim H. K. Novel D-A- $-\pi-A$ coumarin dyes containing low band-gap chromophores for dye-sensitised solar cells. Dyes and Pigments 2012, 94 (3), 469-474.

190. Hara K., Sayama K., Ohga Y., Shinpo A., Suga S., Arakawa H. A coumarin-derivative dye sensitized nanocrystalline $\mathrm{TiO}_{2}$ solar cell having a high solar-energy conversion efficiency up to 5.6\%. Chem. Commun. 2001, (6), 569-570.

191. Hara K., Miyamoto K., Abe Y., Yanagida M. Electron transport in coumarin-dye-sensitized nanocrystalline $\mathrm{TiO}_{2}$ electrodes. J. Phys. Chem. B 2005, 109 (50), 23776-23778.

192. Wang Z. S., Cui Y., Hara K., Dan-oh Y., Kasada C., Shinpo A. A high-light-harvestingefficiency coumarin dye for stable dye-sensitized solar cells. Adv. Mater. 2007, 19 (8), 1138 1141.

193. Wang Z.-S., Cui Y., Dan-oh Y., Kasada C., Shinpo A., Hara K. Thiophene-functionalized coumarin dye for efficient dye-sensitized solar cells: Electron lifetime improved by coadsorption of deoxycholic acid. J. Phys. Chem. C 2007, 111 (19), 7224-7230.

194. Zhang X., Zhang J.-J., Xia Y.-Y. Molecular design of coumarin dyes with high efficiency in dye-sensitized solar cells. J. Photochem. Photobiol. A 2008, 194 (2), 167-172.

195. Roy J. K., Kar S., Leszczynski J. Electronic structure and optical properties of designed photoefficient indoline-based dye-sensitizers with $\mathrm{D}-\mathrm{A}-\pi-\mathrm{A}$ framework. J. Phys. Chem. $C$ 2019, 123 (6), 3309-3320. 
196. Sánchez-de-Armas R., Oviedo J., San Miguel M. Á., Sanz J. F. Direct vs indirect mechanisms for electron injection in dye-sensitized solar cells. J. Phys. Chem. C 2011, 115 (22), $11293-$ 11301.

197. Pastore M., Fantacci S., De Angelis F. Modeling excited states and alignment of energy levels in dye-sensitized solar cells: Successes, failures, and challenges. J. Phys. Chem. C 2013, 117 (8), 3685-3700.

198. De Angelis F., Fantacci S., Mosconi E., Nazeeruddin M. K., Grätzel M. Absorption spectra and excited state energy levels of the $\mathrm{N} 719$ dye on $\mathrm{TiO}_{2}$ in dye-sensitized solar cell models. J. Phys. Chem. C 2011, 115 (17), 8825-8831.

199. De Angelis F., Fantacci S., Selloni A., Nazeeruddin M. K., Grätzel M. First-principles modeling of the adsorption geometry and electronic structure of $\mathrm{Ru}(\mathrm{II})$ dyes on extended $\mathrm{TiO}_{2}$ substrates for dye-sensitized solar cell applications. J. Phys. Chem. C 2010, 114 (13), 6054-6061.

200. Oviedo M. B., Zarate X., Negre C. F. A., Schott E., Arratia-Pérez R., Sánchez C. G. Quantum dynamical simulations as a tool for predicting photoinjection mechanisms in dye-sensitized $\mathrm{TiO}_{2}$ solar cells. J. Phys. Chem. Lett. 2012, 3 (18), 2548-2555.

201. Negre C. F. A., Fuertes V. C., Oviedo M. B., Oliva F. Y., Sánchez C. G. Quantum dynamics of light-induced charge injection in a model dye-nanoparticle complex. J. Phys. Chem. C 2012, 116 (28), 14748-14753.

202. Negre C. F. A., Young K. J., Oviedo M. B., Allen L. J., Sánchez C. G., Jarzembska K. N., Benedict J. B., Crabtree R. H., Coppens P., Brudvig G. W., Batista V. S. Photoelectrochemical hole injection revealed in polyoxotitanate nanocrystals functionalized with organic adsorbates. J. Am. Chem. Soc. 2014, 136 (46), 16420-16429.

203. Marquez D. M., Sánchez C. G. Quantum efficiency of the photo-induced electronic transfer in dye- $\mathrm{TiO}_{2}$ complexes. Phys. Chem. Chem. Phys. 2018, 20 (41), 26280-26287.

204. Ronchi C., Selli D., Pipornpong W., Di Valentin C. Proton transfers at a dopaminefunctionalized $\mathrm{TiO}_{2}$ interface. J. Phys. Chem. C 2019, 123 (13), 7682-7695.

205. Zhang L., Cole J. M. Adsorption properties of $p$-methyl red monomeric-to-pentameric dye aggregates on anatase (101) titania surfaces: First-principles calculations of dye $/ \mathrm{TiO}_{2}$ photoanode interfaces for dye-sensitized solar cells. ACS Appl. Mater. Interfaces 2014, 6 (18), 15760-15766.

206. Monti S., Pastore M., Li C., De Angelis F., Carravetta V. Theoretical investigation of adsorption, dynamics, self-aggregation, and spectroscopic properties of the D102 indoline dye on an anatase (101) substrate. J. Phys. Chem. C 2016, 120 (5), 2787-2796.

207. Marx D., Hutter J. Ab initio molecular dynamics: Basic theory and advanced methods. Cambridge University Press: Cambridge, 2009; 567 p.

208. Car R., Parrinello M. Unified approach for molecular dynamics and density-functional theory. Phys. Rev. Lett. 1985, 55 (22), 2471-2474.

209. Tuckerman M. E., Parrinello M. Integrating the Car-Parrinello equations. I. Basic integration techniques. J. Chem. Phys. 1994, 101 (2), 1302-1315.

210. Doltsinis N. L., Marx D. First pprinciples molecular dynamics involving excited states and nonadiabatic transitions. J. Theory Comput. Chem. 2002, 01 (02), 319-349.

211. Stier W., Prezhdo O. V. Thermal effects in the ultrafast photoinduced electron transfer from a molecular donor anchored to a semiconductor acceptor. Isr. J. Chem. 2002, 42 (2-3), 213-224.

212. Stier W., Prezhdo O. V. Nonadiabatic molecular dynamics simulation of light-induced electron transfer from an anchored molecular electron donor to a semiconductor acceptor. J. Phys. Chem. B 2002, 106 (33), 8047-8054.

213. Stier W., Prezhdo O. V. Non-adiabatic molecular dynamics simulation of ultrafast solar cell electron transfer. J. Mol. Struct.: Theochem. 2003, 630 (1), 33-43.

214. Alvarez-Ramirez F., Ruiz-Morales Y. Ab initio molecular dynamics calculations of the phase transformation mechanism for the formation of $\mathrm{TiO}_{2}$ titanate-type nanosheets from anatase. Chem. Mater. 2007, 19 (12), 2947-2959.

215. Fischer S. A., Duncan W. R., Prezhdo O. V. Ab initio nonadiabatic molecular dynamics of wetelectrons on the $\mathrm{TiO}_{2}$ surface. J. Am. Chem. Soc. 2009, 131 (42), 15483-15491.

216. Vogel D. J., Kilin D. S. Electron dynamics of solvated Ti(OH) $)_{4}$. MRS Proceedings 2014, 1647, art. no. mrsf13-1647-gg08-07. 
217. Brandt E. G., Agosta L., Lyubartsev A. P. Reactive wetting properties of $\mathrm{TiO}_{2}$ nanoparticles predicted by ab initio molecular dynamics simulations. Nanoscale 2016, 8 (27), 13385-13398.

218. Dubot P., Boisseau N., Cenedese P. Large scale full qm-md investigation of small peptides and insulin adsorption on ideal and defective $\mathrm{TiO}_{2}(100)$ surfaces. Influence of peptide size on interfacial bonds. Appl. Surf. Sci. 2018, 440 614-626.

219. Fazio G., Selli D., Ferraro L., Seifert G., Di Valentin C. Curved $\mathrm{TiO}_{2}$ nanoparticles in water: Short (chemical) and long (physical) range interfacial effects. ACS Appl. Mater. Interfaces 2018, 10 (35), 29943-29953.

220. Byrne A., English N. J. A systematic study via ab-initio MD of the effect solvation by room temperature ionic liquid has on the structure of a chromophore-titania interface. Comput. Mater. Sci. 2018, 141 193-206.

221. Tateyama Y., Sumita M., Ootani Y., Aikawa K., Jono R., Han L., Sodeyama K. Acetonitrile solution effect on $\mathrm{Ru} \mathrm{N} 749$ dye adsorption and excitation at $\mathrm{TiO}_{2}$ anatase interface. J. Phys. Chem. C 2014, 118 (30), 16863-16871.

222. Monti A., de Ruiter J. M., de Groot H. J. M., Buda F. A dynamic view of proton-coupled electron transfer in photocatalytic water splitting. J. Phys. Chem. C 2016, 120 (40), 2307423082.

223. Mathew S., Yella A., Gao P., Humphry-Baker R., Curchod B. F. E., Ashari-Astani N., Tavernelli I., Rothlisberger U., Nazeeruddin M. K., Grätzel M. Dye-sensitized solar cells with $13 \%$ efficiency achieved through the molecular engineering of porphyrin sensitizers. Nat. Chem. 2014, 6 (3), 242-247.

224. Ambrosio F., Martsinovich N., Troisi A. What is the best anchoring group for a dye in a dyesensitized solar cell? J. Phys. Chem. Lett. 2012, 3 (11), 1531-1535.

225. Zhang L., Cole J. M. Anchoring groups for dye-sensitized solar cells. ACS Appl. Mater. Interfaces 2015, 7 (6), 3427-3455.

226. Smith J. L. On the simultaneous staining of neutral fat and fatty acid by oxazine dyes. J. Pathol. Bacteriol. 1908, 12 (1), 1-4.

227. Heinz H. Adsorption of biomolecules and polymers on silicates, glasses, and oxides: Mechanisms, predictions, and opportunities by molecular simulation. Curr. Opin. Chem. Engineer. 2016, 11 34-41.

228. Heinz H., Ramezani-Dakhel H. Simulations of inorganic-bioorganic interfaces to discover new materials: Insights, comparisons to experiment, challenges, and opportunities. Chem. Soc. Rev. 2016, 45 (2), 412-448.

229. Liu J., Wang Z., Zeng J., Heinz H. Molecular structure and assembly of peptide-derived nanomaterials. Curr. Opin. Green Sustainable Chem. 2018, 12 38-46.

230. De Angelis F. Modeling materials and processes in hybrid/organic photovoltaics: From dyesensitized to perovskite solar cells. Acc. Chem. Res. 2014, 47 (11), 3349-3360.

231. Casida M. E., Huix-Rotllant M. Progress in time-dependent density-functional theory. Annu. Rev. Phys. Chem. 2012, 63 (1), 287-323.

Надіслано до редакиї 29 квітня 2020 р.

М.М. Блажинская†, А.В. Кириченко†, Д.С. Степанюк†, А.Н. Корсун†, С.Н. Коваленко†, В.В. Иванов†, Ф.-А. Мьяне‡, А. Идриссић, О.Н. Калугин†. Новые достижения в теоретическом исследовании наноматериалов на основе диоксида титана. Обзор.

† Харьковский национальный университет имени В.Н. Каразина, химический фракультет, пл. Свободы, 4, Харьков, 61022, Украина

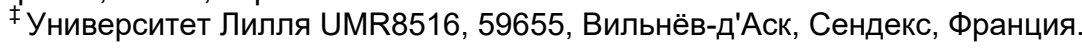

Диоксид титана $\left(\mathrm{TiO}_{2}\right)$ является одним из наиболее широко используемых наноматериалов во многих новых областях материаловедения, включая конверсию солнечной энергии и биомедицинскую имплантацию. Настоящий обзор посвящен рассмотрению и анализу прогресса и последних достижений в области теории и компьютерного моделирования фризико-химических свойств небольших кластеров $\mathrm{TiO}_{2}$, наночастиц среднего размера, а также границы раздела жидкость-твердое вещество. Дан исторический обзор и 
разработка эмпирических силовых полей для классической молекулярной динамики (МД) различных полиморфов $\mathrm{TiO}_{2}$, таких как рутил, анатаз и брукит. Исследовано адсорбционное поведение молекул растворителя, ионов, малых органических лигандов и биомакромолекул на поверхности $\mathrm{TiO}_{2}$ с целью понимания движущих сил и механизмов, которые управляют связыванием и распознаванием между адсорбатом и поверхностями. Обсуждено влияние кристаллических форм, кристаллографических плоскостей, поверхностных дефектов и сред растворителей на процесс адсорбции. Рассмотрены структурные детали и динамика адсорбционных явлений, происходящих на границах раздела жидкость-твердое тело, начиная с ранних эмпирических моделей потенциала до недавнего реактивного ReaxFF МД моделирования, способного улавливать диссоциативную адсорбцию молекул воды. Эфффективность различных теоретических методов варьировалась от квантово-механических (QM) расчетов (ab initio и теории функционала плотности) до классического силового поля и гибридного моделирования MM/QM. Кроме того, обсужден недавний прогресс в вычислительной химии индуцированных светом электронных процессов, лежащих в основе структуры, динамики и функционирования молекулярных и гибридных материалов, с особым вниманием к применению солнечной энергии в сенсибилизированных красителем солнечных элементах (DSSC), которые в настоящее время находятся в стадии разработки. Кроме того, проанализированы принципы конструирования красителей, роль закрепления фрагмента и агрегации красителя в характеристиках DSSC. Наконец, очерчены перспективы и проблемы дальнейшего прогресса в исследованиях и многообещающие направления в разработке точных вычислительных инструментов для моделирования взаимодействий между неорганическими материалами с неидеальными структурами и природными биомакромолекулами в фризиологических условиях.

Ключевые слова: диоксид титана, рутил, анатаз, брукит, сенсибилизация красителем, наночастица, граница раздела жидкость-твердое вещество, молекулярно-динамическое моделирование, ab initio молекулярная динамика.

М.М. Блажинська ${ }^{\dagger}$, О.В. Кириченко ${ }^{\dagger}$, Д.С. Степанюк ${ }^{\dagger}$, О.М. Корсун ${ }^{\dagger}$, С.М. Коваленко ${ }^{\dagger}$, В.В. Іванов ${ }^{\dagger}$, Ф.-О. М'яне ${ }^{\ddagger}$, А. Ідріссі ${ }^{\ddagger}$, О.М. Калугін ${ }^{\dagger}$. Новітні досягнення у теоретичному дослідженні наноматеріалів на основі діоксиду титану. Огляд.

† Харківський національний університет імені В.Н. Каразіна, хімічний факультет, майдан Свободи, 4, Харків, 61022, Україна

Ғ Університет Лілля UMR8516, 59655, Вільньов-д'Аск, Сендекс, Франція

Діоксид титану $\left(\mathrm{TiO}_{2}\right) €$ одним з найбільш широко використовуваних наноматеріалів в багатьох нових областях матеріалознавства, включаючи конверсію сонячної енергії і біомедичну імплантацію. Огляд присвячено прогресу і останнім досягненням в області теорії і комп'ютерного моделювання фізико-хімічних властивостей невеликих кластерів $\mathrm{TiO}_{2}$, наночастинок середнього розміру, а також кордону розділу рідинатверда речовина. Подано історичний огляд і розробка емпіричних силових полів для класичної молекулярної динаміки (МД) різних поліморфів $\mathrm{TiO}_{2}$, таких як рутил, анатаз і брукіт. Досліджено адсорбційну поведінку молекул розчинника, іонів, малих органічних лігандів і біомакромолекул на поверхні $\mathrm{TiO}_{2}$ досліджується з метою розуміння рушійних сил і механізмів, які керують зв'язуванням і розпізнаванням між адсорбатом i поверхнями. Обговорено вплив кристалічних фрорм, кристалографічних площин, поверхневих дефектів і середовищ розчинників на процес адсорбції. Розглянуті структурні деталі і динаміка адсорбційних явищ, що відбуваються на кордонах розділу рідина-тверде тіло, починаючи з ранніх емпіричних моделей потенціалу до недавнього реактивного ReaxFF МД моделювання, здатного вловлювати дисоціативну адсорбцію молекул води. Ефективність різних теоретичних методів варіювалася від квантово-механічних (QM) розрахунків (ab initio і теорії функціонала густини) до класичного силового поля і гібридного моделювання MM/QM. Крім того, розглянуто недавній прогрес в обчислювальній хімії індукованих світлом електронних процесів, що лежать в основі структури, динаміки і функціонування молекулярних і гібридних матеріалів 3 особливою увагою до застосуванні сонячної енергії в сенсибілізованих барвником сонячних елементах (DSSC), які в даний час знаходяться в стадії розробки. Крім того, були проаналізовані принципи конструювання барвників, роль закріплення фррагмента і агрегації барвника в характеристиках DSSC. Hapeшті, окреслені перспективи і проблеми подальшого прогресу в дослідженнях і багатообіцяючі напрямки в розробці точних обчислювальних інструментів для моделювання взаємодій між неорганічними матеріалами 3 недосконалими структурами і природними біомакромолекул в фрізіологічних умовах.

Ключові слова: діоксид титану, рутил, анатаз, брукіт, сенсибілізація барвником, наночастинка, межа поділу рідина-тверда речовина, молекулярно-динамічне моделювання, ab initio молекулярна динаміка.

Kharkiv University Bulletin. Chemical Series. Issue 34 (57), 2020 